Running head: Transvestite Identities in Weimar Queer Media

Transvestit Sucht Gedankenaustausch: The Creation and Control of Transvestite Identities in Weimar Queer Media

A Thesis
presented to
the Faculty of the Graduate School
at the University of Missouri-Columbia
In Partial Fulfillment
of the Requirements for the Degree
Master of Arts
by
Oliver Jesse Seifert-Gram (ze/zim)
Seth Howes, Thesis Supervisor
MAY 2021


The undersigned, appointed by the dean of the Graduate School, have examined the thesis entitled

\section{TRANSVESTIT SUCHT GEDANKENAUSTAUSCH: THE CREATION AND CONTROL OF TRANSVESTITE IDENTITIES IN WEIMAR QUEER MEDIA}

presented by Oliver Seifert-Gram,

a candidate for the degree of master of German Studies, and hereby certify that, in their opinion, it is worthy of acceptance.

Professor Seth Howes

Professor Ilyana Karthas

Professor Kristin Kopp

Professor Sean Franzel 


\section{Acknowledgements}

I would like to thank Seth Howes for believing in me before I did, and always encouraging me to be the kindest, angriest, most empowered Queer I can be.

And I am forever grateful to Grete, Maria Weiss, Lotte Hahm, Willma, Heidi, Heidi S., Gerda Erwin Schröder, P. W., Minna, Elli Richard K, Eduard Henri, E. Raven, Gitta B, and all of the beautiful gender deviants of the transvestite media for the radical act of existing, and for putting your incredible and imperfect selves in print. 


\section{Table of Contents}

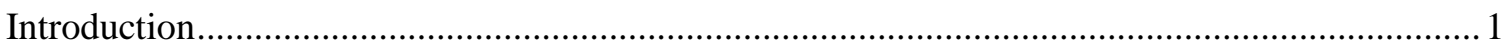

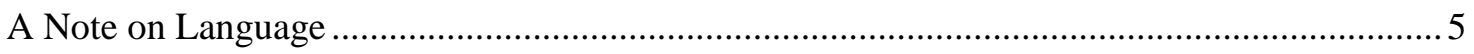

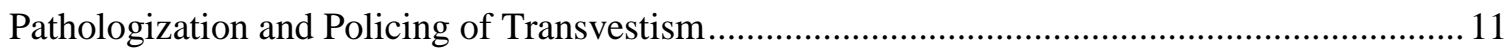

The Bund für Menschenrecht: Organizing Respectable Homosexuality ..................................... 17

Democracy, Censorship, and the BfM founding of a popular Queer Press ..................................2

Image and Respectability: the formation of transvestite identities ............................................. 32

The Case for Handarbeit: Interior Womanhood and Domesticity ..............................................49

Hopeful Negativity and Lonely Community: Conflicting Feeling in the Transvestite Media.......62

“You Clueless Angels:” Publisher-Reader Conflict and Das 3. Geschlecht ................................... 78

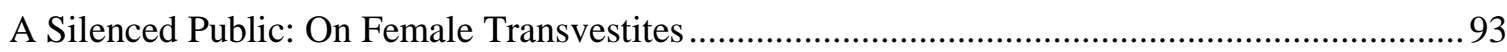

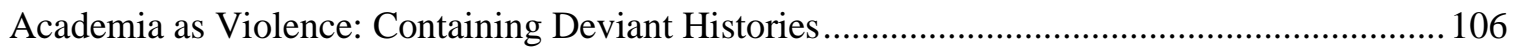

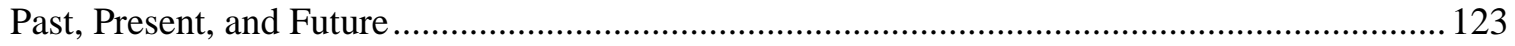

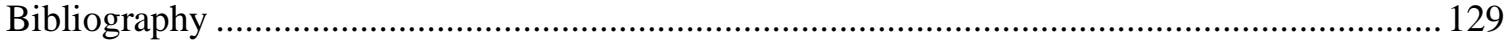




\begin{abstract}
Between 1924 and 1932 room was made in the German gay and lesbian publication house Radszuweit Verlag for gender expansive topics not having to do with sexuality. Specifically, these new sections and periodicals addressed the experiences of transvestites, the first collective identity for gender deviants in modern western Europe. While transvestism had been commonly discussed by law enforcement and the medical establishment throughout the previous decades, these periodicals marked the first attempt at making a publication both by and for transvestites, in their own voices.

The unique circumstances that gave rise to the short-lived Weimar transvestite media was the placement of transvestism in the center of the gender, class, and ideological power struggles of numerous intersecting queer communal factions. As a result, gender deviance was a location for culture-wide debates on respectability, gender identity, and strategies for queer liberation.

This thesis analyses the transvestite media of Weimar Germany, as one of the rare instances of gender deviant voices recorded in history, to formulate a view of the fears, dreams, goals, and self-identity constructions of a pre-transgender community. Reflecting on the transvestite media's own internal and external biases and agendas, it then addresses how this media both does and does not reflect the lived experiences of Weimar Germany's gender deviants. Finally, the impact of these biases and of the violent homoand heteronormative destruction of gender deviant ideas are considered, in order to create a full picture of the interplay of queer community and liberation, loss and oppression on gender deviants over generations.
\end{abstract}




\section{Introduction}

Standing on certain street corners in 1920s Berlin was not dissimilar to standing in an open-air bookstore. With ever-improving printing technology, newspapers, magazines, and pamphlets were all the rage, and many of the city's wider sidewalks were home to large newspaper stands piled high with all kinds of periodicals. Whatever your interest or leanings, you were likely to find something related if you dug for long enough through the stacks. In September 1929, a passerby browsing through one of the many newsstands on the streets of Berlin might spot a new issue of the magazine Die Freundin (The Girlfriend), most likely sporting a photograph of a nude woman, or perhaps a "new woman," on its cover. Slightly taller and wider than the average magazine today, Die Freundin was full of stories, poems, photographs, news and advertisements, all boldly and publicly directed towards a lesbian audience, but it wasn't only lesbians who bought the magazine, or had it shipped to their homes. Some likely cast Die Freundin aside as overlarge packaging for their preferred reading: a small pamphlet tucked loosely inside the larger magazine's pages.

Essen. Young transvestite seeking open exchange (Gedankenaustausch) with the same or with a woman.

Hamburg. Transvestite, stately, elegant appearance, 36 years old, seeking a suitable connection, also transvestite, possibly with own home.

Transvestite as support for household and business wanted (Berlin). Only 
inconspicuous, reliable, unobjectionable

people need not apply. ${ }^{1}$

Seeking correspondence with like-minded transvestites (Berlin or Stettin)

The classified advertisements of the September 4th, 1929 issue of the little pamphlet were squeezed together in little square borders at the bottom of a page, alongside advertisements for transvestite-friendly cafes and clothing stores, support groups, talks on sexology all over the German-speaking world, and events like the transvestite ball held at the Florida Ballroom in Berlin the coming October. The rest of the little pamphlet's pages burst at the edges with fine-printed stories, poems, photographs, autobiographies, and debates. The articles shared personal stories and expressed the opinions on sexology and gendered culture of transvestite writers and readers alike from all over the German-speaking world. Some invited an exchange of opinions (Meinungsaustausch) leading to months-long debates as readers sent in support and counter-arguments. Other writings garnered letters of gratitude, expressing likemindedness, similar experience, and personal validation. While the classifieds shared the potential to turn a text-based community into something more tangible, as in the case of the lone transvestites in Essen, Stettin, and Berlin in September 1929. Despite being hidden away in the pages of a different magazine, this leaflet had an enormous impact on many lives, Der Transvestit, printed boldly in large letters on its little cover, as though it had no more to hide than a knitting magazine.

Der Transvestit came out of one of the first instances of a self-identified, crossgender community in the western world. The reader-writers of this periodical were,

\footnotetext{
${ }^{1}$ Classified Advertisements. Der Transvestit, September 4, 1929.
} 
however, far from the first people whose existence flew in the face of the sex-gender binary. On the contrary, the othering of variant experiences of gender is a somewhat new phenomenon. That is, the cultural belief that one's sex determines their gender and that there are only two categories into which biological sex and gender experience naturally occur is a faulty construction in and of itself that is much younger than most people generally believe. Prior to the 1700s, human was human, and variations in sex-anatomy were simply different presentations of the same general human organs, albeit with the "male" being considered their fully developed form. Then the formation of the sexgender binary occurred some time in the 18th century when, amid several political and cultural upheavals, scientists devised an explanation of human anatomy that allowed for a greater level of control over people's societal statuses and roles. These men established a conception of fact in which only the externally observable mattered, and only they could tell you what those observations meant. The internal experience of gender, externally unobservable, lost priority over observable anatomy. That is, "the body is the body is the body, said a new group of self-appointed experts with ever more authority."2 Sex and gender were thus conflated, allowing the male, wealthy scientists who devised this theory to attribute all kinds of traits to anatomy, streamlining societal roles and solidifying their own position at the top. From that point on in western cultures, a single look at an infant's genitalia could tell you whether they would grow up to be weak or strong, competent or feeble, capable of living independently or confined to domesticity.

\footnotetext{
${ }^{2}$ Laqueur, Thomas. Making sex: Body and gender from the Greeks to Freud. Harvard University Press, 1992, 151-152.
} 
The history of the sex-gender binary is worth mentioning briefly as it reframes the conversation about a history of $20^{\text {th }}$ century queer activism. The transvestites of Weimar Germany did not represent a new way of being in the world, but a new, collective manner of discussing a way in which human beings have always embodied themselves. All too often the stories of those who cannot find a place within this oppressive system are told from the perspective of the oppressor, using era and generalization to reshape and dull a deviant past into something immaterial that can then be disregarded. Treating Weimar transvestites as a new phenomenon would be an example of this tactic, viewing them with a conception of the sex-gender binary as a default from which they deviated for a brief period, rather than as an enforced, mythological normal from which humans have always deviated.

The goal of Transvestit Sucht Gedankenaustausch ${ }^{3}$ is to give an overview of how a very unique collection of Weimar transvestites gathered and defined themselves in a culture that was heavily invested in this formation of the sex-gender binary and of heteronormativity. This text will explore how gender deviants interacted with the oppressive forces around them, who was included or excluded from their ranks, and how the sociopolitical hierarchies and gender mythologies of the status quo impacted their self-conceptions.

In order to complete this task without giving in to the simplicity of these same sexual and gender mythologies, this text strives to center the voices of the transvestites themselves rather than of the popular, political, and medical establishments who observed and critiqued them. Any information given about the reaction of the cisgender population

\footnotetext{
${ }^{3}$ Which translates to Transvestite Seeking an Exchange of Ideas, by the way.
} 
should therefore be considered within the context of how these factors impacted the ideas and structures that the transvestites themselves created. That is, what gay men, sexologists, police officers, or the rest of society said about transvestites should not be considered truths about the transvestite identity, condition, community, or anything else. Instead, these moments should be used as an opportunity to reflect on the nature and intensity with which heteronormative society attempted to control the narrative of queer existences, and how that impacted their experiences and ideas.

\section{A Note on Language}

The language that the writers use in Der Transvestit to describe themselves will, in the eyes of the modern gender-literate, appear offensive and self-denying. Most modern transgender humans consider the term "transvestite" outdated and incomplete, with a long history of being used in a derogatory fashion. In a modern context, the term focuses on gender expression, neglecting the importance of gender experience and in favor of fetishizing the transgender body. That Der Transvestit is full of the accounts of personal gender experience beyond clothing and sexuality would therefore seem to be in conflict with the leaflet's title, but the transvestites of Weimar Germany are not using modern definitions of gender. The context of their moment and their language mean that they defined themselves on completely different terms.

In a short fiction titled simply "Finally - Finally!" an unnamed author tells the story of Max, who dreams of wearing women's clothes. Max saved money and eventually procured a complete women's outfit. He dressed himself up and went out for a cup of coffee, ecstatic when the café waiter called him "Fraulein." Throughout the tale, however, masculine pronouns are used for Max regardless of his presentation, desires, or 
identity. ${ }^{4}$ In the case of one of the many first-person, autobiographical accounts in which no third-person pronoun is indicated, however, feminine referential nouns are often given. One such account is authored by a "Frau Gitte," for which "Frau" indicates feminine pronoun use, in the same manner as "Mädchen" indicates neuter, or “Transvestit" indicates masculine.

Similarly, other forms of gendering within the pamphlet would be highly suspect, even hurtful, in our current historical moment. In the ninth issue of Ledige Frauen (Single Women), a photograph of a person assigned female at birth and dressed in a suit had the title "Elegant female transvestite (Transvestitin), who lives fully as a man." In a modern context it could rightly be said that there is a significant difference in meaning between living as a man, and being a man. We now use phrases like "transmen are men and transwomen are women," in order to advocate for acceptance of gender regardless of sex, and to ensure that such linguistic mistakes aren't made. The transvestites of the early twentieth century were less insistent on this point. The writers of Der Transvestit often reflected through their use of pronouns and gendered language, such as using the feminine "die Transvestitin" to refer to those that would likely now be considered transmale, and "der Transvestit" referring to the opposite. A concept that today is problematized, referring to someone as a woman who lives as a man rather than someone who simply is a man, was the standard conception not just for general society in Weimar Germany, but for the vast majority of vocal gender-divergent people.

The writer-readers of Der Transvestit flowed easily between different forms of masculine and feminine address depending on language construction and context. In the

\footnotetext{
${ }^{4}$ Unknown author. „Endlich - Endlich!“ Der Transvestit, January 15, 1925.

${ }^{5}$ Liebherr, „Elegante Transvestit, völlig als Mann lebend.“ Ledige Frauen, 9th issue, 1928.
} 
pamphlet's first issue, for example, there was the fictional story of a male transvestite named Karl Maria, who lived as a man but dreamed of acting on his internal womanhood. Throughout the tale, Karl Maria is referred to with masculine pronouns by the author regardless of his experience of gender, his gender expression, or his desire to pass as female. ${ }^{6}$ This is partly explained by German noun classes. "Transvestit" is a masculine noun and, as such, masculine pronouns are used to refer to a transvestite who has yet to be names as an individual. Yet, it cannot be denied that the noun is masculine in the first place. That is, "Transvestit" translates as (male) transvestite, a man assigned such at birth who desires or embodies womanhood, and the term takes masculine pronouns. "Transvestitin" translates to female transvestite, or a woman assigned such at birth who desires or embodies manhood, and the term takes feminine pronouns. At the same time, however, male transvestite authors and readers referred to themselves and others as "Misses ___, _ (Frau) “Dear miss ___ _ (Liebe Frau,) "Dear sister" (Liebe Schwester) and other feminine means of address. The "Transvestit" identity resided in linguistic and practical ambiguity, somewhere between womanhood and "das dritte Geschlecht," often wishing to live as women but often failing to find a place within the societal definition of womanhood.

Also worth consideration is the inherent binarism of Weimar transvestite modes of speech. Modern terms like genderqueer, nonbinary, genderfluid, agender demigender, etc, allow for clear, unambiguous discussion of those whose genders do not fit in or reject the sex-gender binary. The conversation of gender in the Weimar era, as discussed in the following chapters, was invariable conducted in relation to man- and womanhood,

\footnotetext{
${ }^{6}$ Henri, Eduard. „Der Tag des Karl Maria Roloff.“ Die Freundin, August 8, 1924.
} 
perpetuating rigid gender roles and the use of heavily gendered speech. At the same time, the term "third-gender," or "third-sex" (dritte Geschlecht) was used often, and the mixing of gendered language that took place demonstrates the confidence with which the transvestite community rejected the sex-gender binary with far fewer rigid controls on clarity and definition than we have today.

As transgender people still struggle for gender- and human- recognition today, to consider a transgender woman anything less than a woman full stop is to fail in common human respect. It can therefore be difficult to imagine why the gender-divergents of the past misgendered themselves by today's standards. But the transvestites of Weimar Germany are not alive today. Rather, they defined their gender experiences upon the language and cultural-political context of their own time. To apply modern terminology, pronouns, and gender theory to the people of the past is therefore both inaccurate and disrespectful. While the internal feelings of the transvestites of the Weimar Era were human, just as human as those of transgender and genderqueer people today, their interpretations of those feelings were wildly different based on the common culture, community, and theory of the day. In attempting to apply modern terminology to the gender-divergent people of the past, a historian would only succeed in misinterpreting and obsessing over the bodies and identities of historical figures instead of recounting their ideas, experiences, and accomplishments.

Just as walking up to a college professor and asking the exact nature of their experience with their own genitals would be dehumanizing, inappropriate, and irrelevant to the knowledge that should be sought from them, it is also the wrong question to ask of the cultural ancestors of the transgender community. Imposing a concrete, modern gender 
identity onto any individual lost to the past only serves to make us, the modern reader, comfortable with the bodies and appearances of those historical figures, instead of honoring their lives and experiences however alien to us their context may be. Therefore, the fluid definition of the terms Transvestit and Transvestitin in the 1920s simply cannot be represented properly with modern discourse on gender, in part by their representation of the flawed, ambiguous nature of sexology, gender studies, and general culture of the time. Instead, the readers and writers of Der Transvestit should be discussed with the same terms and pronouns by which they defined themselves.

For the transvestites of Weimar Germany, these terms carried different meanings than they do today, with far more flexibility and ambiguity in how gendered language reflects gender experience. In the following text, therefore, the vast majority of the individuals discussed will be referred to as transvestites, as they referred to themselves. The names and pronouns used for them will be based on those they used for themselves as well, or inferred from the context of their writing, and will therefore most often mean using "he/him" for those who were assigned male at birth, and "she/her" for those assigned female.

The reader should not allow the stories accounted here to lapse into the realm of abstract theory which, as you will see, many have attempted to do even at the time. Der Transvestit was a community post board for the isolated and oppressed, a how-to guide in a harsh and dangerous world, and an expression of collective dreams and fantasies all printed in tiny font to fit in the little paper leaflet afforded to the gender others of society. 
The accounts, stories, and debates discussed should also not be considered as a collective history of an outdated society regardless of how conceptions have changed in the decades since. Der Transvestit was held in the living hands and read by the eager eyes of thousands of individual people, bought from newsstands and shipped to homes across the German-speaking world. Der Transvestit was an attempt for each reader and author to build a community in print, no longer limited by distance or isolation - an attempt which succeeded for nearly a decade despite censorship and vitriolic misunderstanding. It is thanks to these individuals, who protected these leaflets from destruction or obsolescence through the turbulent twentieth century, that today we can attempt to build a transgender community no longer limited by time, honoring the secretive ancestors of our own progress. Therefore, as you read, consider this not to be an analysis of a historical text, but an analysis of the community, identity, fantasy and humanity the many transvestites who, against the social, physical, and legal dangers of their identity, built the communal space of Der Transvestit through which to live life on their own words. 


\section{Pathologization and Policing of Transvestism}

In Weimar-Era Germany, the term "transvestite" had a broader meaning than it does today. First coined by Dr. Magnus Hirschfeld in a publication titled The Transvestites (Die Transvestiten) in 1910, transvestite was originally rigidly defined as a man with the sexual desire to dress like a woman. ${ }^{7}$ Prior to the 1920 s, however, there was no real terminology for a person who embodied a gender outside of the boundaries of the normative sex-gender agreement beyond mere appearances. In The Transvestites, Hirschfeld first raised the idea in scientific circles that transvestism may not always include a sexual drive, but may also be an expression of gender irrelevant to sexual orientation. In 1923, Dr. Hirschfeld expanded the scope of his research beyond reflections of cross-behavior and dress to include those who wanted to do more than just dress the part. He coined the term "Transsexuel" to describe a person who, in the terms that would have been used at the time, was of the opposite gender and desired to change their sex.

After this single use, however, he would return to his preferred term of "Transvestit" to refer to both a man who wished to wear women's clothes and to as "...the urge to present and conduct oneself in the outer raiment of the sex to which a person does not belong-as regards the visible sexual organs." ${ }^{8}$ Hirschfeld believed the two phenomena were interconnected, representing different points on a gender-diverse continuum. Transvestism and transsexualism wouldn't be fully differentiated in scientific circles

\footnotetext{
${ }^{7}$ Beachy, Robert. Gay Berlin: Birthplace of a Modern Identity. Alfred A Knopf Incorporated, 2014, 87-88.

8 "Transvestitism," Magnus Hirschfeld Society, Magnus Hirschfeld Institute, April 1, 2021, https://www.hirschfeld.in-berlin.de/institut/en/theorie/theo_13.html.
} 
again until Dr. Harry Benjamin brought "transsexual" back into use in the 1950 s. $^{9}$ In the meantime, Hirschfeld's term "Tranvestit" remained the most-used term among sexologists and the gender non-normative alike, even among those who disapproved of his theories. ${ }^{10}$

While crossdressing and non-cisnormative gender experience have always existed, they were completely misunderstood by both the public and by the police in Wilhelmine and Weimar Germany and transvestites were forced to play by a set of degrading and illogical rules in order to survive. While there was no law explicitly banning cross-dressing, 19th century German law punished it to the fullest extent if practiced in public. Specifically, a public crossdresser could be arrested for violating Paragraphs 360/11 and 183 of the RStGB, for causing "gross mischief" or "creating a public nuisance," for which a supposed nuisance-creator could be jailed for up to six weeks and fined 150 marks. To make matters worse, prior to the Weimar revolution in 1918-1919, the police had even more far-reaching power over the social and moral behavior of the people. The laws in question required visible "mischief," and enforcement against cross-dressing was arbitrary and entirely dependent upon the perceptions and whims of individual police officers and judges. Therefore, the public nuisance laws didn't regulate crossdressing as much as they regulated the ability for crossdressers to pass in the eyes of a conservative and moralistic police force. ${ }^{11}$ Harassment by police against those they considered of unacceptable appearance was rampant, and even cisgender women or men who, while not cross-dressing, simply

\footnotetext{
${ }^{9}$ Beachy, Robert. Gay Berlin: Birthplace of a Modern Identity, 178-179.

${ }^{10}$ Sutton, Katie. "WWe Too Deserve a Place Under the Sun': The Politics of Transvestite Identity in Weimar Germany." German Studies Review 35, no. 2 (2012), 336.

${ }^{11}$ Sutton, Katie. "“We Too Deserve a Place Under the Sun”", 337.
} 
possessed ambiguous physical features were arrested. Unlike their crossdressing counterparts, these individuals would eventually be released. But it is nonetheless apparent that the police, knowingly or not, considered the failure to pass as a normative man or woman and not cross-dressing itself as the punishable offense.

It was in response to the legal and social dangers posed to transvestites that Magnus Hirschfeld constructed his theories and began his initial pathologization of transvestism in the early 1900s. He worked with the police and the courts, establishing a differentiation between cross-dressing as "disorderly conduct" and cross-dressing as a symptom of the "pathology of transvestism," in which an individual could not control their own "inverted" feelings or behavior. Over the course of 1908 and 1909, Dr. Hirschfeld along with psychoanalyst Karl Abraham came to the assistance of Katharina T., a transvestite who appealed to the Police President in Berlin for permission to dress as a man in public and to take a more masculine name. With the help of both doctor's testimonies, she won the right to legally cross-dress, but was denied a name change for "formal legal reasons."

Katharina T. was the first of dozens of transvestites to receive a transvestite pass (Transvestitenschein) from the police. Hirschfeld's signature was on every passport, using pathological lack of control as a justification for transvestite protection under the law. If stopped by the police for cross-dressing, Dr. Hirschfeld's patients could present their pass, with pictures of them in both masculine and feminine dress as evidence that a medical professional deemed their cross-dressing congenital, and they would not be arrested. Hirschfeld was a strong advocate of these passports, encouraging transvestites to 
obtain them as a form of legal protection. ${ }^{12}$ While these passes did prevent arrests, they arguably did not increase compassion, but simply changed the nature of police harassment. Rather than changing the law, these passes reinforced it by simply creating an exception and singling out individuals who looked different, and leaving those who could not afford a transvestite passport with arrests and fines. Additionally, the process of acquiring the passport often included private exposure in front of doctors and police, including nude photographs and an admittance of mental illness. While the passports did offer some legal protection, they were a simply a perpetuation of the same regime of visual, medical, and penal surveillance by the police.

Throughout the Weimar era, police officers continued to perceive themselves as responsible for upholding both the law and traditional moral values. After the revolution in 1918-1919 however, the newfounded democratic welfare state diminished the overreaching moral and social power of the police by delegating some of their previous authority to the likes of social workers and other such officials. The establishment of a government that theoretically encouraged individual moral freedom led to a more compassionate official stance by the police on the meaning of "gross mischief." An accusation of gross mischief or public nuisance now had to include prostitution, thievery, homosexual activity, or other such lawbreaking beyond the mere act of crossdressing. At least on paper, these changes indicated that the police could no longer conflate the personal act of cross-dressing with those actions deemed immoral by the law, as expressed in a 1922 police report:

12 Beachy, Robert. Gay Berlin: Birthplace of a Modern Identity, 171-173; Sutton, Katie. "“We Too Deserve a Place Under the Sun'", 337-8. 
"Apart from male prostitution, transvestism in general has no criminal significance. The widespread public opinion that the disguised individuals are generally criminals in disguise (pickpockets, spies, pimps, etc.) is obsolete. With regard to the male transvestites, recent experience shows that even the formerly taken-for-granted view that men in women's clothing are all homosexuals is no longer tenable.... On the basis of this insight emerges a duty of gentle treatment [schonenden Behandlung] of transvestites, as long as they are not engaged in male prostitution." 13

Police harassment and arrest of crossdressers for the mere act of crossdressing continued at only a somewhat diminished rate, and the social dangers of being exposed as a transvestite remained similarly high. This more relaxed sentiment and legal precedent nonetheless paved the way for a more public transvestite counterculture to recruit members and fight for greater recognition in society. Sex work and poverty became the police's new excuse for controlling gender and sexual deviance, so that those crossdressers who could afford transvestite passes and more culturally acceptable lines of work faced less harassment than before.

The nature of the police's relationship to prostitution is unique depending on its nature. Female prostitution was legalized in 1927, while male prostitution and homosexuality remained illegal despite the significant overlap in the struggles of the three groups. ${ }^{14}$ Hirschfeld himself established a careful distinction between homosexual and transvestite men with means and those who used sex work to pay the bills by pointing out the desperation of their situation, but also by claiming that those men who turned to crime and sex work were "feebleminded," and had "criminal dispositions.",15

\footnotetext{
${ }^{13}$ Sutton, Katie. "'We Too Deserve a Place Under the Sun"”, 338.

${ }^{14}$ Marhoefer, Laurie. "Degeneration, Sexual Freedom, and the Politics of the Weimar Republic, 1918-1933." German Studies Review (2011): 532.

${ }^{15}$ Marhoefer, Laurie. "Degeneration, Sexual Freedom, and the Politics of the Weimar Republic, 1918-1933," 540-541.
} 
The lessening of police harassment of middle- and upper-class transvestites shows how effective the poverty-as-degenerate illness strategy was. The scandal was attributed to race rather than sexuality or gender, defining the fight for homosexual and transvestite protections in terms of respectability rather than liberation. 


\section{The Bund für Menschenrecht: Organizing Respectable Homosexuality}

It was in the homosexual and lesbian cafes, clubs, and organizations of metropolitan Germany that transvestites initially found footing as a community and began to form collective identities. Male homosexuals had an advantage over transvestites in terms of cultural formation, because they most often could present themselves to the world in the most culturally idyllic form (as men). Male homosexual identity and culture was therefore already well-established long before transvestites came onto the scene en masse.

In the earlier Wilhelmine era, Homosexual social and legal reform was a common topic of debate as part of a more general conservative, traditionalist "gender crisis" around family dynamics. Most homosexual activist groups, however, tried to separate themselves from debates on feminism, "New Woman" culture, and the legalization of contraception, abortion, and prostitution, as opposed to working alongside these movements. ${ }^{16}$ In a patriarchal society, separating homosexual rights activism into a solely male movement had its advantages, and male homosexuals faced a different challenge than other gender and sexually divergent groups. Where neither lesbianism nor transvestism in private were technically illegal, residing in a murky legal grey area, Paragraph 175 of the German Criminal Code made male homosexual activity in public or private explicitly illegal under harsh penalty. With a far more easily definable threat looming over male homosexuality, the first homosexual rights groups formed decades

\footnotetext{
${ }^{16}$ Ramsey, Glenn. "The Rites of Artgenossen: Contesting Homosexual Political Culture in Weimar Germany."Journal of the History of Sexuality 27, no. 1 (2008): 88.
} 
earlier, in the late 19th century, and were far more unified than any transvestite movement of the Weimar era would become. While the various homosexual rights groups may have disagreed on how to get there, every turn of the century homosexual could gather around a single goal: abolish Paragraph $175 .{ }^{17}$

The two largest homosexual rights groups before that time were the Community of the Special (Gemeinschaft der Eigenen) and the Scientific Humanitarian Committee (Wissenschaftlich-Humanitäres Komitee). Each was defined by their own general political leanings, theories on the nature of homosexuality, ideas on proper homosexualcultural discourse, and their own goals for what the future should entail for homosexual Germans. However different their approaches may have been, both organizations shared the desire to normalize male homosexuality on the grounds of its benefits - or at least lack of harm - towards mainstream society. It wouldn't be until liberalist Weimar fantasies gripped the nation that a third organization would emerge, with the call for freedom of action and individual privacy that we still hear today.

The Gemeinschaft der Eigenen (the GdE) had strong German Nationalist leanings, using the science of "social hygiene" to support their claim for a place in general German society. ${ }^{18}$ They upheld an idealized version of Hellenistic "Greek love," appealing to ancient Greek customs of normalized male-male sex, to popularize an image of the ideal German male that can be, or even is by necessity, at least bisexual. Arguing that bisexuality is the default of humanity, they argued that homoerotic desire was the

\footnotetext{
${ }^{17}$ Ramsey, Glenn. "The Rites of Artgenossen: Contesting Homosexual Political Culture in Weimar Germany," 86.

${ }^{18}$ Ramsey, Glenn. "The Rites of Artgenossen: Contesting Homosexual Political Culture in Weimar Germany," 89.
} 
key to protecting male youth from unsavory sexual connections. ${ }^{19}$ The GdE would regularly use the nationalist dichotomy of "blood and soil," and perpetuate associations between German youth unity movements and homoeroticism, all while using the aesthetic of German Kultur and Greek classicism to attract members of "quality over quantity." ${ }^{20}$ Their goal was to normalize a specific manner of homosexuality which they perceived as in accordance with - or even beneficial to - a German Nationalist society. With this in mind, there was no interest in uplifting more than a rare few German gay intellectuals, and no need to justify homosexuality in its own right.

More generally in homosexual and lesbian circles, however, bisexuality was harshly judged as a form of moral corruption. While bisexual individuals were prominent, they were rarely welcome within the community and their perspectives rarely published in the written sources that survived to this day. When their perspectives did appear, they were often met with sentiments such as "a person [cannot] serve two masters." ${ }^{21}$ Theories of universal bisexuality ${ }^{22}$ were pervasive in general society, such as those outlined in Sigmund Freud's Three Essays on the Theory of Sexuality in 1905, which declared that all infants were essentially attracted to everyone. Through his usual focus on childhood

\footnotetext{
${ }^{19}$ Ramsey, Glenn. "The Rites of Artgenossen: Contesting Homosexual Political Culture in Weimar Germany," 99. Unfortunately for the generations of gay men to come, the Hellenistic attitude of GdE supporters also included the practice of pedophilia. Older men in ancient Greece would often take on a young, adolescent pupil as both student and "lover." The disturbing association of pedophilia and male homosexuality existed long before the GdE, and the organization did nothing but encourage this perception moving into the 20th century.

${ }^{20}$ Ramsey, Glenn. "The Rites of Artgenossen: Contesting Homosexual Political Culture in Weimar Germany," 104.

${ }^{21}$ Espinaco-Virseda, Angeles. "I feel that I belong to you": Subculture, Die Freundin and Lesbian Identities in Weimar Germany. Spaces of Identity vol. 4 (2004), 92-93.

${ }^{22}$ The term "bisexual" was common at the time and had very broad interpretations. The definitions implied here are by no means the same as those today, nor are the all-encompassing of those theories and manners of sexuality to which they were applied in the past.
} 
development, Freud claimed that this universal sexuality would then be refined into "a normative heterosexuality" through proper parenting. ${ }^{23}$ Homosexuality and lesbianism, in this corruption model of sexuality, could be caused by poor parenting or bad external influences, painting gay individuals as sinister deviants. It is unsurprising, therefore, that the homosexual and lesbian communities distanced themselves from bisexuality, scapegoating and isolating them from the rest of the community. The legacy of this rejection stays with us today, as bisexual humans struggle to find a place in LGBT communities.

On the other end of the political spectrum than the GdE was the Wissenschaftlichhumanitäres Komitee (the WhK), whose leadership often had distinctly communist leanings. ${ }^{24}$ The WhK did not appeal to nationalism and Kultur for recognition, instead focusing their efforts on a scientific approach to homosexual acceptance. Magnus Hirschfeld was himself a founding member, and his Institute for Sexual Science was integral to the organization's efforts. It should come as no surprise, therefore, that the WhK used a sexological, or pathological approach to homosexual liberation parallel to Hirschfeld's justification for transvestite passes. The WhK argued for the abolition of Paragraph 175 on the grounds that homosexuality is congenital, cannot be spread from person to person and, most importantly cannot be restrained in the homosexual man, therefore making it a harmless condition for which the homosexual cannot justly be prosecuted. This approach to Paragraph 175 created a necessity for thorough scientific theories on gender and sexuality.

${ }^{23}$ Beachy, Robert. Gay Berlin: Birthplace of a Modern Identity, 151.

${ }^{24}$ Ramsey, Glenn. "The Rites of Artgenossen: Contesting Homosexual Political Culture in Weimar Germany," 86. 
The WhK, and Magnus Hirschfeld, propagated a theory of sexual intermediacy, in which homosexuality is a kind of third gender in-between male and female. Unlike the masculinist ideals of the GdE, sexual intermediacy argued that homosexual men are naturally more feminine than their heterosexual counterparts, even if that femininity didn't present outwardly as "inverted behavior." 25 The sexual intermediacy theory, along with the WhK's political leanings, opened membership in the homosexual community to a much broader range of people, even if the organization itself appealed mainly to a scientific and political minority. Where most bourgeois homosexuals considered male prostitutes indecent and false-homosexuals, for example, Hirschfeld considered prostitution to be a more "innate" character flaw and the legal issues therein (such as blackmail) to be a soceo-economic issue as opposed to a homosexual one. ${ }^{26}$ Transvestites were also regular visitors and patients at the Institut für Sexualwissenschaft.

Hirschfeld's flexible and diverse theories suited the Life Reform Movement in which he took part. He saw various degrees of masculinity, femininity, and hetero- or homosexuality as natural, and believed in the goal of cultural revolution by rejecting previous models of acceptable behavior and demanding that society change in order to include alternative ways of being. The WhK, therefore imagined not only a scientific, clinical view of sexuality, but also a reformation of society into a shape that could include the gender- and sexual-divergent people in its numbers. To them, culture and society as it stood needed to relax its sexual rigidity and, in the process, any kind of healthy sexuality could be collectively accepted.

${ }^{25}$ Ramsey, Glenn. "The Rites of Artgenossen: Contesting Homosexual Political Culture in Weimar Germany," 92.

${ }^{26}$ Ramsey, Glenn. "The Rites of Artgenossen: Contesting Homosexual Political Culture in Weimar Germany," 95. 
The WhK's approach to the homosexual man's place in society was entirely different from the GdE's, although similarly collectivist in nature. Both the WhK and the GdE were founded well before the Weimar political structures tool hold, and as such their strategies for legal reform were based on cultural and scientific justifications to sway a moralistic, hierarchical government as well as a conservative society. Be it by reshaping society or by proving homosexuality's benefit, both organizations sought a place for gay men within society, but not necessarily for the individual homosexual man. The installation of a democratic government in 1919 sparked the homosexual imagination to dream of a new kind of society, a liberalistic society in which individual rights and freedoms could take precedent over moralistic ideology, allowing for freedom to discuss homosexuality in public spheres and for Paragraph 175 to finally be abolished on different terms. Of course, this is not what happened, but the perceived potential caused a dramatic shift in homosexual right's strategy away from theoretical future acceptance and towards bolstering a homosexual identity. This new strategy would knock both the WhK and the GdE off of center stage.

Around the year 1920 a new group, called the German Friendship Association (Deutsche Freundschaftsverband, or DFV), formed out of this newfound boldness. As a loose-knit coalition of smaller, local homosexual groups, the DFV brought local homosexual organizations and individuals out of the shadows and into a brighter spotlight. Unlike the niche scientific or philosophical appeal of its predecessors, however, this new coalition attracted a wider array of middle-class laypeople, centering around homosexual events and practical meeting places like gay clubs, cafes, and ballrooms. The 
DFV grew rapidly, soon rivaling the WhK and the GdE. ${ }^{27}$ Despite attempts by the WhK to assimilate the DFV into a social branch of their organization, the newfounded DFV made it clear that they were done with the WhK's outdated methods of appealing to science and the social elite. Instead, the DFV began something that homosexual rights activism had yet to do in Germany: mass involvement. ${ }^{28}$ The DFV's mass movement strategy would become the foundation of the infamous Queer Weimar Berlin culture, as well as the launchpad for yet another organization, the Federation for Human Rights (Bund für Menschenrecht, or BfM), to become the publisher of the most popular and longest-running transvestite media before World War II.

Friedrich Radszuweit, a former publisher for the WhK, would become the founder of the BfM. Little is known about Radszuweit's personal life, except that at the age of 25 in Berlin, he started a financially successful women's clothing sweatshop and boutique in 1901. There is no evidence of his involvement in homosexual organizations until 1919, when he was already gaining national prominence as a co-publisher of the homosexual magazine Die Freundschaft (The Friendship), as a writer, and a chair of the DFV. By 1923 he had taken over centralized leadership of the DFV, under its new name, the Bund für Menschenrecht. Through his shrewd business skills, the organization grew rapidly, both in membership and financially. Where previously science and cultural theory were central to activism, he had "now created a near identity between the Weimar 'movement' and profit. For Radszuweit, the pursuit of 'human rights' went hand in glove with

\footnotetext{
${ }^{27}$ Ramsey, Glenn. "The Rites of Artgenossen: Contesting Homosexual Political Culture in Weimar Germany," 92.

${ }^{28}$ Ramsey, Glenn. "The Rites of Artgenossen: Contesting Homosexual Political Culture in Weimar Germany," 94.
} 
commercial enterprise. ${ }^{29}$ Yet again the direction of homosexual rights activism changed, as Radszuweit and the BfM became the leading curators of not just sociopolitical strategy or scientific literature, but of popular media directed at homosexual, lesbian, and transvestite individuals.

The BfM's main goals were the same as the other three organizations: abolish Paragraph 175, and reform the criminal code. The BfM supported this goal by claiming that homosexuality is biological, existing in all ideologies, eras, and classes of society. Unlike the WhK or the GdE, the BfM required neither scientific pathology nor appeals to ancient wisdom, because individuals' rights demanded that the private lives of citizens not be meddled in as long as their behavior does not disrupt society. Since these goals lacked any specific political leanings and academic prerequisites the Bfm rapidly grew a large membership consisting of mostly middle-class workers, craftsmen, and merchants from all ends of the especially-polarized Weimar political spectrum. ${ }^{30}$

This is not to say that the BfM lacked an ideology. Every queer individual and community that envisions a future for themselves outside of the margins must create a language by which they can be understood, and a fantasy of the future that they wish to see. Radszuweit brought a new, bourgeoisie imagining of homosexuality to the individualistic $\mathrm{BfM}$, based not on shaping the status quo to make room for alternate ways of being, but instead shaping homosexuality to fit into the status quo. He especially disagreed with Hirschfeld's and a belief that homosexuality was a form of intersexuality, or "third sex," instead advocating for a masculine and respectable homosexuality that

\footnotetext{
${ }^{29}$ Beachy, Robert. Gay Berlin: Birthplace of a Modern Identity, 230-231.

${ }^{30}$ Ramsey, Glenn. "The Rites of Artgenossen: Contesting Homosexual Political Culture in Weimar Germany," 97-98.
} 
suited the more general expectations of male behavior. ${ }^{31} \mathrm{He}$ and the BfM regularly iterated a definition of homosexual that excluded those that they did not consider to be respectable. Male sex workers, effeminate gay men, entertainers, and homosexual transvestites were not only unwelcome, but were placed under the label of "freaks" instead. ${ }^{32}$ Radszuweit's homonormative ideology demonstrated the belief that it was possible to be gay, lesbian, or a transvestite without diverging from the norm, and that the oppressive societal norm was not at fault. His path to individual homosexual liberation, rather ironically, was to control homosexual behavior in the same manner as the gender expression, sexuality, and roles of heterosexual society are controlled, until the two are perceived as indistinguishably respectable.

Incorporating homosexuality into heterosexual society required as little disruption of fammilial architecture as possible. Radszuweit and the BfM, therefore, believed that masculine self-expression, especially in gay men but also in lesbians, was the only "respectable" form of homosexuality. ${ }^{33}$ In the eyes of the BfM, effeminate gay men were considered lesser than masculine gay men, and likewise masculine lesbians were considered superior. While similar to more masculinist, anti-feminist ideologies of the time, Radszuweit's own motivations were "to weave morally respectable homosexuals 'directly into the social fabric."' The BfM praised masculinity insofar as the organization rejected gender non-conformity in a sexual and societal context. ${ }^{34}$ A masculine gay man

\footnotetext{
${ }^{31}$ Sutton, Katie. The Masculine Woman in Weimar Germany. Vol. 32. Berghahn Books, 2011, 63.

32 Ramsey, Glenn. "The Rites of Artgenossen: Contesting Homosexual Political Culture in Weimar Germany," 98.

${ }^{33}$ Sturgess, Cyd. "“Die zarte Haut einer schönen Frau': Fashioning Femininities in Weimar Germany's Lesbian Periodicals." Dawson, Leanne, ed. Edinburgh German Yearbook 10: Queering German Culture. Vol. 10, 56-82. Boydell \& Brewer, 2018, 63-65

${ }^{34}$ Sutton, Katie. The Masculine Woman in Weimar Germany, 63-4.
} 
could still rule a household, wife or no, and a masculine lesbian could fill the role of a husband. Therein, the BfM called for public acceptance of gay relationships, while attempting not to disrupt the status quo of gender roles and household dynamics.

The BfM established these goals in their first publication on April 13, 1923, the Blätter für Menschenrecht (Pages for Human Rights). The magazine sent out the call to organize the homosexual laypeople who were not yet in the movement, and create a mass organization of homosexuals striving for the goal of middle-class respectability by simply shaping homosexual identities around the gender roles and household dynamics of general society. Thus, a blaring contradiction was also sewn into the fabric of the organization's ideologies. The demand for personal freedoms clashed with their own policing of the behavior of their members. "Contrary to its own theoretical claims, the 'private' was very much 'public'” within the organization. ${ }^{35}$ While this controlling, homonormative approach may have been more palatable to the heteronormative status quo, freeing homosexual activism from the niche theoretical corners of German society, it also created a value-hierarchy within gay, lesbian, and transvestite communities, and excluded experiences of gender and sexuality that did not fit their homonormative model.

${ }^{35}$ Ramsey, Glenn. "The Rites of Artgenossen: Contesting Homosexual Political Culture in Weimar Germany," 99. 


\section{Democracy, Censorship, and the BfM founding of a popular Queer Press}

The BfM, as an organization seeking widespread membership, broke with earlier tradition in the publishing of homosexual media. Where earlier the queer press consisted of elite scientific, philosophical, and artistic publications, the Blätter für Menschenrecht and other BfM magazines were also intended to entertain, build community, and spread awareness. The publishing of magazines on homosexuality purely for community and entertainment hardly seems like a radical idea in a social movement, but it wasn't as simple as calling for writers and deciding to publish. On the contrary, strict censorship laws required that any printed word on the topic of homosexuality serve a scientific or artistic purpose, and even then was carefully monitored. Even in the pseudo-enlightened Weimar Republic, fear of social and moral corruption, censorship laws, and myths about homosexuality spreading from person-to-person would make publication a dangerous and difficult task. Freundschaft, a magazine by and for gay men first published shortly after the end of the first world war, would nonetheless set the precedent for the existence of homosexual entertainment in print. Freundschaft would open the door not only for further male publications, but also for those intended for the lesbian, and the transvestite communities.

After the first world war, there was a widespread assumption that with peace and democracy came the end of extensive censorship. The Weimar sentiment of free, democratic speech, however, was regularly contradicted by the growing conservative, traditionalistic and nationalistic ideology from the democracy's earliest days.

Freundschaft, was therefore banned almost immediately after the Weimar government 
was created out of fear that the magazine would tempt otherwise heterosexual men and youth into homosexuality. The publishers went to court in 1921 hoping to dispel this belief, and brought up professional sexologists as witnesses. While still of the opinion that homosexuality had no place in respectable German society, the court was successfully convinced that sexuality was inborn, and the continued publication of Freundschaft posed no threat to the German Family. As long as the magazine was not inherently "obscene," and it pertained to art or science, topics of homosexuality and transvestitism were considered acceptable. ${ }^{36}$ Once the various competing homosexual rights groups heard the news, a boom in German queer publication followed shortly thereafter.

The BfM took advantage of this new possibility with the publication of the Blätter für Menschenrecht. The magazine was intended as an umbrella publication, uniting the homosexual, lesbian, and transvestite communities together. Its heavy focus on male homosexual issues, especially on the repeal of Paragraph 175, meant that lesbian readership of the publication never grew substantially. ${ }^{37}$ Lesbianism resided in a legal ambiguity unknown to male homosexuals. Unlike male homosexuality, there was no law against female love, but it was nonetheless considered morally objectionable, and arrests were often made on the grounds of moral corruption of others. The interests and concerns of the lesbian community were, therefore, significantly different from those of male homosexuals. The BfM realized this and, in 1924, began publication of Die Freundin, a

\footnotetext{
${ }^{36}$ Marhoefer, Laurie. "“The Book Was a Revelation, I Recognized Myself in it': Lesbian Sexuality, Censorship, and the Queer Press in Weimar-era Germany." Journal of Women's History 27, no. 2 (2015): 64-66.

${ }^{37}$ Ramsey, Glenn. "The Rites of Artgenossen: Contesting Homosexual Political Culture in Weimar Germany," 98.
} 
magazine by and for their lesbian membership. Die Freundin focussed more on social dynamics, lesbian works and events, and self expression, as well as the occasional article on Paragraph $175 .^{38}$ Thereby the BfM simply expanded their umbrella, uniting both groups under the same publishing house.

In terms of human rights concerns, transvestites and lesbians had far more in common due to society's and the law's approaches. The similarity, it seems, was not lost on those building the lesbian and transvestite communities, as from its very first issue Die Freundin included an insert of Der Tranvestit, drawing the third group into BfM membership. The magazine was a huge success, written accessibly for a middle-class audience. Despite their socially and legally precarious position, Die Freundin and Der Transvestit could be even found in newsstands across Berlin, right alongside popular newspapers like Berliner Illustrierte Zeitung, Deutsche Illustrierte, Deutsche Zeit, and Vorwärts, Die Freundin's covers often sporting photographs of naked women and headlines like "The Passion of the Alternative Woman." ${ }^{39}$ While there were five different lesbian publications in the interwar German-speaking world, that the most popular with a distribution of around 7,000, Die Freundin, consistently contained a section for transvestites is significant.

While the magazine was sold more openly than most queer media even today, it was far from accepted by the community at large or the law. Die Freundin was forced to halt publication in 1928 in order to avoid obscenity bans or restricted sales. ${ }^{40}$ In a show of stubborn determination, however, the BfM simply changed the name to Ledige Frauen

\footnotetext{
${ }^{38}$ Ramsey, Glenn. "The Rites of Artgenossen: Contesting Homosexual Political Culture in Weimar Germany," 99.

${ }^{39}$ Beachy, Robert. Gay Berlin: Birthplace of a Modern Identity, 106-107.

${ }^{40}$ Marhoefer, Laurie. 'The Book Was a Revelation, I Recognized Myself in it,' 82.
} 
(Single Women), even keeping the same font for the title. The only other major difference during the year in which Ledige Frauen was published was that articles about transvestitism and cross-dressing were dispersed throughout the magazine, as opposed to being housed in a separate leaflet. They continued the publication of Ledige Frauen until Die Freundin was allowed to continue a year later, along with Der Transvestit under the new name Die Welt der Transvestiten (The World of the Transvestites). The first issue of its return in 1929 sported a photograph of Lotte Hahm, a famous lesbian and transvestite who worked with the magazine extensively, triumphant and smiling in a full suit and holding a sign that read "Hurra! Die Freundin is back!" Die Freundin was then published along with Die Welt der Transvestiten, which remained one of only a handful of publications on gender deviance until 1933, when it was halted publication for good. For all intents and purposes, the contents of these differently-named publications were the same, and even had series that overlapped from one to the other.

In addition to the Die Welt der Transvestiten, the BfM published Das 3. Geschlecht (The Third Sex), a periodical exclusively about transvestites in May of $1930 .^{41}$ Around the same time, Lili Elbe sent waves through the transvestite community for successfully completing the gender-affirming procedure to change her genitalia. Although she died from complications the following year, her story helped to reshape what it meant to be a transvestite that were apparent in transvestite media. ${ }^{42}$ As such, Das 3. Geschlecht and the subsequent shifts in perspective that came with scientific

\footnotetext{
${ }^{41}$ Herrn, Rainer (Hg). Das 3. Geschlecht: Reprint der 1930-1932 erschienen Zeitschrift für Transvestiten. Männerschwarm Verlag, Hamburg, 2016, 5.

${ }^{42}$ Sutton, Katie. "“We Too Deserve a Place Under the Sun”", 347.
} 
advancements and the existence of an independent publication for transvestites are discussed independently in this text.

Die Freundin and Der Transvestit, and Das 3. Geschlecht were forever a publication of the BfM, and a creation of BfM members. As a result, it would reflect the goals, ideologies, and biases of the organization. Radszuweit insisted on a centered, universal focus of all BfM media on respectability, activism, and demonstrating a proper image for homosexuality to the public. His rigid expectations on member behavior and insistence in ideological unity therein was strict enough to cause conflict between his and other, minor branches of the BfM throughout Germany. ${ }^{43}$ Die Freundin and Der Transvestit therein, therefore, reflect a particular, bourgeois set of ideas about what it means to be a transvestite, placing a widespread, yet also exclusive transvestite community on display.

${ }^{43}$ Ramsey, Glenn. "The Rites of Artgenossen: Contesting Homosexual Political Culture in Weimar Germany," 99. 


\section{Image and Respectability: the formation of transvestite identities}

In 1927, Germany's transvestite media was sent abuzz by the BfM's founding of a "Coalition of Transvestites." Meeting weekly at the Taverne in Berlin, the short-lived group would inspire the formation of the independent "Special Transvestite Group" and the DFV's “D'Eon Organization" in 1929 and 1930 respectively. These were spaces in which transvestites could express themselves, exchange ideas, attend lectures, and put on social events without the threat of being outed or arrested. Even for transvestites who lived too far away and only heard about these meetings secondhand, this was an exciting new step for the still-young transvestite community. ${ }^{44}$

There was already a well-established public sphere for transvestites in Berlin before these groups had formed, through pamphlets and magazines like Der Transvestit. Gay bars such as the Eldorado were known for their transvestite clientele, and transvestite balls were held to make space for celebration, expression, and fundraising. ${ }^{45}$ Over time community, identity, and a politics of transvestite emancipation grew hand-in-hand, and it was the slow process of banding together through text and in physical space that led to the possibility of an explicitly transvestite-identified group like the Coalition. Just as they found freedom and acceptance in each other, middle-class transvestites began to use their own and the BfM's strategies of acceptance through respectability to define the transvestite as a whole, combining the personal and the political.

In the pursuit of public acceptance, this newly formed transvestite community centered their political strategy on middle class values, nationalism, and citizenship. In

${ }^{44}$ Sutton, Katie. "'We Too Deserve a Place Under the Sun'”, 339.

${ }^{45}$ Advertisement for Eldorado, Die Freundin no. 12, September 4, 1929. 
using the language of a more widely accepted, conservative politics, there was an apparent awareness of the threat that gender ambiguity posed to the rigid roles assigned to the members of a nationalistic society. ${ }^{46}$ The goal of the developing middle-class transvestite community was not to restructure society into a shape that allowed for visible gender ambiguity, but to structure transvestism to mirror society as it was, to not upset the gender-normative status quo, to obtain equality through invisibility. A transvestite ingroup developed around this concept, with acceptance and a belonging to the transvestite identity contingent upon proper behavior. The BfM and Der Transvestit constructed a transvestite "counterpublic," both subordinated to the broader public and intent on their own, independent identity formation. Meanwhile clubs like Eldorado and other newfound interaction developed the concept of "a shared disposition" that required a bourgeois respectability in order to obtain "transvestite citizenship" in which only certain presentations of transvestism (those that benefited a social agenda of respectability) were considered real. ${ }^{47}$

In the 11th September, 1929 issue of Die Welt der Transvestiten, an unnamed transvestite published a piece carefully policing the behavior of his own kind. In order to gain purchase in society, he argued, transvestites must be women in their souls completely. This included enjoying womanly tasks like housework. "But unfortunately," he lamented, "too many have only a partial desire of women's tasks." 48 The readers of transvestite media in Weimar Germany were constantly reminded this of how they should behave, present, and feel about themselves for the sake of respectability and belonging.

\footnotetext{
${ }^{46}$ Sutton, Katie. "'We Too Deserve a Place Under the Sun"”, 340.

${ }^{47}$ Sutton, Katie. "'We Too Deserve a Place Under the Sun'”, 337.

${ }^{48}$ Unknown Author, "Transvestit und Hausarbeit," Die Welt der Transvestiten, September 11, 1929.
} 
Lower class transvestites, sex workers, criminals, and entertainers, and other less respectable presentations were, on the other hand, considered morally inferior and not permitted to be "real" transvestites by this bourgeois subcommunity. These supposed "also-transvestites" (Auchtransvestiten) were assumed to be crossdressing solely for financial gain, as opposed to the middle-class "Transvestit," who cross-dressed out of an inborn, natural need. ${ }^{49}$ For the politically-minded, socially conservative transvestite for whom transvestite literature was made, only those willing to follow strict rules of normative and respectable cross-dressing were allowed. The concept of what is respectable is often unspoken and nonetheless complex, making it difficult to define in any overt manner. By attempting to deliberately give form to a respectable transvestite womanhood, however, the middle- and upper-class writers and activists for the BfM lay out the rules of proper conduct far more clearly than those for, for example, cisgender women. These regulations are nonetheless quite similar to those behavioral pressures given to cis women on the surface, although with some striking dissimilarities. Overall, they can be broken down into a simple set of gender rules:

\section{Behave within (and desire) only respectable bourgeois female behavior.}

A proper transvestite was expected to take joy in the most banal of a woman's tasks. The lack of overlap between transvestite emancipation and the feminist, "new woman" movements is made apparent in how strongly the writers for Der Transvestit conflate their own unpaid domestic labor with successful gender-authenticity.

\footnotetext{
${ }^{49}$ Sutton, Katie. "'We Too Deserve a Place Under the Sun”, 342.
} 
Elli Richard K wrote a detailed and decadent report of his own execution of womanhood in an article titled "The Transvestite and his (female) Partner (Partnerin)." The article can itself be read as a passive how-to guide for performing proper womanhood, validating Elli's own transvestism through the actions he lists while affirming and having them affirmed for him through subsequent reader response as politically and intrinsically essential. He recounts his respectable female behavior:

"It's the most wonderful on Sundays, when I spend the whole day as a woman. I spoil my Hans and do everything he wishes that I can read in his eyes. I wash the dishes after dinner and I feel satisfied when all the work is done. I do my hair and otherwise make myself beautiful for my man, powdering and perfuming myself. Then I leave him to his peace and quiet and begin my housework. These are the most beautiful hours that we have together." 50

On Sundays, Elli is the perfect example of a housewife and paints a picture of an idyllic middle-class domestic scene. She is cooking, cleaning, pampering her "Mann" through pure intuition, and making herself beautiful not for her own enjoyment, but for him. Elli uses these actions to describe his "day as a woman," and is therefore defining his transvestite womanhood by housework, subservience, and beauty for the sake of others.

\section{Be Inconspicuous within general society.}

"When we demand that the public acknowledge us, then we have the duty to dress and conduct ourselves publicly in an inconspicuous manner.... At home each person can do as they choose and as they consider right, but in public they must conform." ${ }^{51}$ In a rather contradictory statement, E. Raven made a demand of his fellow transvestites that is

\footnotetext{
${ }^{50}$ K, Elli Richard, "Der Transvestit und seine Partnerin,” Ledige Frauen 1, no. 10, 1928. ${ }^{51}$ E. Raven, "Das Empfindungsleben der Transvestiten," in Die Welt der Transvestiten, November 9, 1932.
} 
well in line with the magazine's publisher's views: in order to be present in public spaces, you must appear as though you are not present at all. With arrests, harassment, social disgrace, unemployment, and homelessness looming possibilities for any transvestite, the intolerance of the non-transvestite majority for any kind of gender incongruence was well known. A visible transvestite out in public, E. Raven made clear, is therefore subject to intense scrutiny. Rather than question the need for such scrutiny in the first place, however, he argued that it was the transvestite's obligation to blend into society's expectations in order to placate the general public, so that transvestism no longer appeared to be a threat to it. The middle-class reading audience of transvestite media was told that the path to freedom was through making yourself invisible in as many ways as you could, and was consoled with frequent reminders that they could do as they please in the privacy of their own homes.

\section{Dress modestly, fashionably, and with restraint.}

Nearly every issue of Der Transvestit and Die Welt der Transvestiten contained at least one story of a (normally fictional) transvestite's first dress. His fantasies about dress materials and cuts, about underwear, shoes and accessories were described in infatuating detail and often aligned with what he eventually purchased, or borrowed from a sympathetic friend. "The Day of Karl Maria Roloff," a "Skizze” by Eduard Henri on the first page of the very first issue of Der Transvestit, begins with the description of a wonderful night's sleep. Karl Maria dreams of a white silk dress, a dainty pair of patent leather shoes with buckles, and a new pair of ladies' stockings. He would eventually 
obtain them and revel in his ability to walk the streets and go to a ball unharassed. ${ }^{52} \mathrm{~A}$ simple, elegant dress, stockings worn properly (not rolled below the knees as was done in the more radical New Woman and Flapper aesthetics), and simple, stylish shoes would make up the wardrobe of the many other fictional first-timers that were to follow Karl Maria. Each of these stories, through the development of their modest transvestite desires into a successful cross-dressing reality, show the reader the necessity to behave - and to desire - appropriately.

In a later issue of Die Welt der Tansvestiten, Ellen Van Derk expressed his opinions on transvestite fashion, stating that "the simplest dress is, in our case, often the most elegant." 53 With the words "in our case," Ellen made clear the distinction that a ciswoman may be able to stretch the definition of female of respectability while, so he believes, a transvestite could not. As the publisher of these stories and opinion pieces, the BfM held multiple transvestite fashion shows over the years that encouraged a simple, modest aesthetic. The bourgeois transvestite community carefully policed the appropriate expectations not of women's dress and desire, but of transvestites', which consisted of an even more strict adherence to "contemporary, unadorned bourgeois fashion" than for their female counterparts. "Middle-class transvestite commentators bluntly rejected any clothing or accessories they considered excessively opulent, gaudy, or dated, such as corsets, costume rings, or oversized earrings, even as such fashions continued to be favored by female impersonators and entertainers." $" 54$ Anything that could stand out from

\footnotetext{
${ }^{52}$ Henri, Eduard, "Der Tag des Karl Maria Roloff,” Die Freundin 1, no. 1, August 8, 1924. ${ }^{53}$ Unknown Author. "Meinungsaustausch über Modefragen," Die Welt der Transvestiten, August 22, 1927.

54 Sutton, Katie. "“We Too Deserve a Place Under the Sun”, 342-343.
} 
the Platonic ideal of the bourgeois woman was considered inappropriately associated with the lower class, iconoclastic Auchtransvestiten, and should be avoided at all costs.

\section{Pass as female to gender-normative society, or stay in private spaces.}

When a trans or gender non-normative person walks down the street today, there is an elaborate series of tests that a they must pass at a single glance in order to receive the gender authentic seal of approval from cisgender passersby they might meet. Their clothes, voice, facial structure and expression, head and body hair, the size and shape of their body, how they move, the mannerisms they use, and many other subtle cues go into a cisgender man or woman's snap judgement of the sex-gender of everyone they interact with. For a trans person trying to move unnoticed through general society, the failure of even one of these elements fitting into the expectation means that the entire test could be failed, and they'll be clocked as "not really the gender that they claim to be" - as inauthentic.

For Weimar transvestites, public spaces consisted of those areas in which they were likely to be seen by the cisgender general public, such as a mainstream ball, a cafe, or on the street. Spaces in which a transvestite would only be met with scrutiny from themself or their fellow transvestites did not have the same strict rules. These were private spaces such as group meetings, bars like the Eldorado, and home, where a transvestite could dress and exist in women's clothing without fear of being clocked. ${ }^{55}$ Those that passed the tests of gender authenticity could have far more freedom (and far less harassment) outside of these rare safe spaces.

${ }^{55}$ Sutton, Katie. “'We Too Deserve a Place Under the Sun'”, 344. 
Passing requires a great deal of labor and skill in both physical and social presentation. Parents and normative society as a whole train children from a young age in these skills. Just as many struggle to meet up to the expectations of the gender to which they were assigned and explicitly trained in, it is challenging and by no means a natural skill for those that strive to succeed at the gender roles of the opposite. It is not a simple skill for the gender normative and nonnormative alike, and the ability to do so immediately through natural disposition remains in the realm of fiction, despite the widespread belief that certain behaviors and aesthetics (taking up little space, smiling, crying, lyrical speech, soft facial features, etc) are naturally disposed to one gender or the other. Passing, therefore, was both fantasy and goal for Weimar's middle-class transvestites, and the fictional stories that they wrote for the BfM's transvestite publications often demonstrated the unlikely ability of their heroines to pass with ease immediately upon donning their first wig.

In a fictional tale of a later issue of Der Transvestit, a transvestite named Max risks a trip to a local cafe dressed in women's clothing. He is positively overjoyed when the waiter calls him Miss (Fräulein) (“As the waiter left the table, his joy knew no borders. 'Miss,' he said!") ${ }^{56} \mathrm{He}$ is confronted with no challenger, no struggle, no need to hone his skills at female presentation and therein no need to question his womanly nature. Meanwhile the previously-discussed character of Karl Maria, before he ever dons a dress, is described as "the young man with the fine, feminine traits," and a rather blunt house painter proceeds to remark: "You're ugly, because you're a man. - If you were a woman, --- then, - yeah, then I think your beauty would really cause a stir!" This moment takes

${ }^{56}$ Unknown Author, “Endlich - Endlich!” January 15, 1925. 
place during an exposition on the nature of Karl Maria's transvestism. Not only is it confirmed, therefore, that he will be able to pass even among the most gruff and genderscrutinous populations, but also that his ability to pass is considered a justification of his transvestism. That is, being able to pass makes him a more legitimate transvestite than if he could not.

Personal safety was another, far more practical reason to prioritize passing when in public. Transvestites encouraged each other to only go into public in female form if they were certain that they would go unnoticed not only for political purposes, but for fear of the universal threats of ridicule, arrest, and assault, as well as the more bourgeois concern of social disgrace if outed. ${ }^{57}$ That the safety of the community was not the only goal warped the cultural weight of passing nonetheless. If a transvestite's gender validity and political or communal representation were also dependent upon passing, then not only was the bigotry and oppression of the cis-majority responsible for what happened to a clocked transvestite in public, but also the transvestite themself for failing to meet the gender standard for nonviolence.

\section{Be a part-time woman only.}

Rarely did a transvestite in the pages of the Weimar press write the modern cliches of "being born in the wrong body," "wanting to be a woman," or "always having been a woman inside." Indeed, statements like these, or an expression of desire for the very new medical interventions in the form of hormones or surgeries what were in their experimental phases in the early 1930s, were only rarely made, and were in defiance of

${ }^{57}$ Sutton, Katie. “'We Too Deserve a Place Under the Sun”, 343. 
transvestite expectations. ${ }^{58}$ Der Transvestit was instead full of personal accounts that begin: "Since my earliest childhood I've had the irrefutable drive (Trieb) to dress in girl's clothing and underwear; to be able to belong to this gender in some way and to be respected as a girl." 59 The author, in line with the ideologies of the community in which he writes, prioritized the desire of clothing and social status with a complete disregard for the role of the body therein.

That does not mean, that many transvestites did not have bodily considerations or desires, but rather that they were not acceptable. Marie Weis, a frequent writer for Der Transvestit throughout its publication, stated in an article on the "internal requirements" for transvestism that "...one really must lay down limits to one's desires....It is never possible to fulfill all of one's desires, and we must not remove ourselves from this principle. ${ }^{960}$ Marie made clear which desires of embodiment are acceptable, weaving restraint and lack of fulfillment into the identity of the respectable transvestite.

A proper transvestite pursued neither medical intervention nor a full-time life in their feminine form, because he still had to fulfill his role as a man within Weimar society. He would go to work, have a wife, care for his family in all of the ways a man was expected to, and then in his spare time privately enact his other life as a woman. While there appeared to be an understanding within the community that many transvestites held desires to be their womanly selves full-time, these were deemed impossible fantasies that must be regulated. In this way the middle-class transvestite

\footnotetext{
${ }^{58}$ Sutton, Katie. "'We Too Deserve a Place Under the Sun”, 347.

${ }^{59}$ Frau Heidi, "Lebensbild eines Transvestiten," Die Freundin no. 5, July 31, 1929.

${ }^{60}$ Weis, Maria, "Uber die inneren Voraussetzungen," Frauenliebe 2 (1931): 4
} 
community could maintain their position as undisruptive - even supportive - of the rigid gender roles of a conservative, nationalist German society.

\section{Be heterosexual. ${ }^{61}$}

Elli Richard, the perfect Sunday housewife who wrote "The Transvestite and his Partner," does not have a husband despite his use of "Mann," masculine pronouns, and the name "Hanz" to describe his partner. As established in the title with the femininegendered Partnerin, the reader is assured that he is in fact married to a woman. He explains his marriage through the nature of transvestism, speaking not just for himself but for all transvestites: "We (male) transvestites lead the internal lives (Empfindungsleben) of a lesbian woman." With the internal life of a lesbian, female identity and female attraction are made synonymous.

Until he was twenty years old, Elli explained, he believed that he was homosexual. But then he discovered "that as a person with male physiological characteristics, one could very well feel like a woman without loving a man." He explained his homosexual past away as a misinformed expression of his own transvestism (desiring the feminine feeling he derived from being loved by men). His homosexuality and transvestism could thus remain mutually exclusive despite him having practiced both. Elli's description of his romantic expression at the time of writing still have traces of homosexual inclinations, however, made more complex by their outwardly heteronormative appearance. He refers to his wife by the masculine name of "Hanz" and

${ }^{61}$ Given the gender ambiguity of early transvestism, allow me to clarify: A male transvestite in Weimar Germany, or a man who on occasion embodied womanhood, could only respectably have romantic and sexual relationships with cisgender women or female transvestites. 
and role of "Mann," her every action depicting white picket fence husband behavior. She reads the paper, rests, and admires Elli as he cooks, cleans, and dresses up for her. Elli is careful to justify this nearly-homosexual behavior. "There is a seeming contradiction when, as a lesbian-feeling woman, I am always writing of 'my husband,' but I only do so to do justice to his (the wife's) masculine nature." In other words, Elli's wife is masculine to such an extent, that the only means to communicate it clearly is by gendering her as male. Nonetheless, he emphasizes that his wife is still a woman, and the acceptable "lesbian feelings" of a transvestite can still be upheld through her. Where the line is drawn, therefore, is at the genitalia.

The trend of the masculine wife appears often in the first-person accounts in the transvestite media. Grete, a writer who will be discussed in far greater detail in the next chapter, stated that he loves his wife deeply, but that "I love her through my transvestite traits far deeper and more intimately. I love her with all of the great love that only a girl who loves her husband is capable of." 62 Willma, in an article titled "My Makes Me her Wife," described his wife's short hair, and how they both agree that he is better at the housework, and "that overall, I have more womanly virtues than she does." 63 For the sake of womanly identity, not only have the writers obtained some gender affirmation by taking on the role of wife to a husband as a mirrored image of respectable, heteronormative, bourgeois family dynamics, they also gained a form of feminine legitimacy through a performance of the female gender that is comparatively more authentic than that of their cisgender-female wives. For the sake of community and transvestite identity, however, they always reassured the reader that their wives are, in

62 Grete, "Transvestit und Hausarbeit," Ledige Frauen no. 2, 1928.

${ }^{63}$ Willma, "Meine Frau macht mich zu ihrer Frau," Die Freundin no. 11, 11th September 1929. 
fact, women in possession of the correct genitalia to allow for a productive, heterosexual physical compatibility. In this manner, a balance was kept between the desire for masculine (or no doubt in some cases male) romantic partnership and the expression of respectable anatomical sexuality.

The desired separation of moderate and right-wing homosexual activism from scientific views on both male transvestism and homosexuality were partially responsible for this expectation. Radszuweit's and the BfM's masculinist and respectability-based political strategies, for example, depended upon the ability for homosexual men to remain members of the masculine pillars of society. All the while, Hirschfeld's theories of homosexuality as sexual inversion and masculine-presenting homosexuals as the exception rather than the rule spread the opposite conception across Germany's more popular press. ${ }^{64}$ To combat this notion within BfM publications, therefore, there was little to no mention of the possibility for a homosexual man to also be a transvestite.

Similarly, female-to-male transvestites were rarely mentioned at all in transvestite media. Having been qualified within sexological discourse as nearly entirely lesbians, the concept of the existence of female transvestites threatened both masculinist theories for male transvestites, and sexological theories on the role of masculinity and femininity in the formation of sexuality. Only one female transvestite is discussed in the entirety of Hirschfeld's book Die Transvestiten, for example. ${ }^{65}$ While female transvestites were all but neglected and ignored, the heightened scrutiny placed upon male transvestites for

\footnotetext{
${ }^{64}$ Ramsey, Glenn. "The Rites of Artgenossen: Contesting Homosexual Political Culture in Weimar Germany," 99.

${ }^{65}$ Sutton, Katie. "'We Too Deserve a Place Under the Sun'”, 344.
} 
embodying a deviance in gender rather than in sexuality no doubt contributed to the strict and detailed behavioral definitions placed upon middle-class transvestites.

The consequences within the middle-class transvestite community for breaking this particular guideline could be severe. In March of 1928, one well-known homosexual leader in the Chemnitz branch of the BfM was discovered to have been a transvestite, living as "man and wife" with a homosexual man who was prominent in the community. Radszuweit, as leader of the BfM, was outraged that a Hirschfeld-esque "invert" had been working in the higher ranks of his organization, and the transvestite homosexual was stripped of his leadership position. ${ }^{66}$

Disapproval towards the intersection of homosexual and transvestite identities and expressions was not limited to homosexual men, however. There was often a distaintriangle between the homosexual male, lesbian, male and female transvestite communities in which no one group wished to be associated with the other. Just as Radszuweit's masculinist leanings had him and his compatriots pushing homosexual transvestites out of his organization, heterosexual transvestites were known to complain of the "homosexual taint" on their reputations as respectable "manly" men, fathers, and husbands in their day-to-day lives. Certain lesbians resented the association of female transvestism with female attraction as well, similarly attempting to maintain a sense of normativity in the eyes of the public. ${ }^{67}$ The constant exclusion of one group or another as well as the refusal of intersectionality encouraged the harsh control of transvestite identity formation both from without and from within their own community, all based on

\footnotetext{
${ }^{66}$ Ramsey, Glenn. "The Rites of Artgenossen: Contesting Homosexual Political Culture in Weimar Germany," 99.

${ }^{67}$ Sutton, Katie. "We Too Deserve a Place Under the Sun"”, 344-345.
} 
the naive belief that any one of these groups could assimilate into the mainstream if they were willing to throw the others to the dogs.

Bourgeois transvestite identity and regulation was a comparative endeavor. A male transvestite's gender authenticity was always in relation to the behavior of cisgender women and of other transvestites who failed to meet the mark. In order to fulfil the requirement of a lesbian internal life (as compared to the not-feminine-enough homosexual transvestite), the transvestite needed a wife. Yet, in order to fulfil the requirements of femininity and heteronormative behavior, they had to be more successful at female embodiment than their cisgender wives. The return of traditional femininity to the domestic labor sphere in the form of the happy, domestically busy transvestite required the compensatory acceptance of (cis-)women willing to blur the gendered boundaries of work, play, and appearance.

Even as transvestism required a competative spirit and a cisgender woman willing to lose the game of who femmes best, the cis- and heteronormative gaze also played a significant role in the formation of "respectable" transvestite identities. The six steps to correct transvestism above were each intertwined with the purpose of gaining the approval of the cisgender majority. Within their magazines and pamphlets, transvestites were encouraged to find "sympathetic women" to function as "mentors." 68 The presumption was, therefore, that womanhood and femininity was solely defined by how a cisgender woman interprets it, rather than by individual experience and desire.

${ }^{68}$ Sutton, Katie. "'We Too Deserve a Place Under the Sun'”, 343. 
In Der Transvestit's fictional narratives of first-time crossdressers, there was often a cisgender woman - usually a friend, sister, or lover - who appears to guide, encourage, and approve of the naturally-passing transvestite subject. In "The day of Karl Maria Roloff," Eduard includes Karl Maria's friend Hanna who, upon learning of his desire to wear women's clothes, says "Hm; if it makes you happy! - I'll lend you a few of my things!" He is shocked and elated that she understands, and the rest of the story consists of dialogue between the two of them. She helps him dress with a smile, although when he suggests a visit to the "Palais de dance" in earnest, she balks. "No, don't take this nonsense too far. You know that that's illegal (Verboten)!" While his womanly appearance is no problem, she questions his low voice. He answers her "in falsetto," and Hannah is made speechless by his impersonation of a feminine tone. She finally allows Karl Maria to walk down to the store in women's clothes.

In "My love is named Kurty!" by P. W., the transvestite Kurty gains the passing approval of a cisgender man, Dr. Bär. After sitting with Kurty for drinks, Dr. Bär declares that Kurty could easily go out into the world, both as a passing transvestite and with the understanding and approval of himself (“...You can absolutely get dressed up and go out as a woman, since I understand the soul-life (Seelenleben) of the transvestite.") ${ }^{69} \mathrm{Dr}$. Bär's approval indicates Kurty's relative safety in the world. As a transvestite who relies on the cis gaze to determine if he can go unnoticed in public, it is the cis gaze that decides if he should be arrested, accosted, or disgraced. Importantly, however, Dr. Bär also represents the fantasy of societal approval through the cisgender gaze, where the belief by

${ }^{69}$ P. W., "Mein Liebling Heißt Kurty!," Die Freundin 2, no. 3, February 1st, 1925. 
a heteronormative individual that a transvestite is beautiful, womanly, and passing is of higher value than the belief of his transvestite peers or of himself.

The goal of respectability for transvestites, of creating an exclusive identity in which only the most acceptable forms of cross-dressing constitute transvestism at all, was a normative, cis-centric approach to identity formation. It was, and arguably is, a strategy which acknowledges the unwillingness of heteronormative societies to accept anything less than complete assimilation to the norm. That is, this approach hopes that it can somehow appease heteronormative nature instead of questioning it. The writers for transvestite media therefore "created something of a paradox, as demands for legal and social recognition were formulated on the condition that the subjects themselves disappear from public view - a problem that has continued to plague transgender politics in the decades since..."70 The result of their activism was simply a narrowing of the transvestite population that was willing and able to read and include themselves in the transvestite media, so that the fight for respectable transvestite visibility would be lost to its own attempts to make transvestism disappear.

${ }^{70}$ Sutton, Katie. “'We Too Deserve a Place Under the Sun”, 343. 


\section{The Case for Handarbeit: Interior Womanhood and Domesticity}

Respectability was not just a political strategy that appeared in transvestite media when activism was being discussed. On the contrary, respectability was seeped into every element of BfM transvestite's self-conception and interaction, and virtually any article from Der Transvestit could be seen as at least partially motivated by respectability. The 1928 Handarbeit series, published in Ledige Frauen, perfectly demonstrates the complexity of the respectability issue when theory is compared to reality. This call for "thought exchange" (Gedankenaustausch) shows how three male transvestites validated and policed their own transvestism at the expense of those whose experiences may have differed even in the slightest.

Each of them also had to navigate the complex and precarious balancing act between their internal experiences of gender, the external, male gender roles to which they are obligated, and the external, female gender roles that they put upon themselves. Weimar capitalist society was built around the binary of interiority versus exteriority, with internal associations upon women of the home and the body, and external associations upon men with society, labor, and trade. With the conception of the New Woman bringing women out of the home and into social spaces as consumers, the transvestite stood as yet another threat to the gendered binary of interiority and exteriority. As a result, the respectable transvestites of the BfM established their identities in a game of mental gymnastics between feelings and actions, presentation and body, home and labor, male and female, all while perpetuating an antiquated, home-centered womanhood for themselves. The traditional gender values they supported were entirely complicated by their own existences as transvestites, inherently shattering gendered 
expectation. Yet they did their best to conflate the two, attempting to pin down a respectable transvestism when the entire concept of gender was anything but stationary. In the second issue of Ledige Frauen in 1928, Grete wrote a first-person account of some of his experiences as a transvestite. The article begins "As a child I was already more girl than boy, preferring to wear girls' dresses." He recalled a childhood spent wondering in vain why his desire to wear women's clothes was growing ever stronger with age. "Only I never found an explanation for my longing (Sehnsucht)," he wrote of entering young adulthood, and failing to become a soldier in the first world war due to "weakness of the body." After marrying in 1919 at twenty-seven years old, he found that his desires did not wane and he feared the day his wife may discover his secret. He was fully aware that his desires for femininity were inborn, saying “...Through thorough research I recognized entirely the gruesome trick has played with our instinct." While Grete accepted that he could not change who he was, he lamented his situation and isolation.

Grete recounted with relief that when he eventually told his wife, she accepted him and loved him as he was. Grete realized that their marriage was better since his secret had come out. Part of his justification for the improvement was the new, heteronormative balance of masculinity and femininity between them, as his wife possessed distinctly male traits. "Despite her great ability, prudence, and energy, which is nearly manly, she is entirely a woman (Vollweiberl), hence the fact that she has a woman for a husband." Grete believed that the union between the two of them worked because, in spite of his wife's "full-woman" status, she possessed the manly traits necessary to compliment his transvestism. Grete expresses the joy of his weekends and evenings, 
being a wife and Hausfrau ("I must say that I feel far better as a woman. In that way I can let my true feelings run free."), going so far as to say that, as a transvestite, he is able to love his wife more fully and completely. He concludes that the two of them live happily and healthily, not in perversion as the general culture likes to believe, and that they have every right to live as they do.

"All of our longing is not a sickness, even though some people would certainly seek a cure if it were possible: Our longing is inborn in us, we women have the right to such an attitude and recognition in social life." Grete lays out the unrequitable desire for womanhood, declaring the right of transvestites to live out the womanhood in their souls how they can. This radical declaration would, for a moment, appear to conflict with the respectable, highly policed transvestism laid out in the previous chapter. Grete continues, however, to elaborate on what exactly he means by "role in social life," and the exact nature of the recognition he desires:

"The full-transvestite (Voll-Transvestit) strives, in spite of his love for and gender preference of womanhood, to be able to live the life of his true sex, which his body holds inside. He is a woman with ever part of his soul. And what woman isn't happy when she is able to follow her heart's desire in her own home? Which woman isn't happy doing her housework and other lady's tasks...There I find it entirely given that a transvestite, when he has the urge to wear women's clothes, also gives his female "ego" the appropriate impression of womanhood in its entirety. Not only taking on women's clothing, but also her labor in entirety. Only then is he a transvestite in the full meaning of the word."

Grete thoroughly affirms the exclusivity of the transvestite identity as constructed within the framework of respectability, requiring more than just an interest in aesthetic as was presumed about those transvestites who made their livings via said aesthetic as

${ }^{71}$ Grete, “Transvestit und hausarbeit," Ledige Frauen, no. 2, 1928. 
performers or sex workers. Instead, the "full-transvestite" is obligated not only to fulfil female-gendered labor roles, but to instinctively desire those roles. However, Grete does give the definition of transvestite considerably more nuance than the simplistic parameters of proper transvestism outlined in the previous chapter. Grete differentiates total-transvestism from mere transvestism by defining the total-transvestite as a full, true woman. In other words, the Voll-Transvestit must also be a woman internally in his entirety. This definition is situated right alongside the frequent cases made in the very same pages imploring male transvestites to understand that they could never attain fullbodied or full-time womanhood and, even if they could, doing so would harm the respectable image of the transvestite as a still-functioning member of patriarchal society as merely a part-time woman.

What Grete's transvestite community concept of the unattainable physicalpractical embodiment of womanhood (via anatomy and life) is, however, entirely different from the emotional-social embodiment of womanhood (via desires and social roles) that every transvestite was expected to have. To Grete, womanhood is not defined by how a woman appears anatomically or physically, or even by her particular obligations to society. Rather, he is concerned with a woman's desired labor. The alsotransvestite, or the mere transvestite as contrasted to the full-transvestite, is presented by Grete as a kind of incomplete facsimile of womanhood in which the desire to perform socalled womanly chores is not present, instead only desiring the aesthetic, fun parts of womanhood. Total-transvestism, in Grete's own words, is "not only taking on the clothing of the woman, but also her entire work." 
Grete's opinions demonstrate that the identities and lives of Weimar transvestites are not so easily theorized or pinned down to a single definition, even as Grete herself attempts to narrow it to something tangible. Instead, the definition of transvestism shifted and flowed around the needs and agendas of the moment and the individual. Male transvestism was in constant interplay with the definition of general womanhood, which was itself experiencing an identity crisis during the interwar period. Grete's misogynistic view of women's labor and desire for it reflects only one particularly traditionalist, bourgeoisie, patriarchal definition of womanhood in a time when that definition was very much up for debate.

The concept of "Women's labor," for example, was being used to control the lives of cisgender women in this same era in which it was being used to affirm the experiences of transvestites. During World War I women were required to work in many industrial and otherwise modern, male fields, somewhat accidentally giving them a slightly more equal footing in terms of trade skills. After the war, however, the vast majority of women were still unpaid laborers in domestic settings. Of those that had paid work, the majority were returned to non-industrial, traditional, unmodern settings such as retail shops, bars, cafes, and workshops belonging to their male relatives. In addition to their "feminine," old-fashioned labor, women with paying jobs were still obligated to complete the domestic labor of their households as well. Wage-earning women, in other words, worked two jobs simultaneously, neither of which had evolved much with the modernization of labor and culture in the early 20 th century. ${ }^{72}$ The new priorities of the

\footnotetext{
72 Von Ankum, Katharina. Women in the Metropolis: Gender and Modernity in Weimar Culture. Univ of California Press, 1997, 60-61.
} 
Weimar Republic towards modernity and the individual rights and freedoms which that entails were not extended towards women, who were still considered naturally inclined towards domestic and hand labor.

Womanhood was, in this way, defined by the labor systems in which they could (or were required to) participate in. A woman therefore, according to general society, was a human being who necessarily conduct unpaid domestic labor, with additional paid (traditionalist) labor optional. While there are a myriad of other behavioral, cultural, and physiological concepts to draw upon for a definition as well, an emphasis upon labor spheres was certainly beneficial to a bourgeois transvestite community striving for female gender authenticity. One particular flaw, however, is that the BfM's transvestites, upholding their male identities during the working hours of their jobs as bankers, business owners and other middle-class male fields, did not have these womanly obligations pressed upon them.

Grete, it seems, solved this problem by adding the concept of internal drive to the definition, so that a woman becomes one who desires to conduct unpaid domestic labor, with additional paid traditionalist labor optional. Such a definition opens up the possibility of authentic, traditional womanhood to the decidedly untraditional transvestite based not on personal authority, but on culturally-appropriate internal feelings. The concept that all women love doing housework by their very being is, of course, absurd, and it is difficult to believe that Grete would deny womanhood to cisgender women who didn't feel like doing the dishes. He had no issue assessing authentic transvestism along these lines, however, rejecting those who did not keep a spotless home in order to authenticate his own respectable conceptions. 
While those transvestites who only wished to wear the clothes and mannerisms of femininity were, to Grete, incomplete, it is key to acknowledge that his conception of the total-transvestite did include a dress-code. Grete's focus on clothing, especially those clothes associated with traditional roles and modesty (aprons, housedresses, hose) reinforce the conservative, traditionalist values of Der Transvestit, because clothing has always had a vital role in defining and restricting the social expectations and practical capabilities of middle-class women. ${ }^{73}$ Indeed, the newfound creativity in fashion during the Weimar era was an essential tool in the "New Woman" toolkit for dismantling traditional womanhood. In trying on different femininities and masculinities through trends like the Bubikopf (pageboy, literally "little boy head") haircut, collared shirts, pants, shorter skirts, and sheer blouses, Weimar fashion questioned what it meant to embody womanhood successfully. ${ }^{74}$ What to some women was fun fashion, to others was a tool in social liberation, allowing them to participate in physical activities and professional spaces. To the respectable status quo, however, these aesthetics were a threat to the cut and dry categories of the Family, and therefore an endangerment of the German people's future.

From a femme-cut tuxedo being deemed a threat to female fertility to a short skirt affirming a woman's ability to drive a car, clothing can speak volumes. Women's fashion untethered from social obligation could run amok, bringing the entirety of the obligatory bourgeois culture into question. If the BfM's encouragement of modest, simple dress for their transvestite members was a plea for respectable normativity in the context of a

\footnotetext{
${ }^{73}$ You try doing anything in a corset and a hoop skirt and tell me that fashion didn't restrict the jobs available to women in the past.

${ }^{74}$ Von Ankum, Katharina. Women in the Metropolis: Gender and Modernity in Weimar Culture, 10.
} 
broader cultural revolution, then Grete's scathing attitude towards those who take joy in women's clothes without womanly duties was the affirmation of a gender anti-critical stance towards transvestism.

In the fourth issue of Ledige Frauen in 1928, another transvestite by the name of Gitta B. wrote a reply to Grete's Hausarbeit article. Gitta shared his own experiences and opinions, which were similar to Grete's in many respects. He too knew since childhood that he wanted to wear women's clothes and he too found no explanation as to why he did. "Then came the war," he wrote, "when I spent three years, with all the awfulness and danger therein, on the Western Front." The war put a traumatic pause on his introspection, but upon returning to civilian life, Gitta B. accepted his desires and began to dress in women's clothes.

He would go out to the city when he could, experiencing great joy in his ability to pass completely: "The fact that I was completely regarded as a woman in the open aroused a great feeling of joy in me and gave me a perfect, confident appearance on my later trips into the city as a woman." Just like Grete, however, when he eventually married he lived in dread of the day his wife would find out. But his wife could see something was wrong, and Gitta B. eventually broke down and told her the truth. "And how happy was I," he said of the experience, "when I found her to be fully understanding." It was with relief that Gitta B. also found full support from his "fullwomanly" wife.

Gitta B. described his joy-filled days in full-detail. Coming home from work, he would change into a house-dress with a pretty apron and make dinner "the way only a loving housewife can for her husband." He describes doing the dishes with his wife, and 
relishing in every household chore. "As for the housework," Gitta B. concludes, "I am of the same opinion that a transvestite who isn't able or doesn't want to perform his housework is no transvestite at all." 75 Gitta is in agreement with Grete on this definition, the only key difference being that where Grete differentiates between the mere transvestite and the "Voll-Transvestit," Gitta leaves the question open as to what a cross dresser who does not love housework might be called, since they clearly do not belong to the respectable category of transvestite at all.

The original definition of "transvestite" did not leave out any crossdressers. That is, unsurprisingly, the strict housework condition was not included in Magnus Hirschfeld's definition when he coined the term. While he did expand upon the definition detailing certain, more clinical elements, Hirschfeld's original definition was simple: 'It is the urge to present and conduct oneself in the outer raiment of the sex to which a person does not belong - as regards to the visible sexual organs."76 No doubt Grete, Gitte and their compatriots did not approve of this original definition by a non-transvestite sexologist, which included anyone from any background and level of (non)respectability. Indeed, that the Housework letters were deemed a worthwhile discussion makes it clear that the transvestites of the BfM felt the need to revise the definition for themselves, that the mere act of dressing is not enough to constitute true transvestism. It was as if they felt the need to voice directly to the medical, Hirschfeld definition: it's not that simple.

The term "Transvestit" was coined ten years before the Hausarbeit conversation, with plenty of time for the definition to grow and shift. Thanks to Hirschfeld, transvestite

\footnotetext{
${ }^{75}$ B., Gitta, "Transvestit und hausarbeit (Liebe Frau Grete!)," Ledige Frauen, no. 4, 1928. 76 “Transvestitism," Magnus Hirschfeld Society, Magnus Hirschfeld Institute, April 1, 2021, https://www.hirschfeld.in-berlin.de/institut/en/theorie/theo_13.html.
} 
was, by the 1920 s, the universal clinical term for any form of crossdresser. While this singular popular term was spelled and spoken the same within the gender-deviant communities of Germany, it was, for them, a far more hierarchically complex collection of words. First there was the also-transvestite (Auchtransvestit), an often laboring-class cross-dresser, at the bottom of the hierarchy. On the surface, this transvestite enjoyed the wild gay nightlife of Berlin, dressed enthusiastically, and often worked in women's clothes as a sex worker or entertainer. According to the middle-class transvestite media that coined the term, the also-transvestite was not internally motivated to cross-dress but rather financially, criminally, or sexually motivated, as evidenced by his lack of interest in womanly duties.

At the top of the hierarchy is the "Voll-Transvestit," who desires full-womanhood in all respects (subservience, housework, and dress) and who, whatever his internal feeling or true desire, dresses with restraint, strives to pass as the ideal bourgeois woman on the weekend, and returns to his job at the bank on Monday morning.

In the middle, rather ambiguously, are those who do not meet all requirements, but whose feminine internal feeling and desire for respectable womanhood cannot be denied so easily. Those who cannot pass but walk the streets, those who pursue full-time life as their female selves, those who are also homosexual, or who do not want to do housework yet also do not profit financially from their transvestism. Grete called these the mere "transvestites" to the "Voll-Transvestiten" while Gitte B. did not believe that they merited the word at all. While the middle group was the most studied, accepted, and discussed in sexological circles, they were rarely mentioned in transvestite publications, lest the acknowledgement of their existence threaten the respectability of the Voll- 
Transvestiten in the fight for heteronormative acceptance outside of the pathological. The term "transvestite," founded by a cisgender scientist on the grounds of physiology, had been taken and reshaped to suit the middle-class transvestite's conceptions of desire and social status.

In the same issue of Ledige Frauen in which Gitta B.'s ideas were published, a transvestite named Minna also responded to Grete with interest. Minna agreed with the other two, writing "I am also of the view that the two types are difficult to separate and that every transvestite likes to do housework. However, just as there are rulers and servants among women, so are there among transvestites. I personally belong to the latter group, and for me housework is a beloved task." He described his joy in wearing a modest housedress to dust, sweep, mop, do the laundry, and other chores. "Ideally I would love to serve as a maid, and I believe that my master would have nothing to regret Tidy and hardworking during the day, after work a sparkling maiden in a daisy-white apron! - A dream..."77

With that dream Minna's reply ends, and shows us once more how theory cannot easily encompass the reality of the interactions and identities of Weimar's respectable transvestites. Minna agrees wholeheartedly with Grete's view of transvestites even stating that transvestism simply cannot exist without the desire for housework. Minna goes further, however, not remaining within the realm of weekend and after-work transvestism as described by Grete and Gitta, dreaming instead of intersecting his transvestism and his labor by becoming a housemaid. Minna's wording indicates, however, that this dream is not necessarily attainable, but rather a fantasy based upon his

${ }^{77}$ Minna, “Transvestit und hausarbeit (Sehr Geehrte Redaktion!)," Ledige Frauen, no. 4, 1928. 
respectable transvestite desires. Becoming a housemaid is his ideal, his dream, but never his goal.

The role of a housemaid remains in the realm of fiction in other aspects as well. Whether as a result of his idyllic fantasizing or of an ignorance towards the realities of domestic labor, Minna paints a picture of a housemaid's day that is far from accurate. The housemaid in his fantasy spends the day cleaning thoroughly and comes out the other side clean and in a spotless white apron. This belittling of the skill and effort of traditionally women's work is a symptom of the transvestite media's attitude towards women in general. From presuming that women naturally enjoy cleaning their homes and serving their husbands, to using diminutive terms for women like "Weiberl" and "Dirn," the ideals of respectable transvestism were also those of oppressive, traditionalist family values.

While full-time female embodiment is Minna's fantasy, it appears to find its limit at anatomy. There is no mention of a desire for physiological change in the vast majority of Die Freundin and Ledige Frauen. Changes in gendered physiological traits were, after all, just as impossible as they were frowned upon to desire. Similarly missing is any sense of internal womanhood in the manner in which it is often discussed today. Minna's writing defines internal womanly desires solely by the external and social roles of women in society. Yet, this avoidance of intrinsic gender and gendered physiology is not followed for cisgender women. Normative gender is defined by Minna and her compatriots implicitly by how they discuss their wives as compared to themselves. Grete's wife, for example, maintains her "Voll-Weibliche" status even as she takes on the more husbandly roles attributed to her, while by the same account, a transvestite is 
required to remain in a domestic position to authenticate even partial womanhood. The status of "full-woman" is therefore reserved for those who were anatomically determined such at birth and thus socially conditioned throughout their childhoods, and they are able to keep that status even when they reject their expected roles. They were defined by their anatomy, and by a natural intrinsic womanhood (Innigkeit) that the respectable transvestite, in rejecting sexological approaches, was not permitted. The status of "fullTransvestite," on the other hand, was anti-physiological, dependent entirely upon the same social roles that the full-woman may reject.

The womanly Innigkeit of the politically-conscious, respectable transvestite was based not on a feeling of inherent womanhood, but instead upon an intrinsic desire for a particular female socio-cultural position. This desire-based conception allows those like Minna to acknowledge the wish for full-time female embodiment without unbalancing social hierarchies by actually doing so. The plight of the respectable transvestite was always within the constraints of maintaining a gendered power balance, so that the social implications of personal feelings of womanhood made those feelings impossible.

Respectable transvestites like Grete, Minna, and Gitta B. had a different kind of Innigkeit on fantasies of the idyllic bourgeois social relation and desire for women; not only internal to themselves, but to the home, the family and to society. 


\section{Hopeful Negativity and Lonely Community: Conflicting Feeling in the Transvestite Media}

The positive portrayal of life as a transvestite is consistent throughout the Hausarbeit series and in the vast majority of day in the life narratives. More specifically, they often depict suffering and confusion replaced by joy and acceptance after coming to terms with their "condition.” Both Gitta's and Grete's accounts refer to their early understanding of the desire to embody womanhood as akin to nature's cruel joke, suffering through the fear, shame, and isolation that often comes from failing to meet society's gendered expectations. By the end of their stories, however, both have attained their own happily ever after with accepting wives, lovely dresses, unashamed female domestic roles, and comfortable incomes inferred through the possession of homes, weekends, food, and fashion. In other words, both stories conclude in images of uncomplicated - if somewhat unconventional - domestic bliss.

Heidi S. ${ }^{78}$ contributed yet another autobiographical "Life-Image of a Transvestite" in which a similar story is laid out. Beginning with the acknowledgement that he had always had the desire to wear women's clothing, Heidi continues "What earlier I could only undertake with great secrecy and fear of becoming a target of ridicule, since I've been married for a year to a woman who understands my womanly soul-life fully I can act unabashedly." After a mere sentence of dismay, Heidi's problems are resolved with the appearance of his wife and friend. With the full understanding of his wife, Heidi feels free to live out his womanly fantasies. On weekends, at least. He describes the simple dress, apron, and stockings that he wears to cook lunch and clean alongside his wife,

${ }^{78}$ Last name partially obscured in the copies that were available to me. 
before both ladies change into "a better dress" in their "small, comfortable and purely femininely-adorned apartment." Often, he continues, the two will go out on Sunday evening "arm in arm, like two dear friends," to a cafe or a cabaret show. "Overall" he adds, "people consider us two women, and we are rarely interrogated." The only negative comment that Heidi has of his position is the absence of many other transvestites in the city of Hamburg with which to share his experiences, and he ends his tale with the polite request that those also in the city reach out. ${ }^{79}$

Heidi's self-described situation mirrors that of Grete and Gitta in great detail. They each have loving and accepting wives, and they each possess the correct womanly desires in just the right amounts to be sated only roleplaying domestic bliss on the weekends. The only major deviations for Heidi are his small apartment, which makes up for its modest size in feminine decor, and that he and his wife may venture outside of the domestic space. Their excursions to the outside world fulfill one of the greatest dreams of any transvestite since, as Heidi assures us, he passes as a woman, going unharassed with his wife by his side to reinforce their appearance as two real girlfriends. Lebensbilder like these were some of the most common articles in early transvestite media, showcasing the (supposedly) nonfictional lives of the writers as idyllic, attainable fantasies.

Living out their "feminine life of the soul," common descriptors throughout these accounts of weekend domesticity are joy, the most beautiful days, beauty, fully as a woman, great feeling of happiness, love, hope, and the concept of no longer being alone or ashamed. ${ }^{80}$ Each of these words reflects the desires of the readers of the transvestite

79 S., Heidi, “Lebensbild eines Transvestiten” Die Freundin no. 5, 31 Juli 1929.

${ }^{80}$ In their original German: Freude, schönsten Täge, Schönheit, vollkommen als Dame, großes Gluckgefühl, Öffentlichkeit, Liebe, Hoffnung. 
media, presented as the happy facts of the writers' lives. Given the harsh and dangerous reality of transvestism in the Weimar republic outlined in the first chapters (arrest, blackmail, harsh public judgement and pathologization, heavy censorship, high suicide rates and little to no health resources), it may be wise to take Grete, Gitta, and Heidi's self-proclaimed joy and contentment with a grain of salt. Indeed, the vocabulary they use and the areas of their lives that they chose to highlight beg the question of reality and, through the spaces in-between, can give an idea of the real struggles middle-class transvestites faced in the day-to-day.

The existence of the Housework series, for example, implicitly tells a second tale of gender authenticity. Grete and Minna's use of the term "full-transvestite," as discussed previously, indicates a hierarchy of trans-truthfulness in which the Auchtransvestit and the Transvestit are, in crossdressing, lying to society about their gender. Explicitly, this is a curation of respectability, allowing the Voll-Transvestit to exclude those that do not meet his tastes and expectations. Implicitly, this attitude potentially shows a deeper, more personal struggle for self-authenticity and self-belief.

Grete did not invent the concept of the lying, criminally-minded transvestite. Rather, the police did in long essays on criminal profiling, along with voyeuristic, freakshow-esque magazines on criminals and other culturally ostracized peoples. Das Kriminal-Magazin (The Criminal Magazine), for example, ran a piece with images of homosexuals and transvestites, sandwiched between an article on thievery and a murder mystery titled "Revenge." ${ }^{\prime 1}$ Meanwhile sexologists, doctors, social scientists, and popular media would define gender-divergence out of existence as fetish, delusion, and deception,

${ }^{81}$ Unknown Author. "10 Jahre Magnus Hirschfeld Stiftung." Das Kriminal-Magazin. Band 1, Aug 5, 1929, 50-55. 
and especially as illness into the 21 st century. "Gender Identity Disorder" was not removed from the American Psychological Association's Diagnostic and Statistical Manual until 2013, and the World Health Organization listed "transsexualism" as a mental disorder until 2019. ${ }^{82}$ The Housework series writers' use of this concept, therefore, came from heteronormative society's original projection of criminality and deception upon transvestites as much as their own internal misconceptions. Before accepting their own transvestism, Grete, Gitta, and Minna likely only heard tales of transvestites as thieves and murderers - if they heard anything about them at all. Even Magnus Hirschfeld, as stated previously, deemed some forms of transvestism as inherently degenerate cases of "feeble-mindedness." Criminality and transvestism were so culturally intertwined at the turn of the century that it is hard to imagine that these individuals did not, at some point, attribute the immorality, failure, and shame of such a title to themselves as well. This shines a light on the shadowy corners of their fight for respectability, one in which they were not just distancing themselves from those transvestites that they perceived as bad for their image politically, but also struggling to believe that it is even possible to be true to their gender expression without being incurably uninhibited and criminal themselves.

The shadows of negativity lurk around the edges of the transvestite media's Lebensbilder in other ways as well. All but one of the transvestites discussed here limits

\footnotetext{
${ }^{82}$ Heffernan, Dani. “The APA Removes 'Gender Identity Disorder' From Updated Mental Health Guide.” Glaad. December 3, 2012. https://www.glaad.org/blog/apa-removes-gender-identitydisorder-updated-mental-health-guide Fitzsimmons, Tim. “'Transsexualism' removed from World Health Organization's disease manual.” NBC News. June 20, 2018. https://www.nbcnews.com/feature/nbc-out/transsexualismremoved-world-health-organization-s-disease-manual-n885141 “Transgender no longer recognised as 'disorder' by WHO.” BBC News. May 29, 2019. https://www.bbc.com/news/health-48448804
} 
his expressions of womanhood to those that could be performed in the safety of his home. Their female souls were confined to domestic labor, not only to match the abstract concept of the respectable woman, but also because it simply wasn't safe to go outside. Even Heidi, who only leaves the home on occasional Sunday evenings, must reassure the reader that he is able to do so unharassed. If he's not careful, Heidi could be caught, arrested, beaten, disgraced, institutionalized, or killed. With this looming hypothetical in the reader's mind, they can imagine that Heidi could well have already been outed by the time the article was published. With every joyful chore completed and meal cooked comes an implicit awareness of a claustrophobic reality in which there are few safe avenues for self-expression.

Heidi's idyllic scene has other negative implications as well, mainly in the descriptions of the moments immediately before entering the feminine domestic space. "My service at the office is over around 4 o'clock in the evening, and the first thing I do when I get home is throw off my loathsome and detested (verhaßten und verabscheuten) Men's clothes and completely change my clothes." He embodies the ideal respectable transvestite, working as a man during the day and transforming into Heidi immediately upon returning home so that he can relish in a different kind of labor. This moment signifies the daily transition from outside to at-home, from male to female, and from a presentation of external, male propriety to one of internal, female sincerity. While his internal, home life is described at length as perfection, his attitude towards the hours in which he must embody manhood are clearly far from happy.

Heidi describes his male clothes as "loathsome" in this, his only mention of the working hours in which he must embody maleness. The transvestite media gives us little 
more than this for descriptions of male transvestites at their day jobs, so that the approximate quarter of their living hours they spend at work are displayed as dark references to implied suffering. Heidi's loathing of his work clothes, combined with Marie Weiss' call for restraint, in which one cannot responsibly pursue all that they desire, it becomes clear that many middle-class transvestites would eschew their male identities altogether if given the option. Such a move, however, would require sacrificing their social status, financial security, and physical safety. Combined with the pressure to uphold bourgeois family dynamics as well as their own male respectability, throwing out those loathsome male clothes was simply not an option for the majority of transvestites.

Heidi's "Lebensbild" is incomplete. Beginning with his return from work and ending with Sunday night. Perhaps he was presumed to be a "normal" man, those around him projecting that normativity upon him and his male clothes. Or perhaps some of his gender-divergence slipped out through his voice, his demeanor, his interests, or something else, garnering judgement and scrutiny from peers. He may have wondered if any of them could see through his male disguise and destroy his life from the outside in. Maybe he passed as the perfect male specimen, wondering if that heteronormative persona was better than his feminine self, since all but his wife would accept nothing else. Or maybe he was genuinely happy with his male side and simply hated suits and ties. We will never know what he did not describe, but we can be certain that many transvestites suffered at the hands of such secrecy.

The final dark implications of these happy life-snapshots was a question of internal gender authenticity, isolation, and external (cisgender) validation. Once Heidi has on her housedress, his description of his evenings and weekends shifts from the 
singular "ich" to the plural "wir," referring to what he and his wife are doing together. As though mirroring his wife's womanhood, they both cook, clean, dress, and go out in unison. He never does these supposedly womanly acts alone, and fails to list any private expressions of womanhood. He does not return to the singular "ich" in full until the last paragraph, when he expresses his isolation from other transvestites in Hamburg. In other words, Heidi's womanhood is external and social, while his transvestism is internal and lonely.

Gender-normative outsiders play a central role in much of the transvestite media, especially its fictional tales. From accepting best friends impressed by a transvestite's ability to pass, to waiters accidentally inducing gender euphoria by referring to him as "Frau," or "Fräulein," external validation from the status quo is a fantasy shared universally. The love that, for example, Grete and Gitte expressed for their wives is directly contrasted with the isolation, alienation, and fear that they both recalled having before getting married. While these optimistic tales also express the loneliness of being a transvestite, they are certain to frame that state in the past tense. According to them, isolation was a problem easily solved, as long as a single confidant within the privacy of home is satisfactory.

Transvestite media housed many of these happy, married accounts, which did not go unnoticed by those transvestites whose present was much like Gita and Grette's past. In 1928, Gerda Erwin Schröder wrote to Ledige Frauen to raise the question himself in an unusual display of transvestite negativity. In an article titled "Why Do We Transvestites Find No Partners? Utopias and Facts of Transvestism," Gerda questions the self-reported narrative of happy partnerships between transvestites and cisgender women. He begins by 
raising his own critique of the rarely-acknowledged female transvestite, which he compares to that of their male counterparts:

"The female transvestite (Transvestitin) stays exactly as she is in enlightened circles, and a gentleman would never dare make a comment about this woman because she is a lady. The general "normal" masses simply describe her as "mundane", she is surrounded by a overwhelming nimbus of sensuality which the "decent" philistine can feed on. She is simply a lady and is openly treated as a lady. The female transvestite can have a girlfriend, and can even give that girlfriend a kiss in the open, dance with that girlfriend and live together, no one will take the slightest offense to that degree even when that degree is passed...they are simply "ladies". And women's fashion today is just to masculinized already so really only the pants are missing, but even then the female transvestite knows what can help: there are sport and motorcycle suits with pants for women. Cycling pants and so on. The female transvestite doesn't need to marry, she just has it all and can have everything that she might personally want.

But now to the (male) transvestites (Transvestiten). Why does the transvestite want to get married, and why do they so rarely get married? On this point I would like to share my experiences and also eventually hear some opinions." 83

Gerda expresses negativity overtly. The article's thesis, asking why male transvestites so rarely marry despite their desire to do so, paints an entirely different picture of transvestite existence than that of Grete, Gitta, Minna, and Heidi's marital bliss, one in which a transvestite's romantic life consists of shame, rejection, and loneliness.

While the discussion of the immense isolation of male transvestites and its general erasure by respectability politics will continue further in this chapter, Gerda's opening paragraph consists of a different kind of negativity that should not be left unaddressed longer than is necessary: the jealousy, judgement, and Gerda's belittling attitude as a

${ }^{83}$ Schröder, Gerda Erwin, "Warum finden wir Transvestiten keine Partnerin?" Ledige Frauen, no. 6, 1928. 
male transvestite towards his female comrades. His's interpretation of the female transvestite's experience is layered with sexism. Firstly, his description of the female transvestite as sensual reflects a hyper sexualization of women's bodies, especially those that are queer. Gerda is envisioning the female transvestite in a single circumstance and with a single purpose: being sexual. He describes her as surrounded by approving men, kissing and touching women in a manner that is beyond propriety for public space, concluding in an almost sinister manner that she can and does take all that she desires for herself. In his mind, the female transvestite is greedy and hedonistic, running amok in a society that refuses to check or control her overtly-sexual discretions.

Gerda also shows a complete disregard for the female transvestite's struggles within capitalist Weimar society, making it appear as though the cross-dressing women in his imagination are permitted into every male space. As mentioned previously, however, modern labor and reasonable sources of income were all but impossible for those perceived as women to obtain. His declaration that female transvestites neither need nor want to marry fails to consider its complete impossibility under the transvestite media's definition of female transvestites as lesbians. That is, female transvestites accepted in the community often couldn't marry their partners, because both parties were legally women.

The final falsehood in Gerda's depiction of female transvestites as men-abouttown is their own history of harassment, institutionalization, legal barriers and arrests. In fact, the first-known carrier of one of Hirschfeld's transvestite passports was Katharina T, a female transvestite who was forced to appeal to the police for permission to continue dressing in masculine clothes after numerous conflicts over "public nuisance" laws in 
1908 and $1909 .{ }^{84}$ It is clear, therefore, that female transvestites were far from universally accepted in public. And while it is reasonable to assume that such harassment was less pronounced for the female transvestites of the 1920s compared to the male thanks to "New Woman" fashions and attitudes, the misinterpretation and erasure that comes with being confused for a fashionable woman rather than being considered a transvestite or a man posed its own problems.

Because of female transvestites' ambiguous interpretation as lesbians or New Women, dressing masculine for sexuality or fashion rather than as transvestites dressing for personal gender authenticity, female transvestites were rarely discussed and rarely included in gender-deviant communities. Magnus Hirschfeld, in defining the transvestite, made little mention of gender-deviant women, formulating his gender theories in such a way as to question their true existence. ${ }^{85}$ The transvestite media excluded them as well, with few articles written about female transvestites until its final years. Female transvestites were instead expected to participate in lesbian periodicals, despite the frequent hostility of lesbians towards their transvestite siblings. ${ }^{86}$ Gerda's attitudes towards female transvestites are yet another reminder that Weimar Germany's transvestites, or at least those whose voices were recorded and preserved, were not always gender radicals, and were fully capable of harming each other and their own causes.

${ }^{84}$ Sutton, Katie. "'We Too Deserve a Place Under the Sun"”, 337.

${ }^{85}$ Sutton, Katie. "'We Too Deserve a Place Under the Sun'”, 344.

${ }^{86}$ Sutton, Katie. "'We Too Deserve a Place Under the Sun"”, 344-345. 
The female transvestite is not central to the rest of Gerda's article, however.

Instead he details the unpleasant aspects of life as a male transvestite, with a potential explanation of his resentment for female transvestites as well.

"For 7 years I have been searching, as a really handsome 35 yearold with prospects, for a marriage to an understanding lady. With the female acquaintances, all well educated, after making serious commitments to marriage, I have touched on my sexual-scientific problem and eventually come into a conversation about my disposition as a transvestite. What followed was usually a farewell letter or a sudden, harsh admonishment with punishing intent. Then I tried my luck with female transvestites (transestitischen Frauen), through advertisements in related magazines, personal acquaintances in well-known bars and such. Naturally these women understood my disposition and were quite interesting, pleasant companions, but they did not see a (male) transvestite as for marriage."

Gerda gives the reader a glimpse into his world, not unlike Grete and the others had done before him. The glimpse we receive, however, is lonely, hopeless, demonstrating an alternative attitude for mainstream romantic interests. His romantic interests do not accept him like the wives of the others. They respond with scorn, breaking up via letter rather than see him again. After failing to obtain a wife in a female transvestite as well, despite their understanding of his transvestism, the reader is left only with the hopelessness of his situation. Gerda's acknowledgement of the negative aspects of his transvestism and his overall pessimism feel out of place in the pages Ledige Frauen's transvestite sections. This much is clear by the photograph of a smiling, naked person, breasts facing forward, with which his article shared a page.

Gerda does not stop there, however. What others described in a pair of sentences as "loneliness" and "an unexplainable desire to dress in women's clothes" before coming out to themselves, Gerda describes in painful detail. 
"Increasing nervousness, remorse, self-reproach plague the body, one gets older, more mature, one can no longer marry, one ponders and examines oneself, at first one can't grasp it, one doesn't get that Nature gave us a second Ego. One reads books about sexual questions and finally must admit to oneself that they also belong to this category. One fights against it, throwing oneself into an unhappy marriage or comes close to suicide before the spell is finally broken; one gives their female soul that longedfor covering; finally able to breathe, one feels relief; (You people, why don't you understand us, why do you let us suffer so much? Are we so terrible, so despised that we have no worth?)"

In this section, Gerda does something which make clear the benefits of negativity: he questions.

Deeply seeing and feeling his rejection based on something that is neither harmful nor within his control, he asks why. He questions his own worth based on the scorn he receives, but also why those to whom he has revealed his secret would rather cause him harm than try to understand. While his suffering is not a pleasant topic, it empowers him to doubt general society in a way that the respectable positivity of the other life-snapshots do not. Laying bare the treatment rendered by the majority of general society, Gerda understands the allure of such optimism: "Is it really surprising that a transvestite seeks an understanding life-partner?"

Gerda also uses his negativity to bring positive elements of transvestism to the fore, by asking why exactly a potential wife should not write off the idea of marrying a transvestite and should indeed consider its benefits ("What advantages are there for the wife of the transvestite?"). Some of his reasoning is decidedly and sexistly domestic, having to do with sharing household chores and appreciating the importance of house versus home. His final reason, however, strikes at the melancholy center of a peek into a 
transvestite's life: that a he would love his accepting wife "most generously," because “we transvestites only want someone to understand our women's souls, nothing more."

Gerda concludes by refusing the final question: "Why then, in spite of everything, is it so hard for us to find a comrade, a loving woman...? Why? Those who are met with this difficult lot shouldn't experiment, it's better that they stay alone...forever lonely." In other words, his final advice to his fellow transvestites is not to try to find a partner, because the mistreatment at the hands of heteronormative women is too unjust to endure, while the chances of finding anything else is too slim. It is a tragic glimpse into the life of Gerda, one that is disparaging while also affirming, wise while also bitter and, by virtue of its publication, communal while also desperately lonely. Most of all, through the complexity of emotion in its words, it is human, just as Gerda Erwin Schröder was.

Four issues of Ledige Frauen later, two replies were published under the subheader 'In reply to Nr. 6 of 'Ledige Frauen's' open article: 'Why Do We Transvestites Find No Partners?' we have received many letters, some of which we will show you today." The first published response was submitted by Elli Richard K., who we have discussed previously and who disagreed with Gerda for some very distinct reasons:

"After this realization [that I have the emotional life of a lesbian woman], I had decided not to marry, but then I changed my mind when I came into the opinion that we transvestites need a person who understands us more than most, with whom we can talk about our situation. I never came to regret that decision because I found what I need: a love, one who fully understands me, my good Hans." 87

Knowing how difficult it can be for a lone transvestite with no one to talk to, Elli encourages Gerda to marry in a noticeable disregard for the difficulty he has had in trying

${ }^{87}$ K., Elli Richard, “Der Transvestit und seine Partnerin” Ledige Frauen, no. 10, 1928. 
to do just that. Simultaneously, however, Elli presents his own life as proof that what Gerda sees as hopeless is, in fact, possible.

Elli's story of "having heaven on earth" with his wife Hans is discussed in a previous chapter, detailing the elaborate interplay of his feminine features to Hans' masculine ones in a perfect domestic scene. He adds, however, "I wish all my compatriots that they could have it just like I do, which I can see from the many articles about 'single women,' most do not have it as good as me." Even as he describes his own perfect marriage, he acknowledges that the transvestite media has shown him that isolation is the case for the majority.

"Since going out in women's clothes comes with a certain amount of danger for us transvestites, if one doesn't have permission from the police to wear these clothes; it is still better for us if we get married, because behind your own four walls you can do as you please."

Elli points towards an additional meaning of marriage for the transvestite outside of proper displays of traditional womanhood: that marriage and domesticity mean safety. Elli ends his reply without having given much advice beyond his recommendation to marry. From his own position, however, he thanks the publishers of Ledige Frauen for helping his isolated comrades feel less alone.

Vera Lumeny, writing to Ledige Frauen from Vienna, begins his reply to Gerda by expressing sympathy and understanding for his situation. He explains that it is the ignorance of the "normal masses" that causes all of his rejection and isolation.

"It's difficult with today's morality to enlighten people; but in the end that's the only thing that's going to help; the ability to help lies only in one's strength and courage.

The right knowledge being in the world will solve some of these questions; we will no longer be so alone, we will find friends and girlfriends, we will be able to move around more freely; and finally we 
will bet a proper idea of our numbers. We will feel freer, because even if not always love, we will at least be able to expect understanding from many, many people. But the way has so far been only through our magazine, which is why we have to make sure that it is well distributed!

Don't be sad because a loving partner's heart isn't beating for you just yet. Stay full of hope and for the time being, if possible, make acquaintance with other transvestites, because suffering shared is suffering halved. And in the end, we need to help each other."

Vera writes with certainty that, once normative society has widespread access to information about transvestism's true nature, Gerda and every other transvestite will be able to be in public freely, make friends, find lovers, and be free. As such he puts a great deal of faith in a general society for which transvestism contradicts the power, family, and social dynamics that maintain it and affirming, perhaps, the respectability strategies in which projecting the correct image of transvestism will win liberation.

Despite this respectability-tinted narrative, Vera also uses positivity for an alternative purpose. His is not a description of a present tense utopia like in the snapshots, but one of a hopeful future. Vera believed Gerda would find his wife, and that their collective struggles as transvestites would abide. He believed in what the transvestite media stood for and in its ability to bring transvestites together to share the in burden of isolation, ridicule, arrest, and physical danger. He fantasized of a reality in which transvestites were unified and could be liberated through education.

Der Transvestit, Ledige Frauen, and Die Welt der Transvestiten reflected the ideas, questions, fantasies, and fears of a young community centered on a newfound label. Where Heidi's life-snapshot showed off his perfect transvestite life, Gerda saw the realities he ignored. While Grete excluded non-domestic transvestites from validation through the transvestite media, Vera used it to envision a network of support and 
acceptance. The transvestite media had to define feelings, fantasies, fears, and imagined futures. 


\section{"You Clueless Angels:" Publisher-Reader Conflict and Das 3. Geschlecht}

Die Freundin and its transvestite pamphlet continued publication into the late Weimar period. Additionally, the transvestite media expanded beyond Die Welt der Transvestiten to publish the first and at the time only magazine written exclusively about the gender nonconforming. ${ }^{88}$ While Friedrich Radszuweit had attempted to do so in the past, Das 3. Geschlecht (The Third Sex), published by Radszuweit Publishing, was his final and only successful attempt at an independent transvestite magazine. ${ }^{89}$ Little has been written on the topic of this periodical in modern historical or German Studies formats, as no complete copies were widely available in archives or elsewhere until a set was discovered and published as a book in 2016.

Das 3. Geschlecht released five issues between 1930 and 1932, appearing more like a small, raw-bound book than a magazine. Each issue had approximately 40 pages, plus a title page and 3 or more pages of advertisements. It was small, approximately 24 centimeters tall and $15 \frac{1}{2} 2$ centimeters wide. ${ }^{90}$ This set it apart from its much larger-paged sibling publications for lesbians and homosexual men, the BfM's primary bases and political motivators. As such, it should be noted that keeping the transvestite community informed was not Radszuweit's sole motivation in the creation of Das 3. Geschlecht. Each issue contained advertisements throughout for the BfM's better-selling and more central publications, and the judgmental attitude of much of its content towards

\footnotetext{
${ }^{88}$ Herrn, Rainer (Hg). Das 3. Geschlecht, 5.

${ }^{89}$ Sutton, Katie. “'We Too Deserve a Place Under the Sun"”, 340.

${ }^{90}$ Herrn, Rainer (Hg). Das 3. Geschlecht, 6.
} 
transvestites indicates the periodical's drive to control transvestite identities and behaviors rather than act as a platform for transvestites to do this themselves.

There were many photographs of transvestites in Das 3. Geschlecht, most of which were sent in by private individuals. There was a risk, however, in sending your photograph in to the Radszuweit Publishing beyond that of being outed by revealing your face in cross-dress. The photographs sent in for publication were put under intense scrutiny by the publishers and there was a high likelihood of ridicule. Images sent in by readers were given titles such as "Male transvestites as they actually shouldn't dress," "A well-dressed male transvestite," and other value judgements based on the attitudes of the publisher. $^{91}$

Radszuweit made his personal intentions for the magazine known in its fourth issue with a short article titled "On the Fight for the Transvestites." He began with a somewhat antagonistic declaration about his readership: "The vast majority of transvestites still do not seem to grasp that, if one wants to have rights, one must also perform certain duties." He outlined his own commitment to the transvestite cause as an example, which largely involved allowing the well-known transvestite figure Käthe Karl to start a transvestite meeting within the BfM in 1922 and supporting similar projects since. He then stated his belief that transvestites lack his emancipatory drive and are not committed enough to their own liberation. He gave as evidence his attempt to make a magazine like Das 3. Geschlecht monthly instead of twice a year, but that transvestites'

\footnotetext{
${ }^{91}$ Herrn, Rainer. "Das 3. Geschlecht (The 3rd Sex): Illustration Practices in the First Magazine for Transvestites." Others of my Kind: Transatlantic Transgender Histories. University of Calgary Press, 2020: 48.
} 
unwillingness to pay 1 Mark per issue on a monthly basis halted the project. He goes on to mockingly describe the transvestite reaction to his efforts:

"'Pay contributions? No, what for? The League is here to promote the transvestite's cause.' This was the general opinion at the time, and so it has remained to this day. The transvestites would love to be publicly respected as such, but they are unwilling to personally collaborate or hand over a single penny to the cause. One cannot fight for a cause without money, and what interest does, for example, the League for Human Rights have to make sacrifices for transvestite victims when these very victims are entirely disinterested, stand aside, care about nothing, and would rather wait quietly to see what successes the League will achieve?"92

By equating the fight for respect and liberation to an individual investiture of money, Radszuweit reinforced the BfM's prioritization of middle- and upper-class voices. He took it a step further however, by making clear that the BfM has no interest in the liberation of those who cannot pay for it by equating financial and personal investment.

While this attitude was certainly not reserved solely for his transvestite membership, his declaration of transvestite stinginess and lack of gratitude was disproportionate to that of lesbians and homosexual men. Indeed, as advertised within the pages of this very same publication, the majority of the other Radszuweit Verlag magazines, all meant for lesbians and homosexual men and published either monthly or weekly, were one-fifth of the cost. ${ }^{93} \mathrm{He}$ goes on to shame transvestites for their unwillingness to support the BfM by complaining about the price while simultaneously asking for a monthly magazine like homosexual and lesbian supporters had. He made his

92 Radszuweit, Friedrich, “Zum Kampf der Transvestiten.” Das 3. Geschlecht. July 1931, 14.

${ }^{93}$ Das Freundschaftsblatt, weekly, cost 20 Pfg; Blätter für Menschenrecht, monthly, cost 20 Pfg; Die Freundin, weekly, cost 20 Pfg; Die Insel, monthly, cost 50 Pfg.

Advertisement. „Blätter für Menschenrecht,“ Das 3. Geschlecht, September 1930, 22.

Advertisement. „Die Insel,“ Das 3. Geschlecht, September 1930, 14.

Advertisement. „Die Freundin,“ Das 3. Geschlecht, February 1931, 2.

Advertisement. „Das Freundschaftsblatt,“ Das 3. Geschlecht, July 1931, 28. 
point about transvestites' supposed political laziness through a critique of their submissions for the transvestite media:

“Transvestites shouldn't be surprised when the League for Human Rights doesn't stand up for their endeavors as it does for the liberation of homosexuals...I expected the transvestites to work with us and hoped to be able to educated the world about what transvestism really is through sensible articles about their emotional lives. Unfortunately, in the hundreds of personal stories transvestites have sent me, only a very few were worthy of publication. The vast majority of the writings were entirely unusable, since all they did was describe the putting on of women's clothing, describing each piece down to the smallest of details There was not a single word about their soul or emotional life. Only banal ramblings about how they would behave if they had a suitable partner. - And in this area things have also remained to this day."

While its reader- and writership used the publications for their own community building, Radszuweit saw the transvestite media as primarily public outreach. As such he expected their writings to appeal to a more conservative, German cultural attitude. He expects them to appeal to their inner, emotional lives (the German kultur) rather than their interpersonal, materialistic lives (the international, un-German Zivilisation). His distain for the interests of the transvestite writers is clear, using this to justify his own lack of interest and the BfM's only minimal investment in their plight.

He made it clear that it is the transvestites who need the BfM and not the other way around, calling the publication a risk on his part for their benefit. "Your (eure) publication is, however, a necessity of you want public recognition, therefore you must contribute to this small work by buying every issue if you want to get your rights...It's best and most practical if all transvestites purchase memberships to the League for Human Rights." ${ }^{94}$ His explanation for the BfM's negligence of transvestite liberation is

${ }^{94}$ Radszuweit, Friedrich, “Zum Kampf der Transvestiten,” 14-16. 
the supposed laziness, self-centeredness, stinginess, and banality of the transvestite community. He therefore offers them a simple solution: pay the organization if they wish to be taken seriously by it.

On top of criticizing the politics, generosity, and general character of the transvestite community, Radszuweit also showed little concern for upsetting his audience. He used the informal pronoun "ihr" and even called those who found Das 3. Geschlecht too expensive "clueless angels." Radszuweit no doubt wrote with little concern as, while he and his organization clearly cared little for transvestites, they were the only large homosexual organization to give them a platform at all. If a transvestite were angered by his article, therefore, their choices were to continue buying BfM transvestite media, or buy no public transvestite media at all.

Friedrich Radszuweit's article gives much-needed context on the BfM's motivations for publishing transvestite media. He was likely a driving force behind the respectability politics of it, while the newer magazine's cost and advertisements placed transvestites as a (failing) source of revenue for his larger homosexual publishing endeavors and for the BfM as a whole. Shifts in the contents of Das 3. Geschlecht compared to the Die Freundin inserts certainly support Radszuweit's revenue and respectability model. There were reprints (including Grete's writing on Handarbeit under the title "Grete: Transvestite-Marriage), repeating themes such as marriage and respectability, and taking on a wider scope and audience than its predecessors. There were also more advertisements for other BfM publications, long lists of books to order from the BfM and, most notably, more advertisements for shops, cafes, bars, balls, and other transvestite commercial enterprises in places other than Berlin. 
By describing those submissions he received and those which he was willing to publish, Radszuweit demonstrated his direct involvement in the selection of articles. His intervention is far more apparent in Das 3. Geschlecht than it was in Der Transvestit, Ledige Frauen, or Die Welt der Transvestit. More non-transvestite writers were published, often from a medical perspective, and their articles often had a level of disregard for transvestites' self-identity construction. Despite requiring redactions at times after transvestite readers corrected the statements made by sexologists in their articles, those written by non-transvestites better served Radszuweit's purpose of presenting transvestism as something the heteronormative public could understand and pity rather than something transvestites could enjoy reading.

A primary example of Das 3. Geschlecht's misrepresentation of its readership is the extensive coverage of sexual sadism and masochism in the first three issues. The last few pages of each issue are comprised of book lists to be ordered from the BfM under the sub-headings like "interesting novels among women," "transvestism," and, most notably in the first three issues, "books about sadism and masochism" with a large advertisement for a volume titled Flagellantism. "Sadism and Sadists," an article in the first issue by Dr. E. E. Schweitzer, defines sadism as the sexual desire to physically harm, most often by men to women, and masochism as sexual pleasure from receiving pain, most often of women from men. The rest of the article is spent discussing 18th century literary examples of sadomasochism. The writer also, quite radically, ensures the reader that it is a natural, properly-gendered form of sexuality and that it does not indicate a hatred of women on the part of sadistic men. ${ }^{96}$ By this point, however, there is no doubt an

\footnotetext{
95 Advertisement, "Der Flagellantismus" Das 3. Geschlecht. May 1931, 40.

${ }^{96}$ Schweitzer, E. E., "Sadismus und Sadisten” Das 3. Geschlecht. May 1931, 34.
} 
elephant in the room: what exactly is this account is doing in a publication about transvestism? Sadomasochism was likely, like transvestism, deep in the fringes of even homosexual discourse, possibly pushing the discussion into transvestite media rather than tarnish the reputation of homosexual media. But Dr. Schweitzer also defined the sadomasochistic dynamic as a heavily gendered activity.

In the second issue, Prof. Dr. K. F. J. wrote an article titled "Sadistisches und Masochistisches im Sexualleben," in which they detail a more disturbing set of theories on why exactly a man might become sadistic or a woman masochistic. His argument revolved around a particularly grim depiction of humanity's sexual nature, in which, in the longest sentence ever written he paints a picture of sexual assault as a universally natural sexual dynamic.

"If we ignore the unique way in which the phenomenon of sadomasochism emerges for the time being, we can make an observations about the general relationship of sexual intercourse between man and woman (also in animals) is not exhausted by the aggression and activity of the man overcoming the woman while the latter plays the passive role and submits; rather the woman opposes the seduction and attacks of the man, bringing a sexual rage to the fore, the resistance is longer or shorter-lasting, more or less energetic, moving between wild defense and gentle resistance until it finally ends in surrender - the art of flirtation! - and on the other hand, the man resorts to pleading and supplication, falls to the feet of the woman, serving her and often humiliating himself in far-reaching ways to attain his goal of conquering the woman. And in the act itself, the woman often attempts to inflict pain on the man by biting and the like...it is a form of revenge for the woman who, aware of her own weakness, takes the man's strength; of course it is only the idea of superiority that is present here, because in reality, it is (normally) the girl who is the subordinate one. The man, on the other hand, is often willing to trade places, and even perform cunnilingus. ${ }^{97}$

97 J., K. F., "Sadistisches und Masochistisches im Sexuelleben" Das 3. Geschlecht. September $1930,28$. 
Dr. J.'s disturbing normalization of nonconsent and exceptionalization of the reciprocation of sexual pleasure is clearly intended to Dr. Schweitzer's concept that men will be the sadistic party and women the masochistic, depicting the refusal of sexual advances and the proceeding assault of women as a trading of power between them. Through her refusal of the man's seduction, the woman is sadistic and the man is masochistically humiliated. It is only then that the man gains control via, as Dr. J. states, man's natural strength and woman's natural weakness. The man, in this scenario, is then willing to oscillate between the two as justified through Dr. J.'s interpretation of oral sex given to women as an act of submission. In reality, the entirety of the examples used to demonstrate the oscillating of power roles actually consist of how a cisgender man may overpower - and rape - a cisgender woman, contrasted with the woman's refusal to be with him consensually, or the enjoyment of sexual acts intended for her pleasure. ${ }^{98}$

Quite confusingly given its publication in transvestite media, Dr. J.'s presentation of sadomasochism and sexual power did not hold up if the existence of transvestite men or women were considered. A respectable male transvestite was expected to be a husband in public spheres and a wife in private. As made apparent by Gerda's discussion on trying to find a partner, or by Grete and Gitta's coming out stories, courting is often done in male dress and behavior, often to transition after marriage. Meanwhile female

\footnotetext{
98 There is a need, at this point, to make clear that these doctors' descriptions of sadomasochism are incredibly dangerous in their non-consent, gendered expectations based on a poor understanding of basic biology, and tendency to pathologize and stigmatize sexual power exchange. Sexual and non-sexual activity that falls under the umbrella of what is now called kink, BDSM, and power exchange do not include an actual removal of autonomy by force as depicted here. They must instead be carefully negotiated beforehand, and executed so that all parties are empowered by the activity and able to stop at any time. Within these constraints, sadomasochism is (and was in the past) no more wrong than crossdressing.
} 
transvestites are often considered to be lesbians as well, leaving them in a realm of complete ambiguity within the power dynamics and sexual roles laid out by this scientist. Additionally, neither of the articles mentioned transvestism or gender-deviant behavior at all. On the contrary, the gender-propriety of their theories were at odds with the sexual deviance being discussed. Whether Radszuweit or others in charge of publication misconstrued the two or simply put two fringe topics together, the transvestite readership was upset by the implied association of transvestism and sadomasochism. The first page (after the ads) of the periodical's next issue was an editorial note entitled 'Masochist and Transvestite," which attempted to simultaneously repair the damage and justify the inclusion of sadomasochistic topics in the transvestite media.

"It is often said that the vast majority of transvestites are masochistic because this can best explain the nature and disposition of the transvestite. Overall it can be said that it is exactly the female feelings of the male transvestite that brings about strong masochistic feelings. We have asked a number of transvestites whether they have masochistic tendencies, and we were given the explanation that, although they are prone to masochistic feelings, that they are actually not masochists outright in the usual manner.

In some scientific works, transvestites are described as masochists who suffer from a certain kind of fetishism that is concentrated on wearing clothing of the opposite gender..."99

The scientific and the communal definitions of male transvestism are directly compared in the redaction, with scientists often believing that transvestites cross-dress to satisfy a masochistic fetish while the community made clear that this is not the case.

The transvestites queried did admit masochistic tendencies, however. Dr. Schweitzer and Dr. J.'s propositions of the natural masochism of women, the publisher's

${ }^{99}$ Die Redaktion, “Masochist und Transvestit” Das 3. Geschlecht, February 1931, 1. 
and science's interpretation of Transvestism as masochistic fetish, and some transvestites' own association with masochistic feelings is rooted what Halberstam describes as a psychoanalytic, patriarchal conflation of the desires of women and masochism. 'Freud's famous question 'What do women want?'...asks of women why they would want to occupy the place of castration, lack, and otherness from one generation to the next. Answering the question of what men might want is quite simple in a system that favors male masculinity; what women want and get from the same system is a much more complex question...Freud asserts, the little girl must reconcile herself to the fate of a femininity defined as a failed masculinity..." ${ }^{100}$ In such a model of feminine womanhood, the mere act of being feminine is masochistic. And the male transvestite who, unlike a cisgender woman, had the potential to become the ideal of male masculinity, must surely be a masochist. A scientist who buys in to this cultural model would naturally construct a causal link, while a transvestite raised within this model would conflate at least some of his feminine desires as masochistic even with no desire for any truly masochistic sexual play.

Even so, the transvestites of the BfM did not define their own transvestism, womanhood, or femininity along these lines. The need for this redaction, as well as the absence of any articles, book lists, and advertisements on sadomasochistic subjects in any following issues of Das 3. Geschlecht, hint at the transvestite readership's vocal dislike for the implication. The content's removal from the periodical was tacit, however, and the redaction did not include apologies or any acknowledgement of having made any false associations. Instead, it attempts to appease by distancing respectable, heterosexual

${ }^{100}$ Halberstam, Jack. The queer art of failure. Duke University Press, 2011, 125. 
transvestism from sadomasochism while reinforcing the connection between sadomasochism and bisexual also-transvestites.

In the redaction's model, heterosexual transvestites are those "who feel completely normal and only concern themselves with the female gender, wanting to dress and behave accordingly." They have, apparently, very little masochistic desire. Of the masochistic transvestites, the redaction makes clear "that those who openly admit to performing masochistic acts are, for the most part, bisexual." The final category, the homosexual transvestites, are described so: "According to their own description, this sort has a pure compulsion (Zwang) to wear the clothes of the opposite sex and behave thusly. Strangely enough, however, these transvestites deny having masochistic feelings." The "compulsion" of the homosexual transvestite is set apart from the heterosexual via a lack of self-control often associated with more fringe and lower-class expressions of gender and sexual deviance. ${ }^{101}$ Therein his lack of self-reported masochistic tendencies comes as a surprise. Thanks to the popular corruption theory of sexuality, in which everyone, although especially youth had the potential to become bisexual if coerced, bisexuality posed an inconvenience to homosexual and lesbian liberation and was often depicted as perverse, sinister, or deceptive within their media. ${ }^{102}$ Therefore, the bisexual male transvestite took the blame, and the heterosexual transvestite could remain proper without the publishers having to reject popular and sexological opinion of transvestism entirely.

\footnotetext{
${ }^{101}$ Marhoefer, Laurie. "Degeneration, Sexual Freedom, and the Politics of the Weimar Republic, 1918-1933," 540-541.

102 Espinaco-Virseda, Angeles. "I feel that I belong to you": Subculture, Die Freundin and Lesbian Identities in Weimar Germany. Spaces of Identity vol. 4 (2004), 92-93.
} 


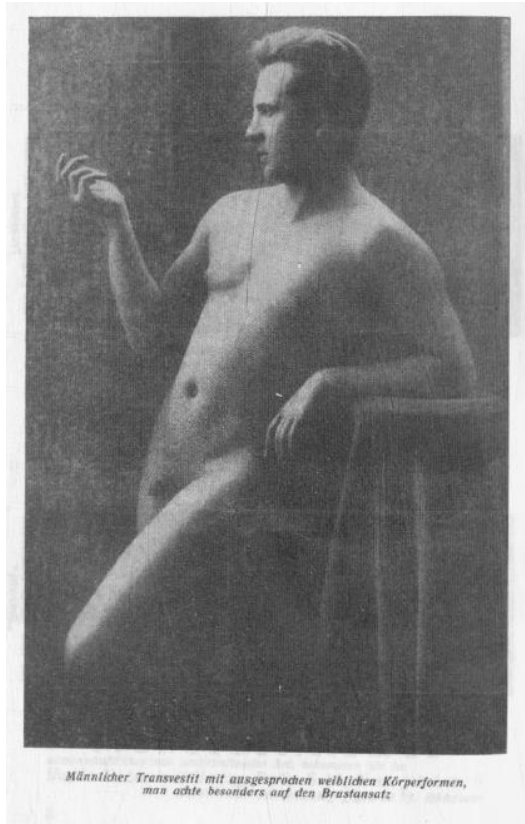

"Male Transvestite with overtly female body parts." Das 3. Geschlecht. July 1931, 10.

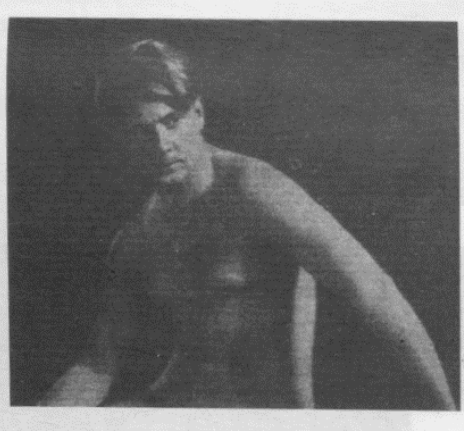

Masentidir Trumestit

“Male Transvestite.” Das 3. Geschlecht. July 1931, 29.

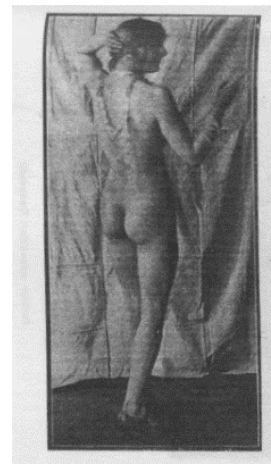

A significant increase in the number of images was another change Das 3. Geschlecht made to the transvestite media, and with a far more affirming impact even despite the far-reaching publisher-reader conflict. Page after page held drawings, paintings, and photography of gender deviants from the Germanspeaking world, and often also from the United States. Most of the images were photographs of transvestites dressed in their clothing of choice and posing elegantly, either in a studio or out in public spaces. Other common photographs were of dancers and entertainers who performed in drag, and many with the label of "oriental dancers." Despite this fascination with the "exotic," every single image in Das 3. Geschlecht was of white transvestites. While photographs like these were known to make their way into earlier publications occasionally, a new category of images also appeared in Das 3. Geschlecht: nude or near-nude images of "Hermaphroditen" and of male transvestites "mit ausgesprochen weiblichen Körperformen." 


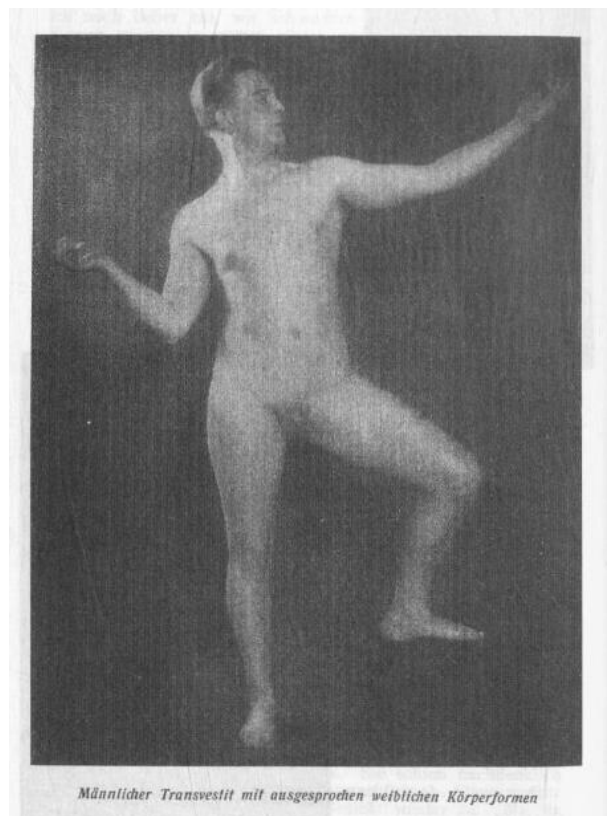

"Male Transvestite with overtly female body parts." Das 3. Geschlecht. February 1931, 10.

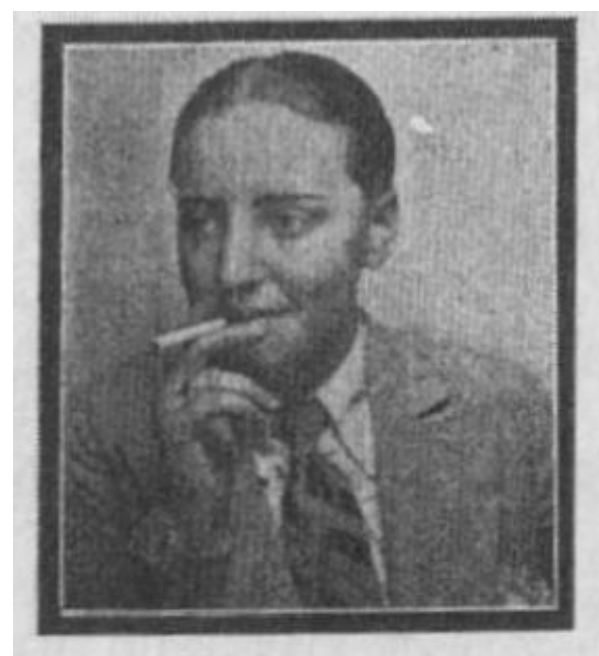

\section{Ein gut angezogener weiblicher Transvestit}

These naked photographs took a very different form than those often seen in sexological works or other publications meant for broader consumption, which often had transvestites in passive, vulnerable poses, facing forward and staring blankly as though for a mug shot or taxonomic catalogue. Meanwhile, nude photos of homosexual men and lesbians were common in all of the BfM's illustrated papers, and were often of a more sexual nature. In Das 3. Geschlecht, however, naked transvestites and those with ambiguous primary and secondary sexual characteristics posed like themselves. They smiled, in the middle of actions, stood like Shakespearian actors, or like Aphrodite. They were alive and active in presenting their bodies' unusual beauty to the camera. The clothed photographs depict a similar agency and personality that is missing from the sexological images used by Hirschfeld and others. They smile, posing with props in elegant dress with titles that indicate their

“A Well-Dressed Female Transvestite.” Das 3. Geschlecht. July 1931, 17. inner worlds: "Men as women, how they feel 


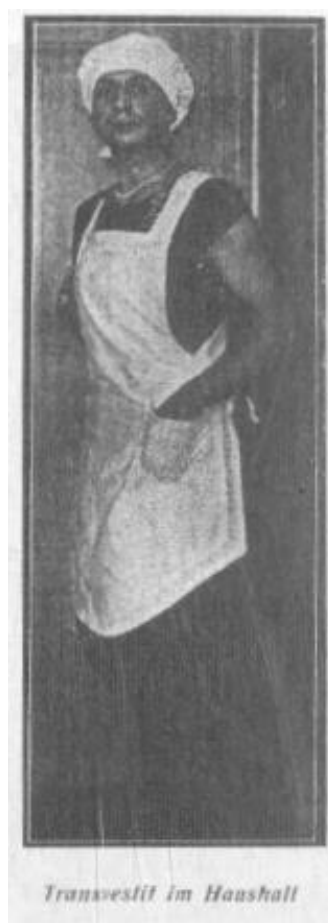

"Transvestite in the Household." Das 3. Geschlecht. July 1931, 30. happy," ${ }^{103}$ or in the middle of activity like housework. ${ }^{104}$ "A welldressed female transvestite" smiles and smokes a cigarette, while the famous female transvestite Lotte Hahn poses ecstatically, in a polkadot bowtie and trousers and holding a sign for Die Freundin, which she helped found. ${ }^{105}$

These images fill a similar, humanizing role as the day-inthe-life narratives in the transvestite media, depathologizing transvestites and presenting them as respectable, happy, active participants in society. In other words, they readily present transvestism in the manner Radszuweit wished. Additionally, however, they fulfil some of the desires of transvestite audience, showing fantasies fulfilled and answering questions about how a

transvestite might dress, stand, smile, and behave in a manner that affirms their collective identity.

Das 3. Geschlecht gave transvestites the opportunity to display more of themselves than ever before, with 20 or more humanizing images in every issue and more room to share their thoughts and opinions. There were no more classified ads with which to find each other personally, but there were more ads for meeting places and businesses. The publication also brings to light numerous tensions that were present between the

${ }^{103}$ Unnamed photographer, "Männer als Frauen, wie sie sich glücklich fühlen." Das 3. Geschlecht. May 1932, 10.

${ }^{104}$ Unnamed photographer, "Transvestit im Haushalt.” Das 3. Geschlecht, July 1931, 30.

${ }^{105}$ Unnamed photographer, "Ein gut angezogener weiblicher Transvestit." Das 3. Geschlecht. July 1931, 17. Unnamed photographer, "Schöne männliche Köpfe, die inflege ihrer weichen Linien als vorbildlich zu betrachten sind.." Das 3. Geschlecht. February 1931, 32. 
young transvestite community and the general public, sexology, the lesbian and homosexual communities, as well as between transvestites.

Additionally, the growing conservatism of Germany as the Weimar era came to a close undoubtedly impacted censorship, so that non-transvestite authors contributed a level of pathologization and status-quo legitimacy that could improve its palatability. As discussed previously, artistic or scientific content was less likely to be censured, indirectly because of its consumability by the general public rather than by a small, ostracized group seeking acceptance among their peers. Even in their own media, therefore, they found themselves misrepresented as sexually motivated and having their femininity perceived as masochistic by those who either never bothered to read the transvestite media in which they were published, or did not trust the transvestites who wrote of their own, unsexual motivations to define their own experiences. Meanwhile, those who did not fit the definitions desired for a respectable image inside the community due to intersectionalities of class, race, or sexuality were still ignored from within.

The publication's high price paired with the critical attitude of the publisher towards his audience further deepened the struggle for self-identification, as Radszuweit's political motivations for supporting transvestite liberation made themselves clear. From all sides - including from within - transvestites were pathologized, sexualized, brutalized, and used, giving the transvestite media conflicting roles. Images of happy, living transvestites and simple, easy tales of clothing and housework and trips to cafes were a rare view into a world in which transvestites were not allowed to just be people. The articles that, for Radszuweit, were vapid and frivolous with no political purpose were, for the readers, a much-needed retreat. 


\section{A Silenced Public: On Female Transvestites}

The previous pages have delved deeply into the writings and identities of male transvestites, whose voices were dominant within the community. Female transvestites had significantly different experiences of the world, however, residing in a far more ambiguous realm and not quite able to pass under the transvestite umbrella. By sexologists, female transvestites were often considered a subcategory of lesbians, alongside "masculine lesbians," "feminine lesbians," "female men” (Männinnen), and "man-women" (Mannweiber). ${ }^{106}$ While the male transvestite was expected to be heterosexual, their female counterparts were considered homosexual by definition. Female transvestites were rarely discussed outside of the context of lesbianism and were considered a presentation of sexuality rather than of gender divergence. Because of this scarcity of information, as well as the focus on sexuality, it is difficult to complete a survey of female transvestites' self-formations. To make things worse, the small amount of information that is available is often about and not by female transvestites. This is not to say that female transvestites did not express their opinions and formulate their own identities, but to say that those discussions were transient and unrecorded.

The earlier transvestite media, intermingled with the lesbian media, was often published beside discussions and images of masculine-presenting women, ambiguously a part of both Die Freundin and Der Transvestit. But when the transvestite media gained an independent platform through Das 3. Geschlecht, a clearer image of the female transvestite was presented, independently of the much louder and more populous lesbian

${ }^{106}$ Espinaco-Virseda, Angeles. "I feel that I belong to you," 85. 
community. The ambiguity of the female transvestite allotted them more freedom in public spaces, while also having their unique experiences and needs lost in the storm of lesbianism, modernity, and the New Woman as just another iteration of deviant womanhood to be interpreted and critiqued. This chapter, therefore, will investigate how transvestite women were perceived, try to untangle the complex web of female deviance to find those with, to adopt the vocabulary of male transvestites, masculine internal lives, and to mourn the voices of those gender rebels who lived as men but whose voices have been lost to disregard and negligence.

As a result of conflating female transvestism with lesbianism, the gender experiences of female transvestites were often overlooked by sexologists, who preferred to focus on their sexuality. Transvestism became a mainstay in the lesbian community of interwar Germany as a result. It is no coincidence, for example, that the transvestite community found its footing in a lesbian magazine or that Lotte Hahm, a female transvestite and lesbian activist, ran Damenclub Violetta, a popular club maintained by lesbian clientele where transvestite meetings, fashion shows, and other events regularly took place for both male and female transvestites. ${ }^{107}$ Despite its location, however, the transvestite media was dominated by male transvestite voices, while conversations about female cross-dressing took place far more often in lesbian media.

The communal relationship between male and female transvestites was somewhat contradictory. According to the transvestite media, they had sympathy for each other's plights and often indicated their similarities through their shared vocabulary. While "der Transvestit" (transvestite man) and "die Trasnvestitin" (transvestite woman) could easily

${ }^{107}$ Espinaco-Virseda, Angeles. "I feel that I belong to you," 86. 
be considered completely separate experiences (like that of man and woman in a binarygendered society), it was not uncommon to specify their shared identity by simply using “der Transvestit" for both and specifying "männlich" (male) or "weiblich" (female). The trend of shared vocabulary became increasingly common, so that by the publication of Das 3. Geschlecht, "weiblicher Transvestit" was used almost universally rather than the older "Transvestitin." On the other hand, the new magazine was still male transvestitedominated, and therefore generalizations and disparaging comments about female transvestites often went unchecked.

Gerda’s “Warum finden wir Transvestiten keine Partnerin?", which was published in Die Freundin and then later republished in Das 3. Geschlecht, demonstrated both sides of this dynamic. His introduction, more-or-less irrelevant to the rest of the article, presented an image of the female transvestite as cosmopolitan and carefree, in which she can do as she pleases with respect. "She is still a lady and will be treated as a lady in public," he wrote, expressing his assumption that female transvestites were treated in a ladylike way in contrast to the poor treatment of their male counterparts. He referenced the masculinity of women's fashion, and the respect allotted to those women who masculinized their features. He ended with the general statement: "The transvestite woman doesn't need to marry, because she has and can have everything that she may desire." ${ }^{108}$ This introduction - and the lack of comment it received in the replies to the article as a whole - make several things clear about the position of the transvestite media on female transvestites.

${ }^{108}$ Schröder, Gerda Erwin, "Warum finden wir Transvestiten keine Partnerin?" Ledige Frauen, no. $6,1928$. 
First, there was a strong divide between the experiences of both male and female transvestites. Gerda constructed a binary of ease and suffering, unrequited desire and satiation, perceiving the lives of female transvestites as public and in vogue while male transvestites were ridiculed and forced to remain home. He was careful to describe how he believed general society, and men in particular, responded to the existences and romances of female transvestites. In Gerda's mind, gentlemen saw female transvestites as ladies and at worst, the general public thought of them as "mundane," or unfashionable. Therefore, female transvestites were not only welcome in public spaces, but were the talk of the town in gentlemanly circles. Female transvestites could also, according to Gerda, live with their romantic and sexual partners, presumably because sex between female partners was not explicitly illegal. Male transvestites were, on the other hand, respected as neither ladies nor as gentlemen, were harassed and arrested, and were therefore unable to enter public spheres to find partners at all.

While there were significant differences in the experiences of male and female transvestites, Gerda's binaristic approach was far from realistic as each group had their own unique benefits and struggles. Female transvestites, for example, would have faced financial concerns that their male counterparts did not. As mentioned previously, women in Weimar Germany were still largely dependent upon family incomes and cordoned off to low- and unpaid traditional and domestic labor. A lesbian transvestite, or one that could not find a tolerant husband, was therefore faced with a considerably higher threat of poverty than a respectable male transvestite with a day job. Additionally, the presumption that female transvestites were completely accepted in public spaces is a troubled one. The first transvestite-pass was, after all, given to a transvestite woman who 
had been so regularly harassed by the police that she was forced to go to court. ${ }^{109}$ By the 1920s, however, the masculinization of women's fashion and the New Woman aesthetic no doubt helped female transvestites move through public spaces with an ease not allotted to male transvestites. Where a female transvestite that failed to pass may have been perceived as an overly-zealous New Woman, a male transvestite had no alternatives to passing perfectly in public spaces. Instead, female transvestites faced a different problem: personal invisibility for the sake of public presence.

The second ideology made clear by Gerda's analysis is that female transvestism was often conflated with the New Woman and the general masculinization of women's fashion. While this was a common assumption and did make navigating the world slightly simpler, it was not that there was a space for transvestism in the New Woman movement but that female transvestism was consumed and erased by it. That Gerda conflated the two so resentfully may explain the considerably smaller presence that female transvestism had in the transvestite media, despite the presence of female transvestites in prominent positions in transvestite activism. Female transvestites were called lesbians, masculine women, New Women, and only occasionally transvestites. Many had overlapping identities, as shown by Lotte Hahm's involvement in both lesbian and transvestite circles, ${ }^{110}$ but the communal needs of a person whose gender, or internal soul-life, is male will inevitably vary from that of one who simply enjoys masculine clothing.

This ambiguity and erasure deeply impact the ability to create histories of femaleto-male gender crossing. In written record, many female transvestites were deemed

\footnotetext{
${ }^{109}$ Sutton, Katie. "“We Too Deserve a Place Under the Sun'”, 337.

${ }^{110}$ Sutton, Katie. The Masculine Woman in Weimar Germany, 119.
} 
masculine women or lesbians, so that it is difficult to differentiate between these experiences in records of female involvement in organizations like the BfM. Additionally, there was a lack of published accounts in the voices of female transvestites in queer media of the time. ${ }^{111}$ Such ambiguity and scarcity on the part of the BfM and the transvestite media often makes determining the actual experiences and identities of those few published accounts immensely difficult. In 1928 for example, a front-page story in

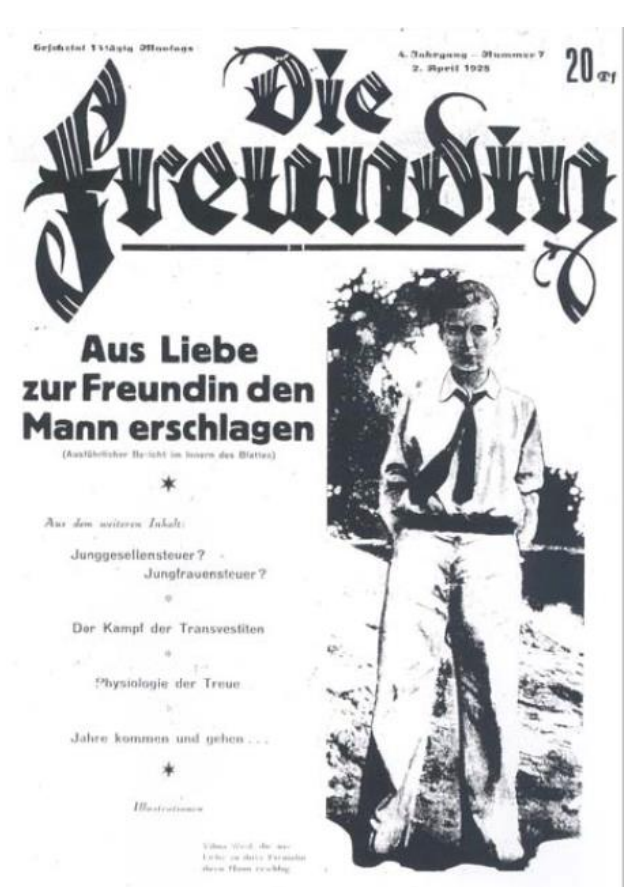

„Vilma West, who killed her husband for love.”

Die Freundin. April 2, 1928. (Sourced from Espinaco-Virseda) the Die Freundin described a woman who killed

her husband for the sake of her lesbian lover. With it was printed an image of the woman with the title "Vilma West, who killed her husband for love."112 The BfM recycled the image a mere two years later for the first issue of Das 3. Geschlecht, where they gave the it the title "American female transvestite," notably beside the article "Is there a third sex?"113 While the image's first appearance resided entirely within the context of Vilma West's sexuality, the second appearance was stripped of its context, with the topic of gender

attributed to it. The publishers constructed two interpretations of West's gender and sexual experiences, using this single image in different contexts at different times. With

${ }^{111}$ Sutton, Katie. The Masculine Woman in Weimar Germany, 118.

${ }^{112}$ Espinaco-Virseda, Angeles. "I feel that I belong to you," 110.

Unknown Author, "Vilma West, die aus Liebe ihrer Freundin ihrem Mann erschlag." Die Freundin. 2. April 1928.

${ }^{113}$ Unnamed photographer, “Amerikanischer weiblicher Transvestit.” Das 3. Geschlecht. Mai 1930, 3 . 


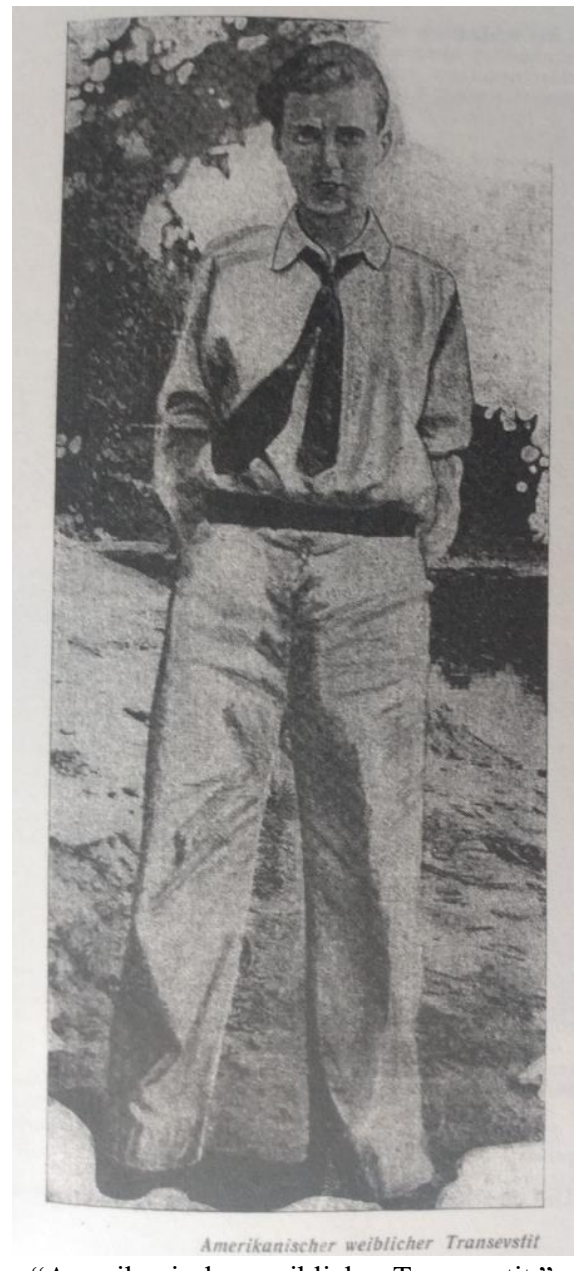

"Amerikanischer weiblicher Transvestit." Das 3. Geschlecht. Mai 1930, 3. so much reinterpretation of material relating to female transvestites in such short spans of time, and with the meanings of masculine presentation and vocabulary in constant ambiguity without reference to personal experience, a historian could easily misinterpret a female transvestite's life from one source of information to the next.

In the transvestite media, male transvestites were presented as a distinct category through their internal gender feeling as much as their presentation, with careful divisions made for those of different sexual orientations. Within the community, at least, a homosexual man could not be confused for a male transvestite, however effeminate he may have been. This was not only because men's clothing was not

feminized to a degree which could create visual ambiguity between these categories, but because the male homosexual did not have the so-called "soul-life of a woman" that was so carefully described in transvestite media articles, and so carefully curated by Radszuweit in order to garner public sympathy.

Female transvestites, on the other hand, were generally defined by their clothing rather than by the possession of male souls. Written content on female transvestites in the transvestite media was rare, whereas images of female transvestites were more common than those of male transvestites up until the publication of Das 3. Geschlecht. This 
demonstrated, therefore, a greater emphasis on outward appearance rather than on internal motivation when defining female transvestism. Meanwhile, female transvestites and lesbians were fully aware of the distinctions between the two identities. While sexologists and even male transvestites saw both lesbians and female transvestites as belonging to the same "third gender" category, the two groups themselves began to distinguish between an identity defined by the objects of an individual's desire, versus one defined by "cross-identifying tendencies." 114 The disregard for feelings and experiences as well as the focus on appearance is also demonstrated in Gerda's analysis. He expresses little concern for the invisibility of female transvestism, or for the ridicule that those perceived as masculine women by the general public received as a result of the "gender panic" of the Weimar era. ${ }^{115}$ Instead he addresses their access to trousers and masculine aesthetics.

Beyond a being a mere misunderstanding based on lack of sympathy, this focus on appearances rather than experiences was, in fact, a symptom of how womanhood as a whole was perceived through the male gaze of the general public. That is, the objectification of women based on appearance rather than on autonomous thought, and the sexualization of any deviance from proper womanhood, was a far more universal problem. Once again Gerda's views on the matter demonstrate the conflation of female transvestism and sexual activity not only through his direct pursuit of female transvestites as sexual and romantic partners, but through his description of what they could supposedly get away with in public: “...she is surrounded by a overwhelming nimbus of sensuality which the "decent" philistine can feed on....The female transvestite can have a

${ }^{114}$ Sutton, Katie. The Masculine Woman in Weimar Germany, 119.

${ }^{115}$ Sutton, Katie. The Masculine Woman in Weimar Germany, 2-3. 
girlfriend, and can even give that girlfriend a kiss in the open, dance with that girlfriend and live together, no one will take the slightest offense to that degree even when that degree is passed...they are simply 'ladies'."116 He describes female transvestites as inherently sensual, and actively sexual in public, and as very little else.

Gerda's account exemplifies two sexualized stereotypes that general society placed upon female transvestites. Sutton describes these as the archetypes of masculine women in popular Weimar media: "the Amazon" and "the Intellectual." Popular culture gave little thought to female transvestism as a gender phenomenon, and therefore these archetypes were placed upon them through their association with New Women, lesbians, and other masculine-appearing women. Both archetypes, Sutton observes, were portrayed in more general popular media as an "implicit rejection of men and disruption of social and gender norms" and were therefore, by a patriarchal public, often portrayed as a threat to society. The Amazon, a mythical woman who lived in a man-free nation, was a term used by proud lesbians, targeted advertisements, and a scorning public alike. Popular media used a particularly sexualized conception of the Amazonian, as exemplified in the novel Die Amazone Gloria. In this novel, a New York woman persuades other women to leave their husbands and children in order to create a "feminist colony," which is quickly destroyed by "a contagious wave of female homosexuality."117 The masculine woman, therefore, becomes a hyper-sexual spectacle; equal parts enticing, corrupting, entertaining, and out of control.

The stereotype of the Intellectual, meanwhile, was a conflation of masculine presentation with the presumed-to-be masculine values of education and reason. As

\footnotetext{
${ }^{116}$ Sutton, Katie. The Masculine Woman in Weimar Germany, 203.

117 Sutton, Katie. The Masculine Woman in Weimar Germany, 95.
} 
women fought for inclusion in intellectual, academic, scientific, and artistic spheres, this particular stereotype became a two-way street in which the presumption of masculinity was attributed to intellectual women, and intellect was attributed to women who took on the aesthetic of masculinity. Demands for equality were highly linked to masculine dress by outsiders, so that intellectual thought and gender inversion were conflated by the "observations" of (male) sexologists as well. In parallel to the representation of male transvestites in media, however, it was only the inversion of middle- and upper-class women that was considered intellectual. Masculinity on the part of working-class women was considered deceptive, dangerous, and generally linked to criminality. ${ }^{118}$

Masculine intellectuality of the mind and masculine virility of the body were similarly intertwined. Unable to parse out the many-faceted traits of male masculinity, bodily virility and sexuality were necessarily mixed into the Intellectual trope. Indeed, in Weimar Germany, "virile woman" was a euphemism for a sexual, masculine lesbian. ${ }^{119}$ This intense focus on the uncontrolled sexuality of masculine women - especially of those who were perceived as rejecting men - helps to contextualize the insistence by sexologists that female transvestites were also always lesbians, as well as the obsession of homosexual and transvestite communities with female transvestites' sexuality rather than, as was the case with their male counterparts, their internal lives.

Indeed, the internal lives of female transvestites were generally not considered at all in the discussion of their sexuality either. That is, it wasn't the female transvestites' own sexual lives that were discussed, but rather their bodies were sexualized by a heterosexual male-dominated media. Gerda's depiction of female transvestism, for

\footnotetext{
${ }^{118}$ Sutton, Katie. The Masculine Woman in Weimar Germany, 97.

${ }^{119}$ Sutton, Katie. The Masculine Woman in Weimar Germany, 100.
} 
example, only discussed female transvestites from a male, sexualized gaze. Addressing what their bodies do, he lists them as kissing, as taking what they want, and living together (with implied acts of sexuality therein). Through the observation of their bodies in sexual acts, he then assumed that they have all that they could want, not at all curious if they too would like to marry or take on male labor in the manner that he could female. The male gaze of the media and of respectable culture were not concerned with the internal lives, needs, and desires of female transvestites, but with the sexual ability of her masculinized body alone.

While written depictions of female transvestites were generally no more internal or distinct of lesbianism in Das 3. Geschlecht than they had been previously, the addition of around 20-30 illustrations of transvestites per issue indicated a significant change in the category. About half of those illustrations were of female transvestites, no longer under the title of "Lesbian" or even of "Transvestitin." Instead, the most common term used to describe them was "weibliche Transvestit." Although the bare, adjective-free term "Transvestit" still denoted a male transvestite (therefore placing male transvestism

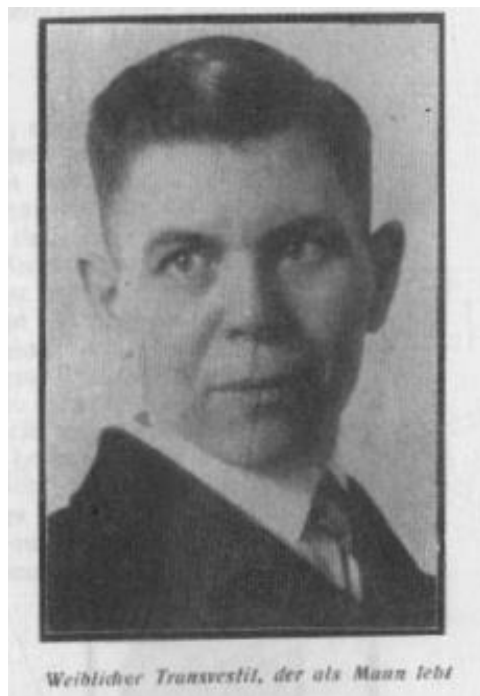

"Female transvestite, who lives as a man.” Das 3. Geschlecht. May 1932, as the default), female and male transvestites were now consistently housed under the same vocabulary umbrella of gender deviance.

The fact that images of female transvestites so greatly outnumbered their voices in transvestite media, however, created a strange contradiction in which female transvestites were often seen, but rarely heard. Mentions of female transvestism occurred most often in short stories or 
through passing comments in theoretical writings. Even in these contexts, however, they were frequently talked about but only rarely spoken to directly or discussed in their own words. Additionally, with the exception of Lotte Hahm, ${ }^{120}$ images of female transvestites did not include names. Instead, there were vague and simple descriptions like "Female transvestite, who lives as a man." Reading through das 3. Geschlecht today, in search of historical remnants, female transvestites appear like fictional creatures heard about only in stories, or like traces of anonymous ghosts caught on film.

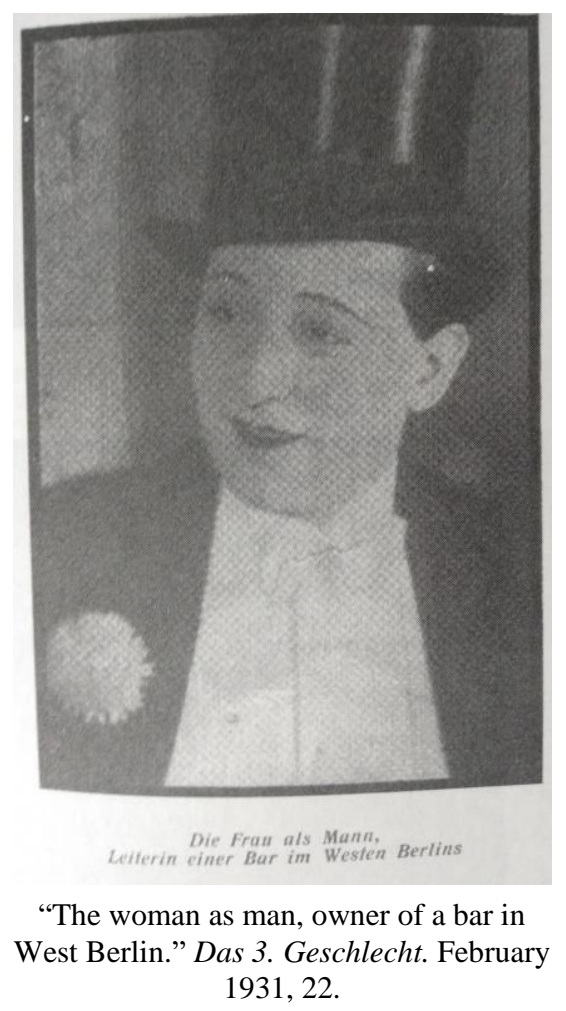

Just like with ghosts, these individuals truly did exist at one time. They lived lives and impacted the world around them. In the Weimar moment, the images of female transvestites would have been contextualized with the experiences and imaginings of the viewer, aware that the transvestite in the image had a name, had ideas and, outside of the publisher-contested printed word, chose when to speak her mind and what to say. Now images with titles like "The woman as man, owner of a bar in West Berlin” give small glimpses into the powerful ways in which she may have engaged in her community. But also like ghosts, the context and the voice, is lost.

\footnotetext{
${ }^{120}$ Lotte Hahm was the most prominent female transvestite activist present in the transvestite media. Hahm appeared in both Die Freundin and Das 3. Geschlecht regularly, along with advertisements for the lesbian clubs and cafes she owned as well as for the transvestite groups that she organized. Her prominence in the community was likely made possible by her ability to be active in both the transvestite and lesbian communities simultaneously. Images of Hahm appeared regularly in both publications, some by name and some not, indicating her celebrity and recognizability within the communities.
} 


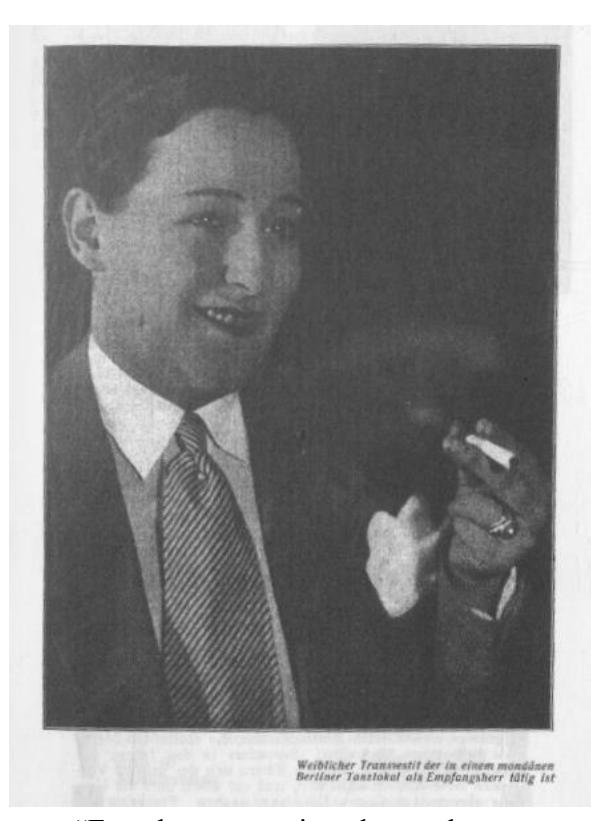

"Female transvestite who works as a receptionist at a trendy Berlin dance hall." Das 3. Geschlecht. May 1930, 4.

Her life becomes abstract and any attempt at a true recollection teeters on the verge of parable or myth.

The sexism and patriarchal insecurities of general society, the self-serving theories of sexologists, the biases and motivations of publishers, and the hierarchies of sex- and genderdeviant voices in interwar Germany created an ambiguity that is impossible to untangle, and a dynamic for female transvestites of visible silence. The little that was recorded at the time and preserved over time of female transvestites leaves more shadow than form. And yet, those shadows can tell a far deeper story of the history of gender deviance. 


\section{Academia as Violence: Containing Deviant Histories}

"The history of Western representation is littered with the corpses of gender and sexual deviants." -Heather Love, Feeling backward, 2007

When I tell new acquaintances that I am a German scholar, they are often very curious about what exactly it is that I do. In the situations in which I feel safe "outing" that what I do is thoroughly read transvestite periodicals from the 1920s and 1930s the reaction is varied, albeit always strong. Members of the general public most often express shock that gender deviants existed in the early 20th century and that they did not, as many believe without much reflection, spring out of the alcohol-stained floors of The Stonewall Inn in 1969. Another common reaction is surprise that gender deviant voices were not better suppressed or destroyed, commonly accompanied by a tacit discomfort at my willingness to declare in public that queer humans did indeed exist in the same decades as the romanticized heterosexuality of the likes of Fred Astaire and Humphrey Bogart.

Heteronormative society already has its history with which it is content, conceptualizing a cohesive and triumphant past upon which a productive future can be constructed. It is, therefore, the reactions of the gender and sexual deviants of today that are most telling. The vast majority were also entirely unaware of their community's work in Weimar Germany, even as it formed the foundations of many of the strategies and ideas in gay and trans activism today. They respond with excitement, even epiphany, that there really was a queer past. They ask for photos of their queer ancestors, for names to 
reflect on and honor, with a uniquely queer understanding of the power of chosen names and chosen family that has traveled defiantly down the unspoken family tree. We are not allowed a past beyond the blood and burned fragments of our predecessors, speaking not for themselves but merely existing as a threatening reminder of what the future holds for deviants: a repeating history of shame, isolation, rejection, and violence; of the death of queer ideas, communities and bodies. For these acquaintances, I am the writer of a long overdue obituary-turned-birth record, acknowledging that there was in the past - and therefore can be in the future - queer life.

The transvestite media of Weimar Germany survived to this day somewhat intact, raising the question of how, exactly, the history-starved trans and genderqueer communities of today are so unaware of its existence. The queer community is, after all, the most impacted by queer history, has the most to gain, and is the most eager to obtain it. Yet, queer communities without roots in university systems do not have access. This brings me to the third most common reaction that I receive to my work, often from German Studies academic circles as they are differentiated from the general public: disinterest. On its own, this would not necessarily be a problem. Every academic has their own specialization and generally not a lot of time to think about anything else. The combination of this general trend with both the academy's tradition of queer exclusion and its procedures on intellectual property and access to information, however, is a problem. The academic archive is a heteronormative, divergent-oppressive space in four ways that greatly impact what histories can be told, how they can be told, and to whom: the academy prioritizes non-radical, conformist knowledge for preservation, uses academic modes of organization and definitions of knowledge that centralize 
heteronormative and patriarchal information, has elitist assumptions about the academy's right to legally own histories, and as a result develops an exclusivity with which university libraries and archives decide who is able to access them.

Let's begin with a question that may, at this point, be crossing your mind: if queer histories are so suppressed by the academy, how is it that Die Freundin and Das 3. Geschlecht survived the 20th century to be preserved in the libraries and archives of today? The answer to this question reflects on much of what I have revealed so far about the hetero- and homonormative contents of these periodicals. Which is to say that it was not out of the goodness of academic hearts that this transvestite history in particular survived. Rather, records of transvestite respectability, conformity, and the writings which were created to appease the status quo were all that was permitted to survive. As we have seen from Radszuweit's disparagement of his transvestite writer-readership, the transvestite media was carefully curated as an attempt to implore to and appease heteronormative society.

Indeed, Rainer Herrn has observed that the frequent images of nude or near-nude cisgender women on the covers of transvestite media were intended to draw in a cishetero male audience. ${ }^{121}$ Despite the readership consisting of nearly entirely genderdivergent individuals, the periodical's intended audience was always the status quo. The goal of respectability and normalization, seeking permission from the dominant forces of society in order to join their ranks, will always place the "normal" on the cover and at the center of the conversation, where they are quite accustomed to being. We cannot be

\footnotetext{
${ }^{121}$ Herrn, Rainer. "Das 3. Geschlecht (The 3rd Sex): Illustration Practices in the First Magazine for Transvestites," 56.
} 
surprised, therefore, when cis-hetero and male-dominated archives and universities

decide that the artifacts worth preserving are those that speak directly to them.

Thanks to Radszuweit and the aims of the BfM, the transvestite media bound and censured the queer lives of Weimar Germany into a shape that could be easily preserved by academia for its conception of time as well as audience. That is, the transvestite media fits perfectly within the heteronormative, mainstream narrative of history as a streamlined, linear timeline of compartmentalized eras and events with consistent, upward progression. In her book Feeling Backward: Loss and the Politics of Queer History, Heather Love situates queerness as something that, in the eyes of normative society, is inherently historically backward. Academic historicism, therefore, is a tool used to divide the "normal" from the gender and sexually deviant on the basis of what is modern and civilized in contrast to what is barbaric and outdated. Modernity, therefore, is an inherently heterosexual and cisgender concept defined by progress, rationality, and advancement. $^{122}$

The work of the transvestite media and the BfM were, therefore, an attempt to combat the position of queerness as abnormal and backwards, and to join the ranks of modernity. But there is a conflict of motivations for queer folx, and a parallel reaction to being pushed into ghosthood.

"For queers, having been branded as nonmodern or as a drag on the progress of civilization, the desire to be recognized as part of the modern social order is strong. Narratives of gay and lesbian progress inevitably recall the painful history of the homosexual's birth as one of modernity's backward children...Over the last century, queers have embraced backwardness in many forms: in celebrations of perversion, in defiant

${ }^{122}$ Love, Heather. Feeling backward: Loss and the politics of queer history. Harvard University Press, 2009, 5. 
refusals to grow up, in explorations of haunting and memory, and in stubborn attachments to lost objects." 123

For those deemed queer by society like myself, there is a desire to become normal, become modern, but also a pull in the other direction to embrace the backwardness attributed to us.

Normative society, and therefore also the academy, participate in what Halberstam calls "heteronormative common sense," or "the equation of success with advancement, capital accumulation, family, ethical conduct, and hope."124 The academy therefore struggles to discuss histories whose subjects did not center productivity, family, and the hope for progress in their lives and bodies. Queerness is not permitted within their normative modes of thought, just as the rational mind must be disconnected from the body, and the productive purposes of the restrained, heterosexual body must shame and attempt to control the radical pursuit of anti-productive, queer bodily pleasure. Or, in other words, the academy and the general public avoid and silence discussions of those queers who embraced their backwardness, followed their bodies and their minds, rejecting family, production, and the potential for societal success in the process.

Whether explicitly or implicitly, the transvestite media of the BfM understood the need to engage in narratives of family, progress, and hope in order to be acknowledged by the status quo. The general refusal to acknowledge the many painful and negative aspects of being a transvestite in the early 20th century stand as a rejection of backwardness and an attempt to partake in modernity. Only lightly addressing their confused and shame-ridden pasts, the authors of transvestite media focused on progress

\footnotetext{
${ }^{123}$ Love, Heather. Feeling backward: Loss and the politics of queer history, 7.
}

${ }^{124}$ Halberstam, Jack. The Queer Art of Failure, 89. 
in the present and future, and on their own respectability rather than on the perversion attributed to them. Discussions of pleasure for its own sake were avoided, instead focusing on the familial, interpersonal, and productive pleasures of acceptance and domestic labor. Radszuweit himself limited the nature of what could be published to those articles that could not be perceived as backward. His scorn for transvestites who "told of clothing pieces, describing them in minute detail" demonstrates how he rejected any pleasures derived from the inherently queer act of cross-gendering and dressing the body for the more respectable, intellectual joy of domestic social roles.

Of course there were transvestites who embraced their backwardness and bodily pleasure, rejecting productivity and progress, but they were not published and were not even welcome in the same communities as those in which the transvestite media circulated. That is, the lives of the gender deviants who attempted normalcy have been preserved over time, while the truly queer experiences of gender rebels, the most marginalized and rejected and backward, have not. Middle-class, heterosexual transvestites produced families and incomes by acceptable means. Bisexuals, homosexual transvestites, female transvestites, sex workers and entertainers could not (or would not) be anything but backward. Should we be surprised that their voices aren't present in the archive?

The academic establishment and general society as a whole have prioritized the stories of those marginalized people who attempted to speak directly to a normative framework, but this is not to say that those who tried were permitted to enter the mainstream narrative of historical modernity. On the contrary, the structure of the academy has been made in such a way as to actively obscure even those elements of 
transgenderqueer history that have been permitted to survived. As I near the end of two and a half years of research, I realize that I have learned far less about my queer ancestors than I have about the devastatingly homo- and heteronormative design of every research tool at my disposal, from university libraries and individual brick-and-mortar archives to online database and search engine algorithms. It has never been more clear to me that, while the people behind each of these systems may pride themselves on the logical, numerical, systematical nature of their products, there are still fallible human beings behind each.

These human beings chose how to prioritize and organize knowledge to disturbing effect. Going into library catalogues and online academic databases, a search for "transvestite," "third-sex," "homosexual," or any other words in relation to Weimar Germany will retrieve page-after-page of medicalizations, fetishizations, and police and Nazi violence against queer bodies. Despite the presence of queer voices in these archives, their search systems prioritize the image of the queer body as an object of torture and dehumanization. At least one of the causes of this problem is not difficult to find. When I would finally find a copy of Die Freundin, or of similar transvestite media, titles and keywords were often misspelled or missing entirely, tables of contents were not digitized, and descriptions of contents were virtually nonexistent at best, and inaccurate at worst. Even the gay, in-person archives I was able to visit before COVID-19 swept the world catalogued lesbian periodicals with little mention of transvestism, forcing my requests to view resources to be broad and vague.

Librarians and archivists were regularly frustrated by my inability to make more specific requests, asking me to specify articles by title and page number, despite the fact 
that the existence of the Der Transvestit booklets were rarely noted and even less likely to be indexed in their records. Librarians at institutions with microfilm copies in their possession have told me that Die Welt der Transvestiten never existed, or simply refused and ignored my requests altogether. Should we be surprised that queer histories are so rarely retrieved for academic work?

And what exactly is the place of queer histories in academic work if their sources are so widely held under lock and key, only to disappear behind more acceptable contents? In my experience, what constitutes academic work is a heavily controlled concept. Academia requires connections to the correct institutions, using the correct vernacular, citing the correct kind of truth and constructing narratives that are palatable to the correct people. Academia hoards knowledge with definitions of intellectual property that carefully exclude anyone without the right prerequisites from accessing it. Then, individual professors, writers, and archivists act as guards at the gate, heteronormative, patriarchal, white, higher-class cultural literacy acting as a passport while peer review disarms any form of radical new thought. Meanwhile, those whose histories are studied in the attempt to modernize and liberalize the academy are not welcome in classrooms without, in a case of bitter irony, rejecting their cultures and experiences altogether. In my work, that means that the academy has controlled the narrative of the resources that I have been able to access, while queer communities are given no ownership over the materials and interpretations of their own histories.

These problems come into clear view through the example of a different piece of Weimar queer history. Anders als die Andern (Different from the Others), a film released in the summer of 1919, told the story of a homosexual man's affair with his student, his 
blackmail by a supposedly fake homosexual criminal, his fall from social grace, and subsequent suicide. Magnus Hirschfeld helped create the film, whose goal was to educate the masses on the harmlessness of homosexuality and the injustice of Paragraph 175. It is thought by many to be the first film to portray homosexuality in in a positive light.

People flooded into theaters to see it as the moral scandal of the film swept across Germany and Austria. Soon enough the film was banned in public, and only available for viewing at Hirschfeld's Institute for Sexual Science. ${ }^{125}$ In 1933 his institute was raided by the Nazis and the last known, complete copies of the film were destroyed, having had little impact on the sympathy of the general public in their short life. Years later, however, in 1971, 24 minutes of the original footage resurfaced in Russia in the form of a short called Gesetze der Liebe (Laws of Love). The footage travelled the world through different queer communities, being shown most often in LGBT community spaces until 1990, when it caught the eye of the Film Museum Munich’s archivists. ${ }^{126}$ The archive took the film's remnants out of the queer community and, having filled in the gaps with their own interpretation of what the full-length feature may have been like, copyrighted it. Now theirs is the only version of the footage available to the public. Only on DVD and with little internet presence legal or otherwise, the film's existence is largely unknown.

The Film Museum's reconstruction begins with a long text scroll of background information, situating the movie as a primary turning point in queer history. Academia often situates certain people, moments, and actions as pivotal, or central to how a movement progressed. But the widespread use of this concept doesn't necessarily make it

\footnotetext{
${ }^{125}$ Beachy, Robert. Gay Berlin: Birthplace of a Modern Identity, 164-167.

${ }^{126}$ Pilcher, Lauren Elizabeth. "Querying Queerness in the Film Archive, the Ephemeral Anders als die Andern (Different from the Others) (1919)." Synoptique 4, no. 1 (Summer 2015), 36-47.
} 
helpful or true. In his article "On the Uses and Disadvantages of History for Life," Nietzsche calls this practice the construction of a "monument" in a historical narrative and likens it to the literary trope of deus ex machina. To construct a monument in a historical narrative is to use our hindsight in order to establish a predeterministic view of historical events. ${ }^{127}$ That is, it assumes that the events that occurred, from the monument to our present day, were always going to happen. To a heteronormative academy, it is no doubt comforting to observe the history of a deliberately destroyed film - and community - and still maintain that the heterosexual-dominant society of today was inevitable - to see the current state of violently oppressive political and cultural heteronormativity as inevitable. This state of reality frees the cis-het academic of any blame for the current state of affairs and, simply waiting to observe the next monumental moment in queer liberation, frees her or him of any future obligation to relinquish his or her privileges. In order to present the film as a monument in queer history, the Film Museum's text scroll situates Hirschfeld as the primary figure in Weimar homosexual emancipation. While Hirschfeld was a prominent figure in the eyes of the general public, Radszuweit, who fundamentally disagreed with Hirschfeld's theories and methods, was certainly more prominent among homosexuals and in public newsstands across the nation. Any sign of contention against Hirschfeld's views is not mentioned by the Film Museum, however, who instead presented a simplified, linear view of the movement. Hirschfeld's third-sex theories and presentations of homosexuality as a harmless condition are presented in the

\footnotetext{
${ }^{127}$ Nietzsche, Friedrich. Nietzsche: untimely meditations. Cambridge University Press, 1997, 69-
} 71. 
film as universal, with no mention of the BfM's and GdE's focusses on homosexuals as productive members of society.

At the same time, the original 24 minutes of footage is padded and filled in with stills and text, using primary as well as secondary sources to more than double its length. Later in the film, for example, cut scenes are replaced with still images of transvestites. Following the Hirschfeldian model, the images are mostly scientifically framed and titled, with people in both masculine and feminine dress as well as naked staring blankly into the camera. How much and what kinds of information should or should not be contained in a restored historical work is, of course, a question with many correct answers depending on the intention of the creator. It is therefore important to have many perspectives, and therein many interpretations of historical truth, present for any one primary source. Whatever the motivation, the Film Museum made the choice to simplify the truth for Anders als die Andern. Then, by copyrighting the film, they also prevented alternative perspectives and readings, ensuring that only one kind of truth, the kind based on a heteronormative model of linear, complacent history, is available.

While it is far easier to construct my own tidy narrative with the story of Anders als die Andern than it is to relate the complexities of the academy's impact on my work with the many, often nameless voices of the transvestite media, there is one element that I hope I have made clear throughout my writing: the transvestite media reflects the lived experiences and perspectives of only some of the transvestites of interwar Germany. Very little from the perspectives of other, more radical modes of gender divergence were written down, and even less of those that were not ignored or actively destroyed by transvestites attempting normativity, by unloving families, by self-ashamed or fearful 
individuals, by police, by society, and yes, by the academy. There will never be a complete picture of the queer Weimar Republic. So many desires were suppressed, diaries burned, human lives taken, and voices lost to time that we will never get to hear.

I have, over the course of this thesis, formulated words around suicide, assault, oppression, shame, fear, isolation, disgust and judgement. But these were not the most difficult sections for me to write. I was so excited to have found queer voices when I started this project that I had not consider the cost they paid to have their voices heard; self-censoring, pandering to male heterosexual erotic fetishization, medical patholigization and circus-like voyeurism. I am angry for them, that they sacrificed their own worth for a seat at the table; a seat which was only given to them after death as an afterthought in the archive. But the most difficult and painful parts to write were those that were missing entirely. The many female transvestites whose voices were not recorded, the sex workers and entertainers who were not welcomed into the queer archive at all. They are the ones whose voices I truly want to hear, the ones I'm most proud of, because they did not sit beside the table begging for scraps of inclusivity.

Telling the fragments of their stories that remain was heartbreaking and emboldening for me. They were my favorite to write, and also the ones I avoided sitting down to work on the most. Heather Love is all too familiar with this feeling. In her book, she explains how queer historians and theorists can so eagerly tackle negativity, and yet struggle to address the fractured and incomplete pieces of queer history. "These are the representations that offer too stark an image of the losses of queer history. What has resulted is a disavowal of crucial aspects of this history and of the conditions of queer 
existence in the present." ${ }^{128}$ Where she sees the consequences of this avoidance (that we miss key truths about queer existence when we avoid its most tragically ethereal elements), I see an explanation that goes deeper than this being simply another negative aspect of queer life.

One of the first things we learn in academic training is to cite our sources. It is incredibly important to give credit for the labor of others that has benefitted your work and, of course, to ensure that you are not stating falsehoods or fabricating information. What constitutes a source, however, is something that has been solidified into unquestionability in the academy, in which we are trained never to trust ourselves.

The queer body is the perfect location for a discussion on truth. For when we ask what is permitted to be a source in a text, we are asking what is real and true, what is to be trusted and what we should ignore. In order to construct a heteronormative society in a world so full of human variation, there must be a true and a false way to be in your body. The true way to be is exactly how you are told: man, woman, a lover of women or a lover of men. But that is often not what our bodies know to be true. Surely then, the queer body which experiences self, love, feeling, and action in a manner which it is not permitted, must me proof that the normative mode of being is not the only way to be. In order to remove this particular source of counter-evidence, however, the academy devised a solution: only the material, the observable matters. Any other source of information can be ignored. If experience, emotion, and internal sensation does not count as a viable source of information, then the man in charge (a wealthy, white man, in this case) can simply control what is observable so that the truth is shaped around him.

${ }^{128}$ Love, Heather. Feeling backward: Loss and the politics of queer history, 17. 
In terms of gender, this informational control is observable throughout life. The scientific concept that there are only two sexes is maintained by performing unconsentable, cosmetic surgeries on any infants whose genitalia visibly appears outside of the "norm." A young boy raids his mothers' closets and play dress-up, demonstrating actively that boys do in fact wear dresses. He is told, however, that they do not; to reject the source that was the joy in his heart and mind at feeling beautiful and playful, and to accept the visual, material source that is your father doesn't do that (at least not where he could be observed). And the harsh punishment for listening to his body and mind instead of his father for his truth teaches that young boy quickly that safety means ignoring his intuition and doing only as he sees his father do. As far as standard modes of evidence are concerned, the lives of transvestite women, sex workers, performers, bisexuals and other radicals in Weimar Germany cannot be discussed at all. The status quo of academia defines evidence as that which can be found in material, and then burns all material that he wishes was not true.

The shadow history of something whose material has been destroyed is, in its essence, nothing but the emotion of tragedy. As such, without the correct, normative form of evidence to call on, even approaching it is anti-academic. Those that might want to discuss these eviscerated queer histories, therefore, bring their own experiences as the little boy in a dress back to the fore of their minds, scared to look to anything amaterial for truth lest it lead down a rabbit hole of dangerous and shameful transgression. We are taught that the emotional, the personal, and the experiential cannot be trusted, and that the only path to truth is empirical. Every fallibility of emotion and experience is used as damning evidence, as though material evidence is not equally fallible. We do not 
question the empirical method every time the laws of physics change, a new text surfaces, or a long-used medication is taken off the market. And even if empirical knowledge was less fallible when compared to intuitive knowledge, the study of history would not benefit from its universality. As Nietzsche stated, "Insofar as it stands in service of life, history stands in the service of an unhistorical power, and, thus subordinate, it can and should never become a pure science such as, for instance, mathematics is."129 The academy's demand that the goal of history is to find an impartial, material truth of the past is to deny history its purpose of helping those that are alive today. The path to healing the damage done to queer lives by the destruction of our histories is personal, wholly in service of the unhistorical - the human, the emotional, the feeling of the body.

Just as Radszuweit praised himself for producing a transvestite media, all while carefully selecting and excluding the elements of gender deviance that did not suit his homonormative ends, universities, academic libraries, and archives do their best to present themselves as supporters and uplifters of queer thought, all while the very foundations of the academy necessitate queer erasure and oppression. The academy steals those queer resources and histories that are permitted to survive from their communities, locking them away where they are lost to disinterested and queerphobic means of organization. The academy then defines legitimate knowledge as that which is observable, destroying and hiding all that does not suit a complacent, heteronormative historical framework. No queer history can be recorded within the standards of academia, and so the academy betrayed me and my work before it even began. I sought out to tell a history of gender rebels, but found that only a history of the placating could be told in an

${ }^{129}$ Nietzsche, Friedrich. Nietzsche: untimely meditations. Cambridge University Press, 1997, 67. 
academically-acceptable format. Even then, every step of the way the spirit of the academy hovered over my shoulder as if with a sharpie, ready to black out anything deemed too vulgar, too beautiful, too emotional, or too personal. As if to say tell the history of only those the academy deems acceptable, or tell no history at all. A history of the gender deviants who did not, or could not speak to a heteronormative society, whose material was so damning that they could not sacrifice their body for a dusty shelf in the archive, cannot be written with footnotes and a bibliography, because there is nothing to cite but shadows and loss, echoes and emotions.

My father's father was in high school when the first issue of Die Freundin was published in 1924. But I am transgender, and he would have burned my diary, silenced my voice, spoken of me in hushed whispers until all record of me was lost but taboo traces and shadows. My ancestors are in and in-between these pages that I have written. My ancestors had pseudonyms and weekend lives. I invited them into my home when I typed their names here, and I carry in my flattened, and sutured chest those whose names have been lost forever but whose actions have led to me. I am transgender, so flesh and blood be damned. It was the transvestites who attended the balls in Berlin in secret, who sold entertainment in the theaters and sex at Tiergarten Park, who sowed the seeds of my existence. I know them in myself, in my friends, in my lovers, in this body that I carry. There is more truth in that than in any library book.

Just as the transvestite media failed gender deviants in order to appease the heteronormative men and women who oppressed them, my work here is confined to the respectable. If I could go back two and a half years with the resources that I have today, it would be proudly unpublishable. This thesis contains many truths that should be told, but 
they are only those that are acceptable and comfortable to a heteronormative academy. But holding someone hostage does not mean that they need you. If I could have one hope (without that hope falling into the realm of Halberstam's heteronormative common sense), it would be that the future of queer history is returned to its communities. Queer history should take the form of personal stories and experiences, of journaling, drag shows, fanfiction, and erotic novels. At the very least, priority should be given to cataloguing the histories of the marginalized, the archive doors should be open to all regardless of education or connection, and the academy should take a back seat in the telling of queer histories. Enough damage has been done by the words and actions of researchers, professors, archivists, and academia as a whole: for once, it's time to sit back and listen. 


\section{Past, Present, and Future}

The transvestite media was immensely positive for those who could participate. It was a location in which a transvestite could build community, see others of their kind, and learn how to survive in a hostile world. Its creators and contributors were remarkably daring, putting their faces and ideas out into a world that would never be ready for them. If this thesis does nothing else, it puts their names on paper with as much care for them as they had for their community, and with enough respect for their impact on the queer lives that came after them to also acknowledge their imperfections and failures.

The end of Das Dritte Geschlecht in 1932 also marked the end of the transvestite media as a whole, when National Socialist politics made a public association with gender and sexual deviance far too dangerous to continue. While writings and pamphlets were distributed in secret throughout the Nazi era, nothing like Der Transvestit or Das 3. Geschlecht would exist again for many years afterwards. ${ }^{130}$ This, if nothing else, demonstrates the nonlinear nature of queer history. Far from being a steady progression towards liberation, the survivability of being trans in the western world waxes and wanes over time. Additionally, the same moment in history may lead to improved and worsened conditions for trans folx simultaneously. The Weimar era denoted a marked improvement for middle class transvestites, who found community and even some small amount of legal change, while full-time transvestites, as well as those in sex work and entertainment, reaped few of these benefits right up until their middle-class equivalents were no longer humored.

${ }^{130}$ Herrn, Rainer (Hg). Das 3. Geschlecht, 5. 
As concise as this summary appears, the task of studying the gender deviants of Weimar Germany will never be complete or completely accurate, nor should it be. There are many aspects of a queer Weimar German history which truly should have been addressed in more detail in this text, for example, but for which there was a lack of space, time, or competency on my part to be able to complete. These include a deeper dive into expected gender behavior, feminist readings, and the role of capitalism in each of these as well as, most importantly, a lack analyses addressing the impact of racism, rising nationalism, and a deeply-entrenched antisemitism on the experiences of the gender nonconforming. Queerer questions arise as well, such as the experiences of bisexual and homosexual male transvestites, bisexual and heterosexual female transvestites (as well as female transvestites as a whole), sex workers, full-timers, binary-rejectors, and others whose stories have not been recorded in, and therefore cannot be explored in an academic context.

These key points aside, if this thesis has raised more questions than answers, then it has done its job. In his analysis of queer and disability theory in composition, McRuer describes an English composition course in which he attempted to queer and "crip" the pedagogy. By turning the focus of the course away from a production of writing towards a "de-composition" of it, he "directed attention to (individual and nonindividual) composing bodies in that the important feature of [writing assignments] was not the product but the ongoing critical conversation that would never be completely finished or orderly (especially since students reported that it spilled into other venues, into conversations they were having with friends or in other classes)." ${ }^{131}$ In the same way, this

131 McRuer, Robert. Crip Theory: Cultural Signs of Queerness and Disability. New York University Press, 2006. 162. 
brief, queer history about a small collection of German transvestite periodicals spanning only eight years decomposes into a far greater navigation of binaries and oppression, negativities and loss, body and society, cultural and academic complacency and erasure.

It is a trend throughout modern queer history that those willing to appeal to the status quo can receive a small, temporary improvement of conditions while those who cannot, or will not reject their queerness are left behind. Heather Love outlines the consequences for the trend of inclusion and acceptance in society without also breaking down the position of the cishet majority as gatekeepers into the present day. "Advances' such as gay marriage and the increasing media visibility of well-heeled gays and lesbians threaten to obscure the continuing denigration and dismissal of queer existence. One may enter the mainstream on the condition that one breaks ties with all those who cannot make it..."132 There is a danger inherent in normalizing queerness and pushing it into a respectable shape. In her example, legalizing gay marriage poses as a solution for gay couples who were unable to share medical insurance plans, were barred from involvement in each other's medical care, struggled to adopt children or establish domestic lives together, among other issues. Unlike addressing the nature of healthcare coverage, medical autonomy, or the insistence upon heteronormative models of family, each of which is steadily crumbling under the weight of late-stage capitalism as it is, opening the institution of marriage to gay folx simply gives those who already have ample means permission to take on heteronormative conceptions of property distribution, family, and bodily control.

132 Love, Heather. Feeling backward: Loss and the politics of queer history, 10. 
The uncanny similarities between the modern treatment of queer liberation and Weimar Germany’s transvestite community and media further dismantle the progress model of history, with optics of hope and change through media representation while at the institutional level, gender divergence is ready to be eradicated at the first sign of real resistance. Today is what Time Magazine named "the transgender tipping point." There is ever more talk about and representation of transness in media, especially of affluent, beautiful, able-bodied and generally well-passing trans men and women like Laverne Cox, Eliot Page, and Caitlyn Jenner. Steinmetz, who wrote the now famous 2014 "tipping point" article about Laverne Cox and the mainstreaming of trans activism for Time Magazine, certainly saw the increased representation of respectable trans folx as a sign of more tangible change to come, anticipating the arrival of the transgender equivalent of gay marriage, whatever that may be. ${ }^{133}$ The reality, however, is that as upper-class representation in mainstream media has steadily increased, so have hate crimes against and murders of trans folx, especially those who are Black, and Latinx. ${ }^{134}$

Just as the Weimar transvestite media spoke of hopeful futures, liberation through awareness, and the ability of transgender men and women to assimilate into the status quo non-disruptively, modern, mainstream media sees itself as the means and the end for transgender liberation. Just like the transvestite media, modern media does not open its doors to any but the most respectable transgender folx. And just as in Weimar Germany, those who are not comfortable for heteronormative consumers to witness are controlled, hidden, or eliminated. There is, therefore, a historical pattern in western queer history in

\footnotetext{
${ }^{133}$ Steinmetz, Katy. “The Transgender Tipping Point.” Time Magazine. May 29, 2014. ${ }^{134}$ Strangio, Chase. "Deadly Violence Against Transgender People Is on the Rise. The Government Isn’t Helping.” ACLU. August 21, 2018.
} 
which queer folx are divided, with a privileged few offered just enough tolerance to believe that, if they disregard the rest, they will be protected by general society.

There was a hierarchy of control for the Weimar Transvestite Community from those who ascribed to heteronormative cultures and laws oppressing transvestite bodies, to homosexual and lesbian men and women controlling transvestite voices, to the respectable transvestites themselves, all three of which violently suppressed and rejected those who did not fit. Each layer of this hierarchy was comprised of real individuals, whose words and actions came together into a failure to support the gender deviants of their time, culminating in their complete, public destruction. Most of this text has brought this hierarchy into view, while the previous chapter demonstrated one way to reject it. A queer history is not merely one in which queer topics are discussed, but one in which violent systems of knowledge and power are rejected.

In way of final thoughts, this final portion of secondary historical text must become a primary one. In 2020, more transgender people were killed than in any previous year on record. ${ }^{135}$ The year of this writing, 2021, broke the record for anti-transgender legislation as early as March, with the majority of those laws preventing trans access to community participation and healthcare, especially for children. ${ }^{136}$ If history truly does repeat itself, then we are on the downward slope of the tipping point.

The systems on display in this queer history of Weimar transvestites are still alive and well today, and they survive by being effective, hidden predators to the others of society. Every one of us has their part to play in dividing and baiting transgender people

\footnotetext{
${ }^{135}$ Hayward, Giulia and Wood, Douglas S. "A Record Number of Transgender and Gender Nonconforming People in the US have been killed in 2020." CNN News. November 20, 2020. ${ }^{136}$ Ronan, Wyatt. "BREAKING: 2021 Becomes Record Year for Anti-Transgender Legislation." Human Rights Campaign. March 30, 2021.
} 
with a false sense of acceptance. To take a step back, to look at the systems which are intent on controlling and eliminating transness today and to choose not to accept your part in it, is to conduct a queer history of the present and the future. 


\section{Bibliography}

Advertisement. „Blätter für Menschenrecht,“ Das 3. Geschlecht, September 1930, 22.

Advertisement. "Der Flagellantismus” Das 3. Geschlecht. May 1931, 40.

Advertisement. „Das Freundschaftsblatt,“ Das 3. Geschlecht, July 1931, 28.

Advertisement. „Die Freundin,“ Das 3. Geschlecht, February 1931, 2.

Advertisement. „Die Insel,“ Das 3. Geschlecht, September 1930, 14.

Advertisement. "Eldorado," Die Freundin no. 12, September 4, 1929.

Beachy, Robert. Gay Berlin: Birthplace of a Modern Identity. Alfred A Knopf Incorporated, 2014.

B., Gitta, “Transvestit und hausarbeit (Liebe Frau Grete!)," Ledige Frauen, no. 4, 1928.

Classified Advertisements. Der Transvestit, September 4, 1929.

K, Elli Richard, “Der Transvestit und seine Partnerin,” Ledige Frauen 1, no. 10, 1928.

E. Raven, "Das Empfindungsleben der Transvestiten," in Die Welt der Transvestiten, November 9, 1932.

Espinaco-Virseda, Angeles. "I feel that I belong to you": Subculture, Die Freundin and Lesbian Identities in Weimar Germany. Spaces of Identity vol. 4 (2004).

Fitzsimmons, Tim. “'Transsexualism' removed from World Health Organization's disease manual.” NBC News. June 20, 2018. https://www.nbcnews.com/feature/nbcout/transsexualism-removed-world-health-organization-s-disease-manualn885141

Grete, "Transvestit und Hausarbeit," Ledige Frauen no. 2, 1928.

Hayward, Giulia and Wood, Douglas S. "A Record Number of Transgender and Gender Nonconforming People in the US have been killed in 2020." CNN News.

November 20, 2020. https://www.cnn.com/2020/11/20/us/transgender-deaths-2020trnd/index.html

Heidi, “Lebensbild eines Transvestiten,” Die Freundin no. 5, July 31, 1929.

Halberstam, Jack. The queer art of failure. Duke University Press, 2011. 
Heffernan, Dani. “The APA Removes 'Gender Identity Disorder' From Updated Mental Health Guide.” Glaad. December 3, 2012. https://www.glaad.org/blog/aparemoves-gender-identity-disorder-updated-mental-health-guide

Henri, Eduard. „Der Tag des Karl Maria Roloff.“ Die Freundin, August 8, 1924.

Herrn, Rainer (Hg). Das 3. Geschlecht: Reprint der 1930-1932 erschienen Zeitschrift für Transvestiten. Männerschwarm Verlag, Hamburg, 2016.

Herrn, Rainer. "Das 3. Geschlecht (The 3rd Sex): Illustration Practices in the First Magazine for Transvestites." Others of my Kind: Transatlantic Transgender Histories. Trans. Taylor, Michael Thomas and Timm, Annette F. University of Calgary Press, 2020: 35-69.

J., K. F., "Sadistisches und Masochistisches im Sexuelleben” Das 3. Geschlecht. September 1930, 27-37.

K., Elli Richard, "Der Transvestit und seine Partnerin” Ledige Frauen, no. 10, 1928.

Laqueur, Thomas. Making sex: Body and gender from the Greeks to Freud. Harvard University Press, 1992.

Liebherr, „Elegante Transvestit, völlig als Mann lebend.“ Ledige Frauen, 9th issue, 1928.

Love, Heather. Feeling backward: Loss and the politics of queer history. Harvard University Press, 2009.

Marhoefer, Laurie. "Degeneration, Sexual Freedom, and the Politics of the Weimar Republic, 1918-1933." German Studies Review (2011): 529-549.

Marhoefer, Laurie. “"The Book Was a Revelation, I Recognized Myself in it': Lesbian Sexuality, Censorship, and the Queer Press in Weimar-era Germany." Journal of Women's History 27, no. 2 (2015): 62-86.

McRuer, Robert. Crip Theory: Cultural Signs of Queerness and Disability. New York University Press, 2006.

Minna, "Transvestit und hausarbeit (Sehr Geehrte Redaktion!)," Ledige Frauen, no. 4, 1928.

Nietzsche, Friedrich. Nietzsche: untimely meditations. Cambridge University Press, 1997.

Oswald, Richard, dir. Anders als Die Andern. 1919; Compilation by Filmmuseum München. Munich, DE: Kino Video, 2011. DVD. 
Pilcher, Lauren Elizabeth. "Querying Queerness in the Film Archive, the Ephemeral Anders als die Andern (Different from the Others) (1919)." Synoptique 4, no. 1 (Summer 2015): 36-60.

P. W., "Mein Liebling Heißt Kurty!,” Die Freundin 2, no. 3, February 1st, 1925.

Die Redaktion, "Masochist und Transvestit” Das 3. Geschlecht, February 1931, 1.

Radszuweit, Friedrich, “Zum Kampf der Transvestiten.” Das 3. Geschlecht. July 1931, 14-16.

Ramsey, Glenn. "The Rites of Artgenossen: Contesting Homosexual Political Culture in Weimar Germany."Journal of the History of Sexuality 27, no. 1 (2008): 85-109.

Ronan, Wyatt. "BREAKING: 2021 Becomes Record Year for Anti-Transgender Legislation.” Human Rights Campaign. March 30, 2021. https://www.hrc.org/press-releases/breaking-2021-becomes-record-year-for-antitransgender-legislation

Schröder, Gerda Erwin, "Warum finden wir Transvestiten keine Partnerin?" Ledige Frauen, no. 6, 1928.

Schweitzer, E. E., “Sadismus und Sadisten” Das 3. Geschlecht. May 1931, 32-38.

S., Heidi, “Lebensbild eines Transvestiten” Die Freundin no. 5, 31 Juli 1929.

Steinmetz, Katy. “The Transgender Tipping Point.” Time Magazine. May 29, 2014. https://time.com/135480/transgender-tipping-point/

Strangio, Chase. "Deadly Violence Against Transgender People Is on the Rise. The Government Isn't Helping.” ACLU. August 21, 2018. https://www.aclu.org/blog/lgbtq-rights/criminal-justice-reform-lgbtqpeople/deadly-violence-against-transgender-people

Sturgess, Cyd. “'Die zarte Haut einer schönen Frau': Fashioning Femininities in Weimar Germany's Lesbian Periodicals.” Dawson, Leanne, ed. Edinburgh German Yearbook 10: Queering German Culture. Vol. 10, 56-82. Boydell \& Brewer, 2018

Sutton, Katie. The Masculine Woman in Weimar Germany. Berghahn Books, 2011.

Sutton, Katie. “'We Too Deserve a Place Under the Sun': The Politics of Transvestite Identity in Weimar Germany.” German Studies Review 35, no. 2 (2012): 335-354.

Unknown Author. "10 Jahre Magnus Hirschfeld Stiftung." Das Kriminal-Magazin. Band 1, Aug 5, 1929, 50-55. 
Unknown author. „Endlich - Endlich!“` Der Transvestit, January 15, 1925.

Unknown Author. "Meinungsaustausch über Modefragen," Die Welt der Transvestiten, August 22, 1927.

Unknown Author. "Transgender no longer recognised as 'disorder' by WHO.” BBC News. May 29, 2019. https://www.bbc.com/news/health-48448804

Unknown Author, “Transvestit und Hausarbeit," Die Welt der Transvestiten, September $11,1929$.

Unknown Author, "Vilma West, die aus Liebe ihrer Freundin ihrem Mann erschlag." Die Freundin. 2. April 1928.

Unnamed photographer, "Amerikanischer weiblicher Transvestit.” Das 3. Geschlecht. Mai 1930, 3.

Unnamed photographer, "Die Frau als Mann, Leiterin einer Bar im Westen Berlins." Das 3. Geschlecht. February 1931, 22.

Unnamed photographer, "Ein gut angezogener weiblicher Transvestit.” Das 3. Geschlecht. July 1931, 17.

Unnamed photographer, "Männer als Frauen, wie sie sich glücklich fühlen.” Das 3. Geschlecht. May 1932, 10.

Unnamed photographer, "Schöne männliche Köpfe, die inflege ihrer weichen Linien als vorbildlich zu betrachten sind..” Das 3. Geschlecht. February 1931, 32.

Unnamed photographer, “Transvestit im Haushalt.” Das 3. Geschlecht, July 1931, 30.

Unnamed photographer, "Weiblicher Transvestit, der als Mann lebt." Das 3. Geschlecht. May 1932, 11.

Unnamed Photographer. "Male Transvestite with overtly female body parts." Das 3. Geschlecht. July 1931, 10.

Unnamed Photographer. "A Well-Dressed Female Transvestite.” Das 3. Geschlecht. July 1931, 17.

Unnamed Photographer. "Transvestite in the Household.” Das 3. Geschlecht. July 1931, 30.

Unnamed Photographer. "Male Transvestite with overtly female body parts." Das 3.

Geschlecht. July 1931, 10. 
Unnamed Photographer. "Male Transvestite with overtly female body parts." Das 3. Geschlecht. February 1931, 10.

Unnamed Photographer. „Vilma West, who killed her husband for love.” Die freundin. April 2, 1928. (Sourced from Espinaco-Virseda)

Unnamed Photographer. "Male Transvestite.” Das 3. Geschlecht. July 1931, 29.

Unnamed Photographer. "This female transvestite is 'Lotte Hahm', head of The Transvestites, manager if the women's club "Violetta." Das Dritte Geschlecht. 1930.

Unnamed Photographer. "Female transvestite, who lives as a man." Das 3. Geschlecht. May 1932, 11.

Unnamed Photographer. "Female transvestite who works as a receptionist at a trendy Berlin dance hall." Das 3. Geschlecht. May 1930, 4.

Von Ankum, Katharina. Women in the Metropolis: Gender and Modernity in Weimar Culture. Univ of California Press, 1997.

Weis, Maria, "Uber die inneren Voraussetzungen," Frauenliebe 2 (1931): 4

Willma, "Meine Frau macht mich zu ihrer Frau," Die Freundin no. 11, 11th September 1929. 